SEASONAL FOOD HABITS OF BURROWING OWLS

(ATHENE CUNICULARIA) IN HUMAN-ALTERED LANDSCAPES

\author{
A Thesis \\ presented to \\ the Faculty of California Polytechnic State University, \\ San Luis Obispo
}

\author{
In Partial Fulfillment \\ of the Requirements for the Degree \\ Master of Science in Biological Sciences
}

by

Carie Marie Wingert

May 2012 
(C) 2012

Carie Marie Wingert

ALL RIGHTS RESERVED 


\section{COMMITTEE MEMBERSHIP}

TITLE:

AUTHOR:

DATE SUBMITTED:

COMMITTEE CHAIR:

COMMITTEE MEMBER:

COMMITTEE MEMBER:
Seasonal Food Habits of Burrowing Owls (Athene cunicularia) in Human-altered Landscapes

Carie Marie Wingert

May 2012

Dr. John Perrine, Assistant Professor

Dr. Emily Taylor, Associate Professor

Dr. Brian Cypher, Adjunct Professor: CSUStanislaus 


\title{
ABSTRACT \\ SEASONAL FOOD HABITS OF BURROWING OWLS (ATHENE CUNICULARIA) IN HUMAN-ALTERED LANDSCAPES
}

\author{
Carie Marie Wingert
}

In 2004, I initiated a year-long study to investigate the food habits of burrowing owls (Athene cunicularia). Burrowing owls have been found in a variety of human-altered landscapes; however, little is known about burrowing owl food habits in urban landscapes. Burrowing owl food habits during the non-breeding season are also largely undocumented, despite increasing concern over the survival of overwintering burrowing owls. Differences in prey consumption between reproductive and non-reproductive owls during the breeding season have not yet been examined. I collected pellets over a 12 month period at four study sites affected by different levels of human alteration in the southern San Joaquin Valley of California. Data was collected at four study sites representing natural (Wind Wolves), semi-natural (Allensworth Ecological Reserve), agricultural (Friant Kern Canal), and urban (Bakersfield) landscapes. Invertebrates, primarily ground dwelling insects, were the most commonly consumed prey type, found in $96 \%$ of all pellets examined. Among vertebrates, mammals were the most commonly consumed $(18.5 \%$ of all pellets). Shannon-Weiner diversity indices identified differences in prey diversity consumed between seasons within each site and between sites within seasons, except during the breeding season where diversity was the same at all sites. The diversity indices at Wind Wolves (natural site) and Bakersfield (urban site) were the same, while the diversity indices at Allensworth Ecological Reserve (semi-natural site) and Friant Kern Canal (agricultural site) were the same. Binary logistic regression was used to determine if consumption of individual prey types varied by site, season, and a site/season interaction. Mammals were consumed in greater proportions during the breeding season at most sites compared to other seasons. The proportion of pellets containing mammals during the breeding season decreased as the level of human-alteration increased, with mammal consumption highest at Wind Wolves (60.0\%) and lowest at Bakersfield (13.1\%). Consumption of several insect categories differed by site and/or season (Coleoptera, Dermaptera, and Orthoptera), but overall consumption of insects was not different by either factor. To assess differences in prey consumption between reproductive and non-reproductive owls, pellets collected during the 2005 breeding season were classified as having come from a nest burrow or a non-nest burrow based on positive identification of reproduction. ShannonWeiner diversity indices and binary logistic regression were calculated for this data set. No differences were detected in overall diversity or in the proportional consumption of individual prey categories. The results of this study indicate that burrowing owls have a highly variable diet and may have sufficient ecological plasticity to allow them to adjust their food habits to the prey species available in human-altered landscapes. However, the implications of altered food habits on burrowing owl fitness in heavily disturbed landscapes, particularly urban landscapes, needs further study.

Keywords: California, diet, pellet analysis, urban, agriculture, natural, human-alteration, prey diversity 


\section{ACKNOWLEDGEMENTS}

This study was made possible with generous funding from the U.S. Bureau of Reclamation and the California Department of Fish and Game. Extraordinary guidance was provided by Dr. John Perrine, my thesis advisor, and by Dr. Brian Cypher, who provided special guidance during the data collection phase of my study. Special thanks to Dr. Emily Taylor for her participation and support as a member of my thesis committee, and to Dr. Steve Rein for providing guidance and input on the statistical analysis. Special thanks also goes to all of those who provided valuable assistance in the field, including: Christine Van Horn Job, Sam BremnerHarrison, Stephen Harrison, Craig Fiehler, Alex Brown, Curtis Bjurlin, James Murdoch, and Justin

Brown. Thanks also to Navdeep Singh who provided valuable assistance with pellet analysis. I greatly appreciate the assistance provided by Michelle Selmon, Shari Hoetkotter, and Stephen Juarez of the California Department of Fish and Game for providing information and access with respect to Allensworth Ecological Reserve; by Dave Clendenen of The Wildlands Conservancy for providing information and access with respect to Wind Wolves Preserve; by the City of Bakersfield for providing access to city-owned property; by the U.S. Bureau of Reclamation for providing access to canals under their jurisdiction; and by the California Department of Water Resources for providing access to canals under their jurisdiction. Thanks also to Greg Warrick for providing insect specimens for comparison during pellet analysis and to Dr. Kingston Leong for assisting with insect identification. 


\section{Table of Contents}

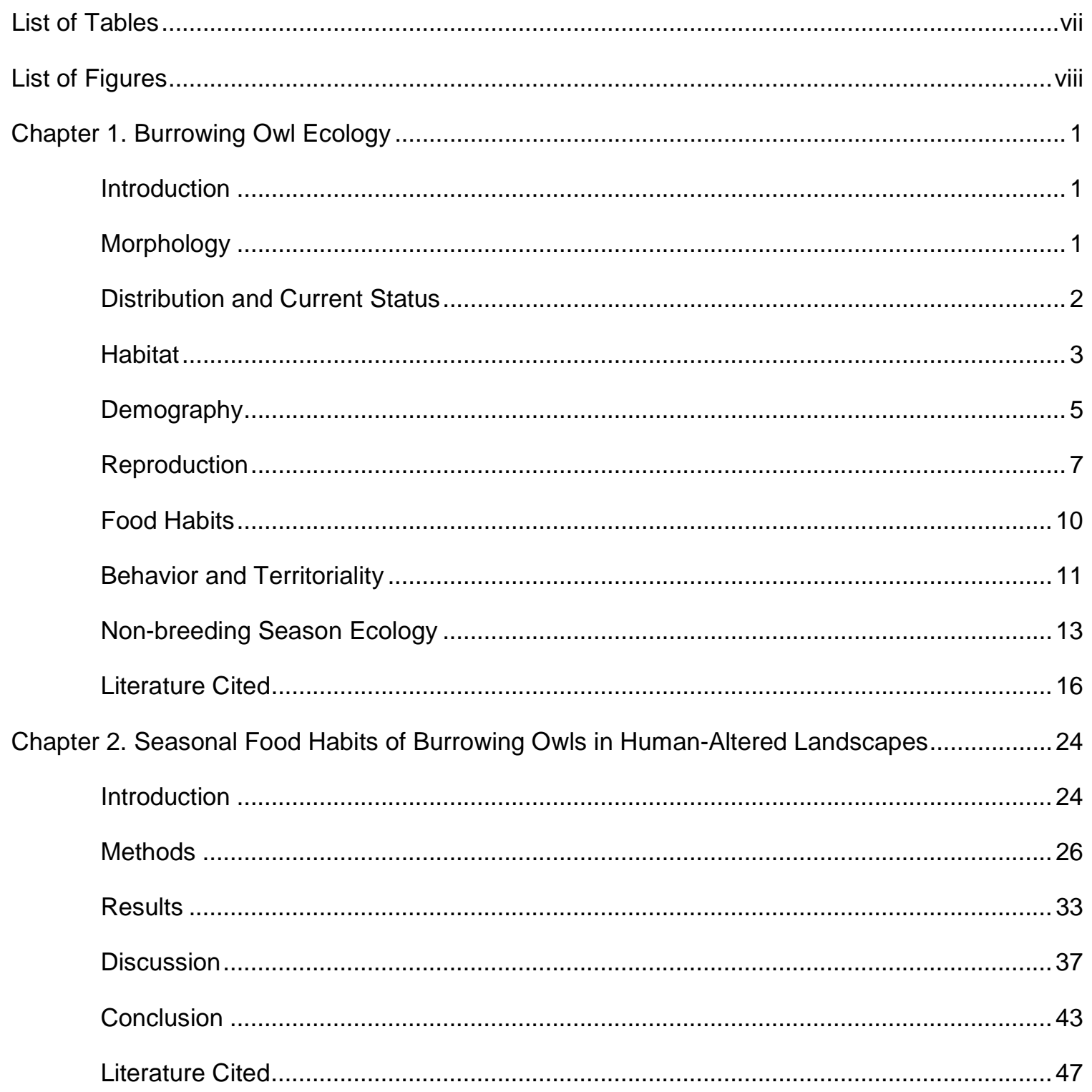




\section{List of Tables}

Table 2.1. Prey identified by proportion of total pellets collected at natural study site Wind Wolves Preserve (WW).

Table 2.2. Prey identified by proportion of total pellets collected at natural study site Allensworth Ecological Reserve (AER)....

Table 2.3. Prey identified by proportion of total pellets collected at natural study site Friant Kern Canal (FKC).

Table 2.4. Prey identified by proportion of total pellets collected at agricultural study site Bakersfield (BAK).....

Table 2.5. Species richness (S), Shannon-Wiener diversity indices $(H)$, and evenness $(J)$ calculated for each season and for the entire 12-month study period for each study site.

Table 2.6. Calculated $t$-values, degrees of freedom, $95 \%$ critical t-values, and $p$-values for pair-wise comparisons of Shannon-Weiner diversity indices for seasons within a site..

Table 2.7. Calculated $t$-values, degrees of freedom, 95\% critical t-values, and $p$-values for pair-wise comparisons of Shannon-Weiner diversity indices for seasons between sites, and between sites for the entire 12-month study period..

Table 2.8. Chi-square $\left(X^{2}\right)$ values and $p$-values for logistic regression analysis of pellet contents based on Site, Season, and Site $x$ Season, with degrees of freedom (df) reported in parentheses

Table 2.9. Proportion of pellets containing specific prey categories compared across site and season

Table 2.10. Species richness (S), Shannon-Wiener diversity indices $(H)$, and evenness $(J)$ calculated for nest and non-nest burrows for the 2005 breeding season for each study site.

Table 2.11. Calculated $t$-values, degrees of freedom, 95\% critical t-values, and $p$-values for pair-wise comparisons of Shannon-Weiner diversity indices nest versus nonnest burrows within a site..

Table 2.12. P-values for logistic regression analysis of pellet contents based on nest vs. non-nest burrows, as reported for each site. Degrees of freedom (df) $=2$. 


\section{List of Figures}

Figure 1.1. North American distribution of the burrowing owl (Athene cunicularia). Source: Manitoba Wildlife and Ecosystem Protection Branch (2011)................................. 22

Figure 1.2. Current and former breeding range of burrowing owl in California, with percent of statewide populations as estimated from surveys completed in $2006-2007 . \ldots \ldots . .23$

Figure 2.1. Regional view of study sites. AER - Allensworth Ecological Reserve; FKC Friant Kern Canal; BAK - Bakersfield; WW - Wind Wolves Preserve 52

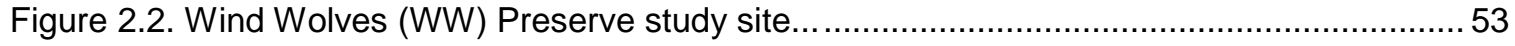

Figure 2.3. Allensworth Ecological Reserve (AER) study site …............................................ 54

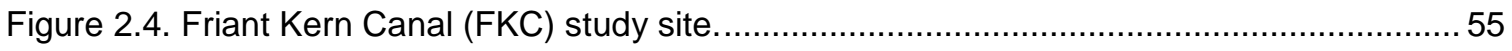

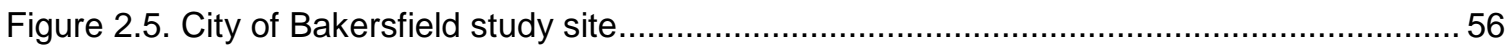

Figure 2.6. Daily temperature (Fahrenheight) and precipitation (inches) data from January 1, 2004 to December 31, 2005 acquired from MesoWest for Bakersfield, California (University of Utah, 2011).....

Figure 2.7. Total number of pellets collected by season for WW (138), AER (149), FKC (280), and BAK (910). 58

Figure 2.8. Total number of taxa represented in the pellets per season per study site. 59

Figure 2.9. Shannon-Weiner index $(H)$ calculated for each season and for the full 12-month study period for each study site

Figure 2.10. Diversity evenness $(J)$ calculated from Shannon-Weiner Index for each season and for the full 12-month study period for each study site

Figure 2.11. Proportion of pellets containing mammal prey items. 62

Figure 2.12. Proportions of pellets containing reptile/amphibian prey items for each season ......63

Figure 2.13. Proportions of pellets containing bird prey items for each season ......................... 64

Figure 2.14. Proportion of pellets containing Coleoptera prey items for each season ..................65

Figure 2.15. Proportion of pellets containing Dermaptera prey items for each season.................66

Figure 2.16. Proportion of pellets containing Orthoptera prey items for each season. ................67

Figure 2.17. Proportion of pellets containing Insect prey items for each season ....................... 68

Figure 2.18. Proportion of pellets containing Arachnida prey items for each season ................... 69

Figure 2.19. Proportion of pellets containing Crustacean prey items for each season ................ 70

Figure 2.20. Proportion of pellets containing soil for each season. ......................................... 71 
Figure 2.21. Proportion of pellets containing vegetation for each season.

Figure 2.22. Proportion of pellets containing man-made items for each season.

Figure 2.23. Shannon-Weiner index values calculated for nest and non-nest burrows for each study site.

Figure 2.24. Diversity evenness $(J)$ calculated from Shannon-Weiner index values $(H)$ for nest and non-nest burrows for each study site.

Figure 2.25. Proportion of pellets containing prey categories for nest and non-nest burrows for each study site. 


\section{Chapter 1. Burrowing Owl Ecology}

\section{Introduction}

Burrowing owls (Athene cunicularia) are arguably one of the most conspicuous and charismatic owl species in North America. Their habit of using subterranean structures for nesting and shelter is unique among owl species, but this habit also makes them particularly vulnerable to habitat disturbance. They have historically ranged across large areas of the Great Plains and western North America, but their current distribution has contracted substantially due to the many different ways in which humans alter the natural landscape, both through development of natural lands for agricultural and urban uses and through elimination of sympatric fossorial species such as prairie dogs (Cynomys spp.).

Burrowing owls appear to be able to adjust to the changing environment and may persist in human-altered landscapes, but the long-term viability of burrowing owls in these altered landscapes is still in question. Increasingly, research on burrowing owl ecology is turning towards owls residing in agricultural and urban landscapes to identify the benefits and consequences for burrowing owls fitness. This research provides new information for resource agencies, land managers, and conservation biologists who strive to develop conservation strategies to preserve burrowing owl populations and prevent further declines.

In this chapter, I present a review of the published literature on burrowing owl ecology.

\section{Morphology}

Burrowing owls are one of the smallest owl species in North America and are unique because of their habit of occupying subterranean burrows for shelter and reproduction (Poulin et al., 2011). These owls stand up to 25 centimeters (cm) tall and weigh up to 150 grams $(\mathrm{g})$. Burrowing owls have long legs, a rounded head lacking ear tufts, and a short tail. Their wings are long and round with 10 brown and buffy-white barred primaries. Their breast feathers have brown and buffy-white barring and they have a distinctive facial pattern consisting of a buffy-white eyebrow and malar stripe. Their iris is yellow. Burrowing owls are generally sexually 
monomorphic, though males tend to be larger and lighter in color than females (Martin, 1973; Poulin et al., 2011). This is usually not readily apparent unless males and females are standing near each other, and the variation in plumage color between males and females is likely a result of males spending more time above ground during the nesting season and, thus, having greater exposure to the sun (Martin, 1973; Thomsen, 1971). The plumage differences are least evident immediately following molt, which is broken into a partial pre-nuptial molt in March and a postnuptial molt in either June or July, depending upon reproductive status (Thomsen, 1971).

\section{Distribution and Current Status}

Burrowing owls occur throughout western North America, Florida, Central and Southern America, Hispaniola, Cuba, the northern Lesser Antilles, and the Caribbean (Figure 1.1) (Gervais et al., 2008; Klute et al., 2003; Poulin et al., 2011). Seven subspecies are recognized, two of which have ranges in North America: the Florida burrowing owl (A. c. floridana), which occurs in Florida and the Caribbean, and the western burrowing owl (A. c. hypugaea), which is widespread across the Great Plains and westward (Klute et al., 2003; Poulin et al., 2011). The establishment of these subspecies is based upon presumed geographic isolation as the systematics of these sub-specific designations have not been evaluated (Poulin et al., 2011).

Burrowing owls are designated as federally Endangered in Canada and federally Threatened in Mexico (Klute et al., 2003). In 2009, they were categorized as Least Concern on the International Union for Conservation of Nature's (IUCN) Red List of Threatened Species (BirdLife International, 2009). Within the United States, burrowing owls are federally protected under the Migratory Bird Treaty Act (1918) and included on the United States Fish and Wildlife Service's (USFWS) Birds of Conservation Concern (2008) list for seven Bird Conservation Regions and three USFWS Regions. In addition, burrowing owls are listed as state Endangered in Minnesota, state Threatened in Colorado, and designated as a species of concern by another seven states. Burrowing owls have experienced both range shrinkage (Woodin et al., 2007) and a range-wide decline throughout their North American range (James and Ethier, 1989), primarily due to habitat destruction (Poulin et al., 2011). Throughout the Great Plains region, prairie dogs 
(Cynomys spp.) create burrows and modify the conditions of the grassland, creating conditions which burrowing owls find highly suitable (Butts and Lewis, 1982; Desmond et al., 1995; Klute et al., 2003; Mulhern and Knowles, 1996). As a result of the co-occurrence of these species, the decline of burrowing owls throughout the Great Plains region largely mirrors the decline of the black-tailed prairie dog (C. Iudovicianus), which has been reduced to about $2 \%$ of its historic range (Desmond et al., 2000; Mulhern and Knowles, 1996).

The state of California recognizes burrowing owls as a Species of Special Concern, due primarily to a steady population decline, particularly in urban areas (DeSante et al., 2007; Klute et al., 2003; Wilkerson and Siegel, 2010). Surveys conducted in the early 1990's and compared to surveys conducted in the 1980's identified an average annual population decline of approximately 8\% (DeSante et al., 1997, DeSante and Ruhlen, 1995). Recent surveys conducted in 2006 and 2007 identified a non-significant total statewide decline of $10.9 \%$ since the early 1990 's studies, with the sharpest declines recognized in the San Francisco Bay area and the Bakersfield area (Wilkerson and Siegel, 2010). In California, burrowing owl populations are concentrated in the Imperial Valley ( 69\%) and the southern Central Valley ( 12\%) (Wilkerson and Siegel, 2010) (Figure 1.2). The western Mojave Desert is occupied by about $6 \%$ of the statewide population and the middle portion of the Central Valley is occupied by about $5.9 \%$ of the statewide population. The remaining state-wide population is distributed along the remaining areas of the Central Valley, valleys between the Central Valley and the Central Coast (e.g., Carrizo Plain), the San Francisco Bay Area, southern coastal areas, the Sonoran Desert, the northern and eastern Mojave Desert regions, and the Modoc Plateau.

\section{$\underline{\text { Habitat }}$}

Burrowing owls are historically common to open, tree-less habitats dominated by shortgrasses and/or small scattered shrubs (Grinnell and Miller, 1944; Poulin et al., 2011). The majority of the habitat they occupy is relatively flat with slopes of $10 \%$ or less (Rich, 1986). Presence of water is apparently not required, though burrowing owls have been observed drinking water in captivity (Coulombe, 1971). Sparse, low-growing vegetation is important (Rich, 
1986; Klute et al., 2003; Poulin et al., 2011). Throughout the Great Plains, suitable habitat typically consists of short-grass prairies dominated by blue grama (Bouteloua gracilis), buffalo grass (Buchloe dactyloides), wheatgrass (Agropyron dasystachyum), and carices (Carix spp.) (MacCracken et al., 1985; Poulin and Todd, 2006). In the desert southwest, suitable habitat is typically a shrub-dominated community with a sparse understory, dominated by a wide variety of shrubs such as saltbush (Atriplex spp.), rubber rabbitbrush (Ericameria nauseosus), mesquite (Prosopsis sp.), and creosote (Larrea tridentata) (Botelho and Arrowood, 1998; Martin, 1973). In the northwest, habitat occupied includes a mosaic of shrub-steppe and grassland with dominant plant species such as big sagebrush (Artemisia tridentata), cheat grass (Bromus tectorum), and tumble mustard (Sisymbrium altissimum) (King and Belthoff, 2000; Moulton et al., 2006).

Burrowing owls have adapted to a wide range of human-altered landscapes including dry-farmed agricultural fields (personal observation), irrigation ditches through dense agricultural areas (Coulombe, 1971; DeSante et al., 2004; Rosenberg and Haley, 2004), golf courses (Thomsen, 1971), military facilities (Plumpton and Lutz, 1993a), airports (Thomsen, 1971), vacant lots in residential areas (Millsap and Bear, 2000; Poulin et al., 2011), university campuses (Holmes, 1998; Poulin et al., 2011), railroad right-of-ways (Martin, 1973), and fairgrounds (Haug and Oliphant, 1990). Burrowing owls are nearly always associated with subterranean burrows created by fossorial mammals (Coulombe, 1971; Thomsen, 1971), but burrowing owls are capable of digging their own burrows under certain soil conditions (Florida Fish and Wildlife Conservation Commission, 2010; Klute et al., 2003; Rosenberg et al., 2007). In the Great Plains, prairie dogs are the primary providers of burrows (Butts and Lewis, 1982; MacCraken et al., 1985). In New Mexico, rock squirrels (Spermophilus variegates) are common creators of burrows (Martin, 1973). In California, the California ground squirrel (S. beecheyi) is the primary provider of burrows. In northern Mexico, burrowing owls often use burrows constructed by kangaroo rats (Dipodomys spp.) (Rodriguez-Estrella, 1997). In Oregon and Idaho, burrowing owls depend largely upon Amercian badgers (Taxidea taxus) for burrows (Belthoff and King, 2002; Green and Anthony, 1989; King and Belthoff, 2000). In the desert southwest, the desert tortoise (Gopherus agassizii) and desert kit fox (Vulpes macrotis arsipus) are substantial contributors to burrow 
availability (Poulin et al., 2011; Rodriguez-Estrella, 1997). Other species that create burrows that could be utilized by burrowing owls include coyotes (Canis latrans), other foxes (Vulpes spp.), and various larger rodent species such as antelope ground squirrels (Ammospermophilus spp.) (personal observation).

Owl burrows typically have multiple entrances. Entrance size varies greatly and is largely influenced by the species that created the burrow as well as the age of the burrow (Martin, 1973). The inner tunnel size typically conforms to the size of an adult burrowing owl. Occupied burrows most commonly have tunnels which angle gently downward from the entrance inward, a left or right turn approximately one meter inside from the entrance, and a mound of dirt present outside of the entrance (Coulombe, 1971; Martin, 1973). King and Belthoff (2002) found that tunnel angles of nesting burrows were less steep than non-nest burrows. The direction of the burrowing opening apparently does not matter (Coulombe, 1971; King and Belthoff, 2002; Martin, 1973; Rich, 1986). Burrowing owls frequently renovate and maintain burrows by digging with their feet and shaping the walls with their wings and beaks (Martin, 1973; Thomsen, 1971). Coulombe (1971) analyzed temperature and humidity within burrows and found that while temperature did not differ depending upon depth within the burrow, absolute humidity increased to as much as $70 \%$ greater than ambient air as depth increased.

Burrowing owls have also been found to occupy artificial structures such as pipes, culverts, holes in the ground under cement sidewalks, holes burrowed into piles of hay, and scrap-lumber piles (Botelho and Arrowood, 1998; Botelho and Arrowood, 1996; Center for Biological Diversity, 2003; Grier, 1997; Stoner, 1932). In addition, artificial burrows have been constructed deliberately for the purpose of housing and studying burrowing owls (Henny and Blus, 1981; Woodin et al., 2007).

\section{Demography}

Burrowing owls typically live an average of five years (Kennard, 1975); the longest-lived burrowing owl known to occur in the wild was a banded bird that lived to be 8 years and 8 months of age. Annual survival rates (based upon return rates of banded birds) vary across North 
America and range from $37 \%$ to $58 \%$ for adults in migratory populations (Poulin et al., 2011) and up to $81 \%$ for non-migratory populations (Thomsen, 1971). The return rates for first year owls are considerably lower than older adults and ranges from $14 \%$ for migratory populations to $30 \%$ for non-migratory populations. The low return rates may be influenced by low site fidelity exhibited by juveniles (Millsap and Bear, 1997) as most juveniles tended to settle near their rearing grounds rather than return to them.

Due to the lack of information on the non-breeding season ecology of this species, it is hard to explain the low return rates for banded birds because sources of mortality during the nonbreeding season are difficult to document (Thomsen, 1971). Primary causes of mortality documented during the breeding season include predation (Coulombe, 1971; Green and Anthony, 1989; Rodriguez-Estrella, 1997; Thomsen, 1971) and exposure to elements (Haug, 1985). Starvation was also noted in the literature (Thomsen, 1971; Todd et al., 2003), but was not common. Anthropogenic causes of mortality are rising as burrowing owls increasingly occupy human-altered habitats and include collision with vehicles (Haug and Oliphant, 1987; Millsap, 2002; Millsap and Bear, 1988; Todd et al., 2003), collision with wind turbines (Smallwood et al., 2007), destruction of burrows by cattle (Rodriguez-Estrella, 1997), nest destruction from roadside maintenance (Catlin and Rosenberg, 2006), and plugging or flooding of occupied burrows (Millsap and Bear, 2000; Thomsen, 1971). Mortality has also been caused by research activities (Gervais et al., 2006; Henry and Blus, 1981). Disease and parasites have also been documented as causing burrowing owl mortality (Millsap and Bear, 1988), though the effects of these have been considered an insignificant contribution to overall population reduction (Thomsen, 1971). Contamination from agricultural pesticides and secondary poisoning from rodent control programs may also be contributors to the decline in burrowing owl populations (Gervais et al., 2000; James, 1987; MacCracken et al., 1985).

Annual reproductive success varies throughout North America, with rates of $100 \%$ in New Mexico (Martin, 1973), to 77\% in Florida (Millsap, 1997), to 55\% in northern Mexico (RodriguezEstrella, 1997). In California, reproductive success is highly variable based on location and year, ranging from a low of $26.3 \%$ to a high of $90 \%$ (Rosenberg et al., 2007; Thomsen, 1971). 
Reproductive success is influenced by a number of variables, with prey availability believed to be a primary contributor. Thomsen (1971), in comparing two reproductive seasons, noted that reproductive success was greater during the year in which the vegetative growing season started earlier and lasted longer, suggesting better growing conditions for prey species. A clear relationship between food availability and reproductive success has further been demonstrated through food supplementation studies (Haley, 2001; Todd et al., 2003; Wellicome, 2005), in which food-supplemented nests achieved greater reproductive output. Moulton et al. (2006), examined nest site selection relative to agricultural habitat and found that prey availability was the primary driving factor in the location of nests. Millsap and Bear (2000) proposed a similar relationship for burrowing owl occupancy of urban habitat when they found that reproductive success was higher for owls in partially-developed residential areas compared to undeveloped areas in Florida, suggesting that the prey base that occupied landscaped urban areas was higher and more stable throughout the year.

Another factor associated with reproductive success is the timing of nest establishment. Nests established earlier in the season tended to have larger clutches and healthier broods (Griebel and Savidge, 2003; Griebel and Savidge, 2007), and early nest establishment may also allow for rare opportunities of double-brooding (Gervais and Rosenberg, 1999; Millsap, 1990). Nest density has also been shown to affect reproductive success, with higher reproductive output for owls nesting in lower densities within a given area (Griebel and Savidge, 2007).

\section{Reproduction}

Burrowing owls are capable of reproduction during the first breeding season following hatching (Poulin et al., 2011). The timing and duration of the breeding season for the burrowing owl varies across the species' range (Baicich et al., 1997). For most burrowing owl populations in North America, the breeding season is influenced by climate, which affects migration timing. Breeding generally begins from February to early May, with the breeding season generally starting earlier in lower latitudes (Martin, 1973; Poulin et al., 2011); the breeding season may extend as late as October (Coulombe, 1971). In southwestern North America, including 
California, where burrowing owls are partially migratory or resident, the breeding season typically ranges from March through August (Gervais et al., 2008; Martin, 1973; Thomsen, 1971; Zeiner et al., 1999). In rare cases, breeding has been documented as early as January (Millsap, 1990).

Burrowing owls demonstrate high site fidelity for breeding sites (Klute et al., 2003; Martin, 1973; Plumpton and Lutz, 1993b; Rosenberg and Haley, 2004), even returning to the same nest burrow during consecutive years (Martin, 1973). Nest burrows are most commonly found in subterranean earthen burrows constructed by fossorial mammals, but have also been established in man-made structures such as pipes and culverts, (Botelho and Arrowood, 1998) and artificial burrows constructed specifically for research and conservation purposes (Belthoff and King, 2002; Wellicome, 2005).

Males and females typically establish mating pairs upon arrival at the breeding site, and subsequently identify suitable nest burrows (Martin, 1973; Poulin et al., 2011). In some cases, owls have been documented arriving at breeding sites already paired (Martin, 1973). Pair bonds may persist for many years for non-migratory populations (Coulombe, 1971; Poulin et al., 2011), while pairs in migratory or partially migratory populations may reestablish pair bonds in successive years (Rosenberg and Haley, 2004). However, Martin (1973) observed banded owls selecting new mates during subsequent breeding years, despite both members of a pair returning to the breeding site the following year.

In natural habitats, shredded cow or horse manure is typically used to line burrow tunnels and nest chambers and decorate burrow entrances (Martin, 1973; Smith, 2007). Several theories have been proposed for why burrowing owls do this, including controlling temperature and humidity (Green, 1983; Martin, 1973), attracting prey such as beetles (Levey et al., 2004; Smith, 2007), and masking the scent of the nest (Desmond et al., 1997; Green and Anthony, 1989; Martin, 1973). The prey-attraction hypothesis is currently the most commonly accepted based on recent research (Levey et al., 2004; Smith, 2007). It has been suggested that the behavior of decorating/lining nest burrows is so deeply instinctual that burrowing owls must decorate their nest burrows, regardless of the habitat conditions. Hence, the reason why unusual and seemingly useless objects may be found at nest burrows in urban environments. Items observed at nest 
burrows include divots from a golf course, foil, gum wrappers, cigarette butts, plastics, paper, and metal screws (personal observation; Millsap, 1997; Thomsen, 1971).

Nest burrows are typically proximal to a number of satellite burrows (King and Belthoff, 2000; Martin, 1973). Satellite burrows are utilized as escape burrows for adults and young as they venture away from the nest burrow. They are also occupied by the owlets as they grow and require more space, and as the original nest burrow becomes overwhelmed by parasites (Butts, 1973).

Females lay an average of 6-9 eggs per season (Baicich et al., 1997; Poulin et al., 2011) and have been documented lay up to 12 eggs (Center for Biological Diversity, 2003). Eggs are laid at a rate of approximately one egg per day over an 8 to 17 day period (Henry and Blus, 1981; Wellicome, 2005). Incubation occurs over 27 to 30 days (Baicich et al., 1997) though it not yet understood at which point during egg laying incubation begins. Asynchronous hatching has been observed and suggests that incubation may begin when the first egg is laid (Martin, 1973; Thomsen, 1971), but other researchers have found full clutches cold, indicating that incubation may not begin until the full clutch is laid (Haug, 1985; Henry and Blus, 1981). Recent research suggests the onset of incubation may be dependent upon clutch size (Wellicome, 2005). As such, burrowing owls apparently follow no specific pattern with regards to initiation of clutch incubation.

Female burrowing owls remain at the nest during the spring months in the early part of the nesting season, rarely emerging from the burrow throughout the duration of incubation and brooding (Martin, 1973; Thomsen, 1971). During this period, the male provides food to the female and the owlets (Baicich et al., 1997; Martin, 1973; Poulin et al., 2011). The female may perform limited amounts of foraging within the immediate vicinity of the nest, but does not venture far (Poulin and Todd, 2006). Owlets are altricial and downy, and begin to emerge from the nest burrow around 14 days of age (Baicich et al., 1997). Once the owlets begin to emerge and are capable of thermoregulation, the female will gradually reduce the amount of time spent at the nest and increase the amount of time spent foraging and provisioning the owlets (Martin, 1973). At about 26 and 48 days, the owlets begin to fly and to utilize satellite burrows (Thomsen, 1971; King and Belthoff, 2000). As the owlets near fledging at 40 to 45 days of age (Baicich et al., 
1997), they will accompany the adults during foraging excursions. They also become more isolated from each other (Martin, 1873; Thomsen, 1971), relying more on satellite burrows within the vicinity of the nest burrow. Owlets disperse at an average age of 58 days, with dispersal defined as moving more than $300 \mathrm{~m}$ from the nest burrow (King and Belthoff, 2000).

\section{Food Habits}

Foraging can occur over a wide variety of habitats including open grassland (Poulin et al., 2011), grazed pasture, irrigation canals (personal observation), golf courses (Thomsen, 1971), airports, lighted parking lots (Hoetker and Gobalet, 1999; personal observation), and roadways (Coulombe, 1971; personal observation). The majority of foraging occurs within $600 \mathrm{~m}$ of a burrow throughout the year (Gervais et al., 2003; Haug and Oliphant, 1990; Rosenberg and Haley, 2004), with males documented foraging as far as 2.7 kilometers $(\mathrm{km})$ from nests during the breeding season. Typical hunting behavior includes running and hopping along the ground, observing from a perch, hawking, and hovering as high as $30 \mathrm{~m}$ above ground (Martin, 1973; Poulin et al., 2011; Robertson, 1929; Thomsen, 1971; personal observation).

Burrowing owls are dietary generalists, consuming a wide variety of prey species. Arthropods are most commonly consumed (Coulombe, 1971; Rodriguez-Estrella, 1997; Thomsen, 1971; Woodin et al., 2007), and typically consist of ground dwelling insects such as beetles (Order Coleoptera) and grasshoppers (Order Orthoptera) (Plumpton and Lutz, 1993c; Thomsen, 1971; York et al., 2002). Other arthropods consumed include earwigs (Order Dermaptera), bees and ants (Order Hymenoptera), praying mantis (Order Mantodea), arachnids (Class Arachnida), and mollusks (Class Gastropoda). Rodents are also consumed in great numbers and are the primary vertebrate prey consumed (Coulombe, 1971; Rodriguez-Estrella, 1997; Thomsen, 1971; Woodin et al., 2007). Burrowing owls consume with less frequency young jackrabbits (Thomsen, 1971), bats (Thomsen, 1971; Botelho and Arrowood, 1996; Hoetker and Gobalet, 1999), birds (Coulombe, 1971; Thomsen, 1971; MacCracken et al., 1985), reptiles (Coulombe, 1971; Plumpton and Lutz, 1993c; Rodriguez-Estrella, 1997), amphibians (Coulombe, 1971; MacCracken et al., 1985; Thomsen, 1971), fish (MacCracken et al., 1985), and 
anthropogenic items (Martin, 1971; Plumpton and Lutz, 1993c). Cannibalism has been documented (Robinson, 1954), but is not commonly reported in the literature. Many studies have documented the consumption of vegetation and soil (mostly small pebbles) (Thomsen, 1971), but it is likely that these items are ingested incidentally as other prey items are consumed (MacCracken et al., 1985). Thomsen (1971) also suggested that soil particles may be ingested when a burrowing owl is digging out a burrow in preparation for the coming nesting season.

Relatively few studies have examined food habits outside of the breeding season and most of these have been incidental to other research being conducted concurrently, or were the result of unusual owl sightings (Coulombe, 1971; Maser et al., 1971; Morgan et al., 1993; York et al., 2002). However, one recently published study has comprehensively examined the food habits of burrowing owls wintering in southern Texas (Littles et al., 2007). In this study conducted over four winters, invertebrates were found to be the dominant prey item each year, while vertebrates (primarily small rodents) made up just $2 \%$ of the total number of prey items identified. Elsewhere, Morgan et al. (1993) found no mammals in the pellets from a single owl overwintering on Vancouver Island, and Thomsen (1971) observed vertebrate consumption lowest during the winter months in Oakland, California. In contrast to these observations, Maser et al. (1971) observed rodents consumed in greater proportion during the winter in central Oregon and attributed this to the dieback of vegetation, resulting in a greater likelihood of rodents being caught by the owls.

\section{Behavior and Territoriality}

Burrowing owls are unique among owl species in that they may be active during any period of the day or night (Coulombe, 1971; Martin, 1973; Thomsen, 1971). Burrowing owls are considered both solitary and colonial throughout much of their range (Center for Biological Diversity, 2003; Desmond et al., 1995), and this may be an artifact of their association with the fossorial mammals that provide the burrows they use. However, Desmond et al. (1995) found that burrowing owls tended to aggregate in larger prairie dog colonies, despite abundant burrow availability that would allow for a more dispersed arrangement. 
Burrowing owls display aggressive anti-predator behaviors, often mobbing grounddwelling predators that come close to nest burrows (Martin, 1973; Thomsen, 1971). When a ground-based predator approaches a burrow occupied by owlets, the adult owls may flush from the burrow to another burrow or perch location and call attention to themselves, presumably to encourage the predator to pursue them away from the nest burrow (Coulombe, 1971; Martin, 1973; Thomsen, 1971). When an aerial predator is nearby, adult owls will typically retreat into their burrow. In all situations, owlets will retreat into a burrow and may rapidly click their bills, creating a sound that mimics an agitated rattlesnake (Coulombe, 1971; Thomsen, 1971). Adults have also defended nests from conspecifics by holding their wings over their backs and exposing the white patches on their throat and brow, while simultaneously making hissing calls (Coulombe, 1971; Martin, 1973). When there is no nest burrow to defend, burrowing owls will normally retreat to escape a predator (Thomsen, 1971).

The breeding season home range size is highly variable and appears to vary by location and individual. Gervais et al. (2003) documented breeding season home ranges at the Lemoore Naval Air Station in California as varying from 98 hectares (ha) to 189 ha. Haug and Oliphant (1990) documented home ranges in Saskatchewan as varying from as little as 14 ha to as large as 481 ha. The home range of overwintering burrowing owls has not been documented.

Burrowing owls display a nest burrow-specific territoriality (Coulombe, 1971; Martin, 1973), which is typically only defended through the nesting season until the young fledge (Thomsen, 1971). This territory generally includes the burrow and the immediate surrounding area, but does not include the sum of foraging habitat (Martin, 1973), which is part of the larger home range (Thomsen, 1971). Thomsen (1971) noted that the male was the primary defender of the territory, with females engaging in defensive activities only when intruders encroached upon the burrow.

Several studies have attempted to establish a territory size around a nest burrow with widely varying results (Butts, 1973; Grant, 1965; Hamilton, 1941; Haug and Oliphant, 1990). This can vary substantially based upon habitat type. Rosenberg et al. (2007) found that nest density in 
grassland habitat was lower $\left(1.4 \pm 0.1\right.$ nests $\left./ \mathrm{km}^{2}\right)$ than urban habitats $\left(2.9 \pm 0.2\right.$ nests $\left./ \mathrm{km}^{2}\right)$, with both much lower than agricultural habitat $\left(690.1 \pm 35.6\right.$ nests $\left./ \mathrm{km}^{2}\right)$.

A more commonly measured metric is the nearest neighbor distance between nests, and this is also highly variable. In north-central Oregon, Green and Anthony (1989) found that when nesting burrows were located within $110 \mathrm{~m}$ of each other, one of the nesting pairs abandoned their nest. Thomsen (1971) observed nearest neighbor distances at the Oakland Municipal Airport in California ranging from $9 \mathrm{~m}$ to $118 \mathrm{~m}$. Martin (1973) observed a nearest neighbor distance between nests of 166 m near Albuquerque, New Mexico. Rosenberg and Haley (2004) documented an average nearest-neighbor nest distance of $147 \mathrm{~m}$ in the Imperial Valley, but observed pairs successfully nesting as close as seven meters to each other. Rosenberg et al. (2007) compared nearest neighbor nest distances for natural, agricultural and urban study sites in California and found that nearest neighbor distances varied considerably by site, likely driven by a combination of burrow availability and prey availability. Distances between nests were as low as $2.2 \mathrm{~m}$ in agricultural study areas where burrowing owls are restricted to irrigation canals, roadside ditches, and small patches of unfarmed land. In contrast, the observed distance between nests was greatest in natural habitats were nests were located as much as $9.2 \mathrm{~km}$ apart (this observation is biased towards the high end because it is expected that not all nests were located during this study). Distance between nests in the urban study site ranged up to $3.0 \mathrm{~km}$; however, the distance between nests in urban habitat is largely a function of the availability of undeveloped microhabitats. Territorial behavior during the winter is unknown. Thomsen (1971) suggested that attachment to specific burrows during the winter is expected to be low; however, Woodin et al. (2007) did find that burrowing owls wintering in Texas showed strong roost site fidelity.

\section{Non-breeding Season Ecology}

Generally, the non-breeding season range of burrowing owls in North America occurs in the southern Great Plains and desert Southwest of the United States, south through Mexico and Central America (Klute et al., 2003; Poulin et al., 2011) (Figure 1.1). The ecology and mortality of burrowing owls during the non-breeding season is not well understood. This is likely a function of 
the migratory nature of this species across most of its range, leading to a much lower population of owls available for study during the non-breeding season. Coulombe (1971) banded owls in the Imperial Valley and tracked the population over the non-breeding season months and determined that approximately $20-25 \%$ of the breeding population remained at the site throughout the year. Butts (1976) investigated the winter status of burrowing owls in the Oklahoma Panhandle and observed a winter population of less than $1 \%$ of the population that had occupied the same study area during the previous breeding season. He also observed that all of the overwintering owls he banded had remained in the area to breed during the following year and concluded that these overwintering owls were permanent residents.

It has been observed that burrowing owls become predominantly nocturnal and spend most of the daytime underground during the non-breeding season, further making them more difficult to detect (Thomsen, 1971). LaFever et al. (2008) reported on the diurnal time budget of burrowing owls during the non-breeding season and found that females spent a greater amount of time in the burrow compared to males, which spent more time alert and away from the burrow.

Several studies that report non-breeding season ecology information have gathered information opportunistically. James and Ethier (1989) used Christmas Bird Counts to identify trends in burrowing owl distribution and abundance in the northern portion of their wintering range. While they found that burrowing owl populations were stable over a 33-year period, they did find an increasing trend in Florida and a decreasing trend in California. McIntyre (2004) conducted a census of burrowing owls in Texas and found that the overwintering population has declined from 1960 to 2001, but did not state the amount of the decline or estimate the rate of decline.

Recently published comprehensive investigations of burrowing owls overwintering in Texas have examined multiple aspects of this species' ecology (Woodin et al., 2007). The researchers determined that burrowing owls showed high roost-site fidelity. Roost sites included culverts, natural burrows, artificial burrows, and other unusual locations including piles of concrete rubble and oilfield equipment. The diet of these overwintering owls consisted largely of 
invertebrates. Vertebrates, primarily rodents, were present at a moderate frequency ( $40 \%$ of all pellets) in the diet.

The majority of research conducted on burrowing owls has been conducted in natural landscapes throughout North America. Several ecological studies have been conducted in agricultural landscapes, but burrowing owl ecology in urban landscapes is less well known. Additionally, less is known of the winter ecology of burrowing owls. Understanding how burrowing owls survive in altered landscapes throughout the year is important to developing successful conservation strategies aimed and preventing further decline of this species. 


\section{Literature Cited}

Baicich, P.J., and C. J.O. Harrison. 1997. A guide to the nests, eggs, and nestlings of North American birds. Second Edition. Academic Press, San Diego. 416 pp.

Belthoff, J. R. and R. A. King. 2002. Nest-site characteristics of burrowing owls (Athene cunicularia) in the Snake River Birds of Prey National Conservation Area, Idaho, and applications to artificial burrow installation. Western North American Naturalist 62(1):112-119.

BirdLife International. 2009. Athene cunicularia in IUCN, 2011. IUCN Red List of Threatened Species. Version 2011.2. Available at www.iucnredlist.org. Downloaded on February 4, 2012.

Botelho, E. S. and P. C. Arrowood. 1996. Nesting success of western burrowing owls in natural and human-altered environments. Pages 61-68 in Raptors in Human Landscapes: Adaptations to Built and Cultivated Environments. Academic Press, San Diego. 396 pp.

Botelho, E.S. and P. C. Arrowood. 1998. The effect of burrow site use on the reproductive success of a partially migratory population of western burrowing owls (Speotyto cunicularia hypugaea). Journal of Raptor Research 32(3):233-240

Butts, K. O. 1973. Life history and habitat requirements of Burrowing Owls in western Oklahoma. Master's Thesis. Oklahoma State University, Stillwater, OK.

Butts, K. O. 1976. Burrowing owls wintering in the Oklahoma Panhandle. Auk 93:510-516.

Butts, K. O. and J. C. Lewis. 1982. The importance of prairie dog towns to burrowing owls in Oklahoma. Proceedings of the Oklahoma Academy of Science 62:46-52.

Catlin, D. H., and D. K. Rosenberg. 2006. Nest destruction associated with mortality and dispersal of burrowing owls in the Imperial Valley, California. Southwest Naturalist 51(3):406409.

Center for Biological Diversity. 2003. Petition to the State of California Fish and Game Commission and supporting information for listing the California population of the western burrowing owl (Athene cunicularia hypugaea) as an endangered or threatened species under the California Endangered Species Act. Available at: http://www.biologicaldiversity.org/species/birds/western_burrowing_owl/

Coulombe, H. N. 1971. Behavior and population ecology of the burrowing ecology, Speotyto cunicularia, in the Imperial Valley of California. The Condor 73:163-176.

DeSante, D.F. and E.D. Ruhlen. 1995. A census of Burrowing Owls in California, 1991-1993. The Institute for Bird Populations. Point Reyes Station, California. USA.

DeSante, D. F., E. D. Ruhlen, S. L. Adamany, K. M. Burton, and S. Amin. 1997. A census of burrowing owls in central California in 1991. Raptor Research Reports No. 9:38-48.

DeSante, D. F., E. D. Ruhlen, and D. K. Rosenberg. 2004. Density and abundance of burrowing owls in the agricultural matrix of the Imperial Valley, California. Studies in Avian Biology 27:116-119.

DeSante, D. F., E. D. Ruhlen, and R. Scalf. 2007. The distribution and relative abundance of burrowing owls in California during 1991-1993: evidence for a declining population and 
thoughts on its conservation. pages 1-41, in Barclay, J.H., K.W. Hunting, J.L. Lincer, J. Linthicum, and T.A. Roberts (Eds.). 2007. Proceedings of the California Burrowing Owl Symposium, November 2003. Bird Populations Monographs No. 1. The Institute for Bird Populations and Albion Environmental, Inc., Point Reyes Station, CA, vii + 197pp.

Desmond, M.J., J. E. Savidge, and R. Ekstein. 1997. Prairie partners. Nebraskaland 75:16-25.

Desmond, M. J., J. A. Savidge, and K. M. Eskridge. 2000. Correlations between burrowing owl and black-tailed prairie dog declines: a 7-year analysis. Journal of Wildlife Management 64(4):1067-1075.

Desmond, M.J., J.A. Savidge, and T.F. Seibert. 1995. Spatial patterns of burrowing owl (Speotyto cunicularia) nests within black-tailed prairie dog (Cynomys ludovicianus) towns. Canadian Journal of Zoology 73(7): 1375-1379.

Florida Fish and Wildlife Conservation Commission. 2010. Burrowing owl. http://myfwc.com/WILDLIFEHABITATS/BirdSpecies_BurrowingOwl.htm

Gervais, J. A. and D. K. Rosenberg. 1999. Western burrowing owls in California produce second broods of chicks. Wilson Bulletin 111(4):569-571.

Gervais, J.A., D.K. Rosenberg, and R.G. Anthony. 2003. Space use and pesticide exposure risk of male burrowing owls in an agricultural landscape. Journal of Wildlife Management 67(1):156-165.

Gervais, J. A., D. H. Catlin, N. D. Chelgren, and D. K. Rosenberg. 2006. Radiotransmitter mount type affects burrowing owl survival. Journal of Wildlife Management 70(3):872-876.

Gervais, J. A., D. K. Rosenberg, and L. A. Comrack. 2008. Burrowing owl (Athene cunicularia) In Shuford, W. D., and T. Gardali (Eds.), California Bird Species of Special Concern: A Ranked Assessment of Species, Subspecies, and Distinct Populations of Birds of Immediate Conservation Concern in California. Studies of Western Birds 1. Western Field Ornithologists, Camarillo, California, and California Department of Fish and Game, Sacramento.

Gervais, J. A., D. K. Rosenberg, D. M. Fry, L. Trulio, and K. K. Sturm. 2000. Burrowing owls and agricultural pesticides: evaluation of residues and risks for three populations in California, USA. Environmental Toxicology and Chemistry 19(2):337-343.

Grant, R. A. 1965. The burrowing owl in Minnesota. Loon 37:2-17.

Green, G. A. 1983. Ecology of breeding burrowing owls in the Columbia Basin, Oregon. Master's Thesis. Oregon State Univ., Corvallis.

Green, G. A. and R. G. Anthony. 1989. Nesting success and habitat relationships of burrowing owls in the Columbia Basin, Oregon. Condor 91:347-354.

Griebel, R. L. and J. A. Savidge. 2003. Factors related to body condition of nestling burrowing owls in Buffalo Gap National Grassland, South Dakota. Wilson Bulletin 115(4):477-480.

Griebel, R. L. and J. A. Savidge. 2007. Factors influencing burrowing owl reproductive performance in contiguous shortgrass prairie. Journal of Raptor Research 41(3):212-221.

Grier, D. A. 1997. Scrap-lumber roost used by burrowing owls (Speotyto cunicularia). Journal of Raptor Research 31(4):391. 
Grinnell, J. and A. H. Miller. 1944. Distribution of the birds of California. Pacific Coast Avifauna No. 27.

Haley, K. L. 2001. Effects of food limitation on the reproductive success of burrowing owls. Master's Thesis. Oregon State University, Corvallis, Oregon.

Hamilton, W. J. 1941. A note on the food of the western Burrowing Owl. Condor 43:74.

Haug, E. A. 1985. Observations on the breeding ecology of burrowing owls in Saskatchewan. M.S. Thesis, University of Saskatchewan, Saskatoon, Saskatchewan, Canada. 89 pp.

Haug, E. A. and L. W. Oliphant. 1987. Breeding biology of Burrowing Owls in Saskatchewan. Pages 269-271 in Endangered species in the Prairie Provinces. (Holroyd, G. L., W. B. McGillivray, P. H. R. Stepney, D. M. Ealey, G. C. Trottier, and K. E. Eberhart, Eds.) Provincial Museum of Alberta Occasional Paper, No. 9.

Haug, E. A. and L. W. Oliphant. 1990. Movements, activity patterns, and habitat use of Burrowing Owls in Saskatchewan. Journal of Wildlife Management. 54:27-35.

Henny, C. J. and L. J. Blus. 1981. Artificial burrows provide new insight into Burrowing Owl nesting biology. Journal of Raptor Research 15:82-85.

Hoetker, G. M. and K. W. Gobalet. 1999. Predation on Mexican free-tailed bats by burrowing owls in California. Journal of Raptor Research 33(4):333-335.

Holmes, B. 1998. City planning for owls. National Wildlife Oct/Nov: 46-53. (Available at http:// www.nwf.org/nationalwildlife/article.cfm7article Id=672\&issueld=68).

James, P. C. 1987. Effects of some insecticides on productivity of burrowing owls. Blue Jay 45(2):65-71.

James, P. C. and T. J. Ethier. 1989. Trends in the winter distribution and abundance of burrowing owls in North America. American Birds 43(4):1224-1225.

Kennard, J. H. 1975. Longevity records of North American birds. Bird-Banding 46:55-73.

King, R. A. and J. R. Belthoff. 2000. Post-fledging dispersal off burrowing owls in southwestern Idaho: characterization of movements and use of satellite burrows. Condor 103:118-126.

Klute, D. S., L. W. Ayers, M. T. Green, W. H. Howe, S. L. Jones, J. A. Shaffer, S. R. Sheffield, and T. S. Zimmerman. 2003. Status Assessment and Conservation Plan for the Western Burrowing Owl in the United States. U.S. Department of Interior, Fish and Wildlife Service, Biological Technical Publication FWS/BTP-R6001-2003, Washington, D.C.

LaFever, D. H., K. E. LaFever, D. H. Catlin, and D. K. Rosenberg. 2008. Diurnal time budget of burrowing owls in a resident population during the non-breeding season. The Southwestern Naturalist 53(1):29-33.

Levey, D. J., R. S. Duncan, and C. F. Levins. 2004. Use of dung as a tool by burrowing owls. Nature 431:39

Littles, C. J., D. Williford, M. K. Skoruppa, M. C. Woodin, and G. C. Hickman. 2007. Diet of western burrowing owls wintering in southern Texas. Journal of Raptor Research 41(4):307313. 
MacCracken J. G., D. W. Uresk, and R. M. Hansen. 1985. Burrowing owl food in Conata Basin, South Dakota. Great Basin Naturalist 45(2):287-290

Martin, D. J. 1971. Unique burrowing owl pellets. Bird-Banding 42(4):298-299.

Martin, D. J. 1973. Selected aspects of burrowing owl ecology and behavior. Condor 75:446-456.

Maser, C., E. W. Hammer, and S. H. Anderson. 1971. Food habits of the burrowing owl in central Oregon. Northwest Science 45(1):19-26

Mclntyre, N. E. 2004. Historical and current status of breeding and wintering western burrowing owls (Athene cunicularia hypugaea) in Texas. Journal of Raptor Research 38(1):91-95.

Millsap, B. A. 1990. Double-brooding by Florida burrowing owls. Wilson Bulletin 102(2): 313-317.

Millsap, B. A. 1997. Florida Burrowing Owl. in Rare and endangered biota of Florida volume V: Birds. (Rogers, J. A. and H. W. Kale II, Eds.) Univ. Presses Florida, Gainesville.

Millsap, B. A. 2002. Survival of Florida burrowing owls along an urban-development gradient. Journal of Raptor Research 36(1):3-10.

Millsap, B. A. and C. Bear. 1988. Cape Coral Burrowing Owl population monitoring. Ann. Performance Report of the Florida Game and Freshwater Fish Commission, Tallahassee, FL.

Millsap, B.A., and C. Bear. 1997. Territory fidelity, mate fidelity, and dispersal in an urban-nesting population of Florida burrowing owls. Raptor Research Reports No. 9:91-98.

Millsap, B. A. and C. Bear. 2000. Density and reproduction of burrowing owls along an urban development gradient. Journal of Wildlife Management 64(1):33-41.

Morgan, K. H., R. J. Cannings, and C. S. Guppy. 1993. Some foods eaten by a burrowing owl overwintering on southern Vancouver Island. Northwestern Naturalist 74:84-87.

Moulton, C. E., R. S. Brady, and J. R. Belthoff. 2006. Association between wildlife and agriculture: underlying mechanisms and implications in burrowing owls. Journal of Wildlife Management 70(3): 708-716.

Mulhern, D. W. and C. J. Knowles. 1996. Black-tailed prairie dog status and future conservation planning. Pages 19-29 in Conserving biodiversity on native rangelands: symposium proceedings; August 17,1995; Fort Robinson State Park, Nebraska. (Uresk, Daniel W.; Greg L. Schenbeck; James T. O'Rourke, tech. coords.). Genera1 Technical Report RM-GTR-298. Fort Collins, CO: U.S. Department of Agriculture, Forest Service, Rocky Mountain Forest and Range Experiment Station. 38 p.

Plumpton, D. L. and R. S. Lutz. 1993a. Influence of vehicular traffic on the time budgets of nesting burrowing owls. Journal of Wildlife Management 57(3):612-616.

Plumpton, D. L. and R. S. Lutz. 1993b. Nesting habitat use by burrowing owls in Colorado. Journal of Raptor Research 27(4):175-179.

Plumpton, D. L. and R. S. Lutz. 1993c. Prey selection and food habits of burrowing owls in Colorado. Great Basin Naturalist 53(3):299-304.

Poulin, R. G. and L. D. Todd. 2006. Sex and nest stage differences in the circadian foraging behaviors of nesting burrowing owls. Condor 108:856-864. 
Poulin, R. G., L. D. Todd, E. A. Haug, B. A. Millsap and M. S. Martell. 2011. Burrowing owl (Athene cunicularia), The Birds of North America Online (A. Poole, Ed.). Ithaca: Cornell Lab of Ornithology; retrieved from the Birds of North American Online: http://bna.birds.cornell.edu/bna/species/061.

Rich, T. 1986. Habitat and nest-site selection by burrowing owls in the sagebrush steppe of Idaho. Journal of Wildlife Management 50(4):548-555.

Robertson, J. M. 1929. Some observations on the feeding habits of the burrowing owl. Condor 31(1):38-39.

Robinson, T. S. 1954. Cannibalism by a burrowing owl. Wilson Bulletin 66(1):72.

Rodriguez-Estrella, R. 1997. Nesting sites and feeding habits of the burrowing owl in the Biosphere Reserve of Mapimi, Mexico. Journal of Raptor Research 9:99-106.

Rosenberg, D. K. and K. L. Haley. 2004. The ecology of burrowing owls in the agroecosystem of the Imperial Valley, California. Studies in Avian Biology 27:120-135.

Rosenberg, D.K., L.A. Trulio, D. Catlin, D. Chromczack, J.A. Gervais, N. Ronan, and K.A. Haley. 2007. The ecology of the burrowing owl in California. Unpubl. report to the Bureau of Land Management., $212 \mathrm{pp}$.

Smallwood, K. S., C. G. Thelander, M. L. Morrison, and L. M. Rugge. 2007. Burrowing owl mortality in the Altamont Pass Wind Resource Area. Journal of Wildlife Management 71(5):1513-1524.

Smith, M. D. 2007. Use of mammal manure by nesting burrowing owls: a test of four functional hypotheses. Animal Behaviour 73:65-73.

Stoner, E. A. 1932. Burrowing owls occupying unusual quarters. Condor 35(1):36.

Thomsen, L. 1971. Behavior and ecology of burrowing owls on the Oakland Municipal Airport. Condor 73:177-192.

Todd, L. D., R. G. Poulin, T. I. Wellicome, and R. M. Brigham. 2003. Post-fledging survival of burrowing owls in Saskatchewan. Journal of Wildlife Management 67(3):512-519.

United States Fish and Wildlife Service. 2008. Birds of Conservation Concern 2008. United States Department of Interior, Fish and Wildlife Service, Division of Migratory Bird Management, Arlington, Virginia. 85 pp. [Online version available at $<$ http://www.fws.gov/migratorybirds/>]

Wellicome, T. I. 2005. Hatching asynchrony in burrowing owls is influenced by clutch size and hatching success but not by food. Oecologia 142:326:334.

Wilkerson, R. L., and R. B. Siegel. 2010. Assessing changes in the distribution and abundance of Burrowing Owls in California, 1993-2007. Bird Populations 10:1-36.

Woodin, M. C., M. K. Skoruppa, and G. C. Hickman. 2007. Winter ecology of the western burrowing owl (Athene cunicularia hypugaea) in southern Texas, 1999-2004. U.S. Geological Survey Scientific Investigations Report 2007-5150, 33p. 
York, M. M., D. K. Rosenberg, and K. K. Sturm. 2002. Diet and food-niche breadth of burrowing owls (Athene cunicularia) in the Imperial Valley, California. Western North American Naturalist 62(3):280-287.

Zeiner, D.C., W.F.Laudenslayer, Jr., K.E. Mayer, and M. White, eds. 1999. Burrowing owl updated from 1988-1990 California's Wildlife. Vol. I-III. California Department of Fish and Game, Sacramento, California. Available at: http://dfg.ca.gov/biogeodata/cwhr/cawildlife.aspx 


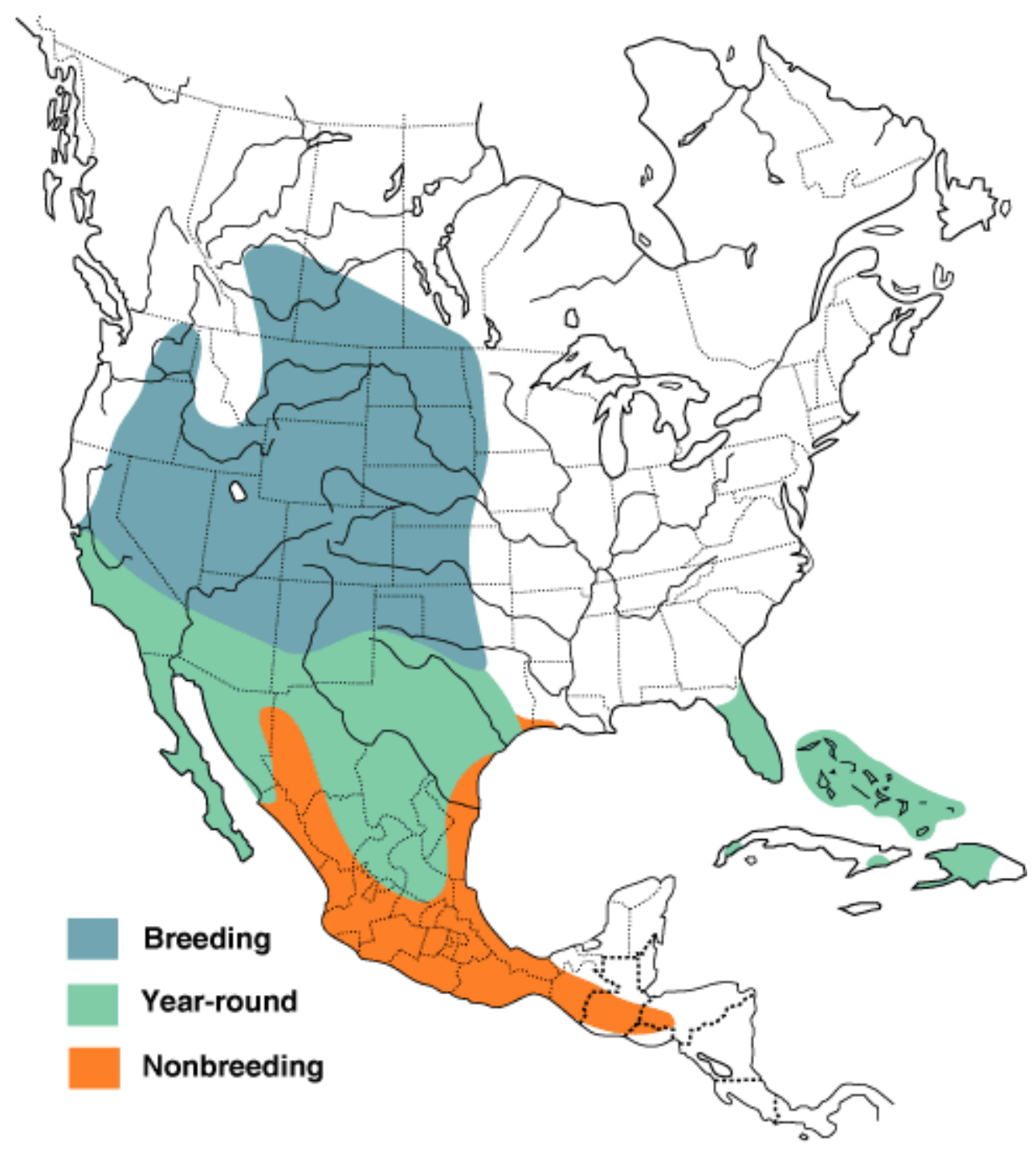

Figure 1.1. Distribution of the burrowing owl (Athene cunicularia) in North and Central America. Source: Poulin et al. (2011). 


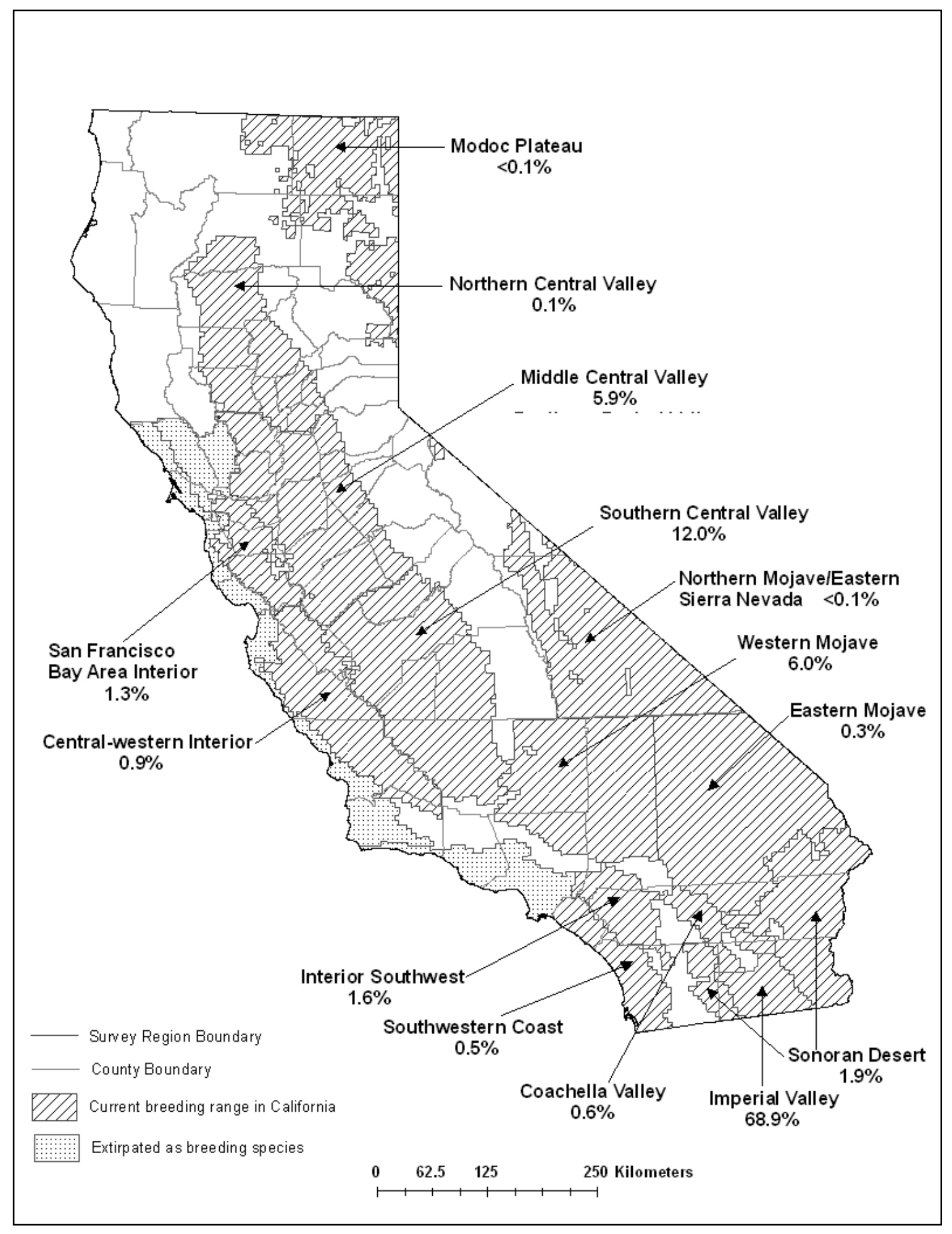

Figure 1.2. Current and former breeding range of burrowing owl in California, with percent of statewide populations as estimated from surveys completed in 2006-2007. Source: Wilkerson and Siegel (2010). 


\section{Chapter 2. Seasonal Food Habits of Burrowing Owls in Human-Altered Landscapes}

\section{Introduction}

The State of California designated the burrowing owl (Athene cunicularia) as a Species of Special Concern in 1978 (Remsen, 1978) due to population declines throughout the state.

Breeding populations have been impacted the greatest in areas with ongoing urban development, and they have been extirpated from areas they historically occupied (Wilkerson and Siegal, 2010). Despite these declines, burrowing owls appear to be capable of adapting to agricultural and urban landscapes (Gervais et al, 2008; Mrykalo et al., 2009; Rosenberg et al., 2007; Wesemann and Rowe, 1987; Wilkerson and Siegal, 2010); however, the ecology of this species in urban landscapes is not well-studied.

In addition, though breeding habitat requirements are well studied (Lincer and Clark, 2007), little is known about non-breeding season ecology. Recent studies have focused on burrowing owl ecology during the non-breeding season (Holroyd and Trefry, 2010; Littles et al, 2007; Mrykalo et al., 2009; Williford et al., 2007; Woodin et al., 2007), but most reports of nonbreeding season observations have been opportunistic in nature. Knowledge of burrowing owl ecology in human-altered landscapes, as well as non-breeding season ecology, is important to the development of conservation strategies for the preservation of this species.

Food habits are one of the most commonly studied aspects of burrowing owl ecology (Gervais et al., 2008; Poulin et al., 2011). However, food habit studies overwhelmingly focus on prey consumption during the breeding season. Relatively few studies have identified food habits during non-breeding months (Littles et al., 2007; Morgan et al., 1993; Schlatter et al., 1980), and though these studies showed that patterns of prey consumption during the non-breeding season were similar to the breeding season (i.e., invertebrates more numerous than vertebrates) they did not examine relative differences in prey consumption between the breeding and non-breeding seasons. Studying burrowing owl food habits is difficult due to the migratory nature of the burrowing owl throughout most of its range, resulting in a limited time frame during which data 
can be collected in a given area. Access to non-breeding season populations may also be restricted as many owls overwinter in Mexico. Furthermore, most studies occur during the breeding season due to the fact that resource utilization during the breeding season is highly important to a species' reproductive success; however, this approach overlooks the importance of understanding the relationship between food habits and non-breeding season survival.

Most studies of food habits have been conducted in natural settings (MacCracken et al., 1985; Martin, 1973; Maser et al., 1971; Plumpton and Lutz, 1993; Rodriguez-Estrella, 1997). Fewer studies have examined food habits in relation to agricultural or urban development. The most comprehensive research on burrowing owls in agricultural landscapes has been in the Imperial Valley of California, where a network of earthen channels conveys water for irrigation of crops (Coulombe, 1971; Poulin, 2003; Rosenberg and Haley, 2004; Rosenberg et al., 2007; York et al., 2002). Burrowing owls have also been studied in agroecosystems in Idaho (Moulton et al., 2006), Texas (Littles et al., 2007; Woodin et al., 2007), and Canada (Poulin, 2003). Relatively few studies of food habits have been conducted in urban areas with most in California (Rosenberg et al., 2007; Thomsen, 1971) and Florida (Hennemann and III, 1980; Mrykalo et al., 2009). Given the increasing conversion of natural lands into agricultural and urban uses, it is imperative that an understanding of how burrowing owls adapt to human alteration of their habitats is thoroughly developed.

The goal of my research is to determine if the food habits of the burrowing owl vary seasonally and by human alteration of landscapes within the San Joaquin Valley. I was also interested in determining if reproductive burrowing owls consumed prey in different proportions than non-reproductive burrowing owls, an aspect of their ecology that has not been addressed. The San Joaquin Valley is home to the second largest concentration of breeding burrowing owls in California, with breeding populations concentrated in Kern, Tulare, and Kings Counties (Wilkerson and Siegel, 2010). Several studies have examined burrowing owl ecology throughout the San Joaquin Valley (Conroy and Chesemore, 1987; DeSante et al., 1997; DeSante et al., 2007; Gervais et al., 2006; Roberts and Gaber, 2007; Rosenberg et al., 2007; Wilkerson and Siegel, 2010), but there are few published reports on burrowing owl ecology in southern portion of 
this region (Hoetker and Gobalet, 1999; Koshear et al., 2007). California is ranked number one in the nation for agricultural production, and most of the top producing counties are located in the San Joaquin Valley (United States Department of Agriculture, 2011). This region comprises a rich agricultural landscape that produces about $12 \%$ of the nation's produce. The San Joaquin Valley has also experienced rapid expansion of urban and petroleum development. This continually changing landscape presents challenges to burrowing owls and to resource managers who wish to preserve burrowing owl populations.

\section{Methods}

\section{Study Sites}

My study was conducted in Kern and Tulare Counties in the southern San Joaquin Valley of California (Figure 2.1). The San Joaquin Valley has a characteristic Mediterranean climate with cool, wet winters and hot, dry summers. Average high temperatures range from ca. $36^{\circ}$ Celsius (C) in July to ca. $13.9^{\circ} \mathrm{C}$ in January and average low temperatures range from about $20^{\circ} \mathrm{C}$ to about $2.8^{\circ} \mathrm{C}$ in January (Western Regional Climate Center, 2009). Average annual precipitation is 13.7 centimeters $(\mathrm{cm})$, primarily in the form of rain, which falls mostly from October to April. During the winter rainy season, the San Joaquin Valley experiences a unique weather phenomenon known as Tule fog, a thick ground fog which forms when there is a combination of high relative humidity following a rainfall event, calm winds, and rapid ground cooling (National Oceanic and Atmospheric Administration National Weather Service, 2000). Visibility can reach as little as 200 meters $(\mathrm{m})$.

I selected four study sites representing commonly occupied burrowing owl habitat, including an undeveloped "natural" area that resembles the natural habitat burrowing owls likely historically occupied in the region, a naturalized area that had formerly been in agricultural production, an irrigation corridor through agricultural lands, and an urban area. Each are described below in order of most natural to most altered.

Wind Wolves Preserve (WW). WW is located in southwestern Kern County, south of Highway 166, west of Interstate 5, and along the northern edge of the Temblor Range (Figure 
2.2). Formerly known as the San Emigdio Cattle Ranch, the preserve was acquired in 1996 by The Wildlands Conservancy, a non-profit organization dedicated to the conservation of natural lands throughout California. WW encompasses approximately 39,000 hectares, and includes valley floor, alluvial fans, hills, and mountainous terrain. Elevation across the preserve ranges from approximately $195 \mathrm{~m}$ above mean sea level to more than 1,800 m above mean sea level. Surrounding land uses include the Los Padres National Forest to the south, grazing lands to the east and west, and citrus orchards to the north. Limited cattle grazing continues on-site as a habitat management tool.

My study focused on the northern portion of the property dominated by valley floor and alluvial fans (see burrow locations depicted on Figure 2.2). The study area ranges in elevation from approximately $195 \mathrm{~m}$ above mean sea level to approximately $457 \mathrm{~m}$ above mean sea level and is depicted on Corner SW, Pentland, Santiago Creek, and Eagle Rest Peak USGS 7.5 minute topographic quadrangles. The study area is found within several sections in Township $11 \mathrm{~N}$ and Ranges $21 \mathrm{~W}$ and $22 \mathrm{~W}$. Vegetation on-site is dominated by non-native grasses, with scattered patches of Russian thistle (Salsola spp.).

Allensworth Ecological Reserve (AER). AER is located in southwest Tulare County immediately north of the Kern County line and west of Earlimart (Figure 2.3), in Township 24S and Ranges 24E and 25E. The site is depicted on the Allensworth and Delano West USGS 7.5 minute topographic quadrangles. The topography of the reserve is generally flat with elevations ranging from approximately $70 \mathrm{~m}$ to $76 \mathrm{~m}$ above mean sea level. The reserve is owned and operated by the California Department of Fish and Game and encompasses more than 2,306 hectares of non-contiguous parcels, primarily in two clusters. Historical uses include grazing and row crop agriculture. Low intensity grazing continues infrequently as a management tool. Vegetation across the site consists of a mosaic of non-native grassland dominated by invasive annual grasses such as bromes (Bromus spp.) and shrublands dominated by saltbush (Atriplex spp.) and bush seepweed (Suaeda moquinii). Grasslands on-site range from dense to sparse in vegetative cover. Shrublands range from dense canopies with little to no understory, to sparse canopies with numerous open areas vegetated with annual herbs and forbs. Shrub density tends 
to be highest towards the western portions of both of the southern and northern portions of the reserve. Surrounding land uses include grazing lands, row crop agriculture, orchards, vineyards and scattered rural residential.

I surveyed the entire reserve and surrounding areas for burrowing owls; however, owls were found primarily in two areas: in the southern section and adjoining grassland areas and in the southern extent of the northern section (see burrow locations depicted on Figure 2.3).

Friant Kern Canal (FKC). The FKC is a canal system owned by the U.S. Bureau of Reclamation and jointly operated by the Friant Water Authority. The FKC begins at the Friant Dam on the San Joaquin River northeast of Fresno and traverses 245 kilometers $(\mathrm{km})$ south to the Kern River in Bakersfield. The primary purpose of the FKC is to provide water for agriculture. The FKC is cement lined on the lower two-thirds of the interior banks, and dirt lined on the upper one-third of the interior banks and entire outer banks. Water is present year-round. The dirt-lined portions of the inner banks (facing the water) and top of banks are largely absent of all but a few herbs and forbs due to frequent vegetation removal activities including grading and herbicide application. The outer banks are typically vegetated with non-native grasses, forbs, and scattered shrubs such as Russian thistle (Salsola tragus) and buckwheat (Eriogonum spp.). Surrounding land uses include orchards, vineyards, row crops, grazing lands, patches of undeveloped habitat, as well as industrial, commercial, and residential development. My study focused on an approximately 3.2-km long and 41-m wide section of the southern portion of the FKC surrounded by agricultural land uses north of 7th Standard Road, just north of Bakersfield (Figure 2.4). The study area is located in both the Rosedale and Oildale USGS 7.5 minute topographic quadrangles and is found in Township 28S, Range 26E, and Sections 25 and 26. The elevation across the site averages approximately $119 \mathrm{~m}$ above mean sea level.

City of Bakersfield (BAK). BAK is located in north-central Kern County at the junction of State Routes 99 and 58 (Figure 2.5). The population of Bakersfield as determined by the 2010 census was approximately 347,483, a 40\% increase since 2000 (City of Bakersfield, 2011). The land area occupied by BAK has grown from 29,554 hectares in 2000 to 37,192 hectares in 2010, 
equating to an annual increase of approximately $2.5 \%$ per year. This study focused on the western portion of the City, west of State Route 99, and primarily sampled drainage basins, parks, canals, small undeveloped parcels, railroads, and the banks of the Kern River. The majority of these areas experience periodic disturbance and contain sparse to thick vegetation consisting of non-native grasses, native and non-native forbs, and few shrubs. The topography throughout the study area is generally flat with an average elevation of approximately $116 \mathrm{~m}$ above mean sea level. Data were sampled in four USGS 7.5 minute topographic quadrangles includes Oildale, Rosedale, Stevens, and Gosford.

\section{Pellet Content Analysis}

I collected pellets generally every two weeks at each study site from April 2004 to October 2005 by revisiting all known burrow locations. During the winter months, intervals between pellet collections exceeded two weeks due either to poor road conditions prohibiting access to a burrow/site or to lack of pellets present at burrows. Pellet collection duration for each study site varied between 12 and 14 months. When I encountered a new burrow, I removed all pellets present and discarded them to ensure that subsequent pellets collected would be fresh and would reflect prey consumption during the sampling period. Each individual pellet was stored in a small paper bag labeled with the date, study site, and burrow identification number.

Each individual pellet was carefully picked apart under a dissecting microscope and all prey items were identified to the lowest taxonomic level possible (minimally to order). Prey items were identified with the aid of reference specimens from the mammal and insect collections at California Polytechnic State University and from insect specimens collected near the study sites. The dependent variable was presence of a specific type of prey; numbers of individuals of each prey item within a pellet were not counted or estimated.

I identified 12 species of mammals; however, I was unable to identify mammals to species in one-third of the pellets due to the lack of suitable diagnostic features (e.g., teeth). Bird, amphibian, and reptile remains lacked features suitable for identification below class level. With the exception of crustaceans, arthropod remains were identified to order or family wherever 
possible. Less than one percent of the arthropod remains were unidentifiable. Non-food items were identified to the greatest extent feasible.

\section{Defining Seasons}

For this analysis, I defined seasons based first on burrowing owl ecology and second on regional climate patterns. The length of the breeding in California generally occurs from March to August (Gervais et al., 2008). To define seasons climatically, I obtained temperature and precipitation data for the period during which my study was conducted from Meso West for a weather station located at Bakersfield Airport (University of Utah, 2011). Upon review of these data I divided the non-breeding season into two climatically different subseasons: a hot/dry season (September to November) and a cold/wet season (December to February) (Figure 2.6). The climate throughout the breeding season (March to August) was generally hot and dry throughout, so this season was not subdivided.

\section{Statistical Analysis}

For each study site, I calculated species richness (S), Shannon-Weiner diversity index, and evenness for each season and for a 12-month study period for prey categories only. Nonprey categories (soil, vegetation, and man-made) were excluded.

Species richness $(\mathrm{S})$ is the total number of unique species in the sample. The ShannonWeiner diversity index is calculated by:

$$
H^{\prime}=-\sum_{\mathrm{i}=1}^{\mathrm{S}} \mathrm{p}_{\mathrm{i}} \ln \mathrm{p}_{\mathrm{i}}
$$

where $\mathrm{S}$ is the species richness and $\mathrm{p}_{\mathrm{i}}$ is the proportion of observations found in category $i$ out of the total number of observations. The Shannon-Weiner diversity index is then used to calculate evenness:

$$
J^{\prime}=\frac{H^{\prime}}{H^{\prime}{ }_{\max }}
$$


$H_{\text {max }}^{\prime}$ represents the maximum diversity index for a population and is calculated by taking the natural $\log$ of $\mathrm{S}$. The Shannon-Weiner diversity index ranges from 0 (specialists) to $H^{\prime}{ }_{\max }$ (generalists) and Evenness ranges from 0 (specialists) to 1 (generalists).

Differences between Shannon-Weiner diversity indices within each site were tested using a $t$-test based on Hutchinson (1970):

$$
t=\frac{H_{1}^{\prime}-H_{2}^{\prime}}{\sqrt{\operatorname{Var} H_{1}^{\prime}+\operatorname{Var}_{2}^{\prime}}}
$$

The variance for each $H^{\prime}$ is calculated as:

$$
\operatorname{Var} H^{\prime}=\frac{\sum p_{i} \ln ^{2} p_{i}-\left[\sum\left(p_{i} \ln p_{i}\right)\right]^{2} / N}{N^{2}}
$$

where $N$ is the total number of prey for that sample. The degrees of freedom for the $t$-test are calculated as:

$$
d f=\frac{\left(\operatorname{Var} H_{1}^{\prime}+\operatorname{Var} H_{2}{ }_{2}\right)^{2}}{\frac{\operatorname{Var}{H^{\prime}}_{1}{ }^{2}}{N_{1}}+\frac{\operatorname{Var}{H^{\prime}}_{2}{ }^{2}}{N_{2}}}
$$

The 95\% critical t-value and $p$-value were calculated for each $t$-test using Excel (formulas TINV and TDIST, respectively). The calculated $p$-value was compared to Bonferroni-corrected alpha values to determine if the null hypothesis $(H=0)$ should be rejected. The Bonferroni-corrected alpha level was calculated by $\alpha / n$ where $\alpha$ is 0.05 and $n$ is the number of tests. For the comparison of seasons within a site, the Bonferroni-corrected alpha value is $0.05 / 18=0.003$. For the comparison of sites within seasons, the Bonferroni-corrected alpha value is $0.05 / 36=0.001$. Binary logistic regression was performed in Minitab 16.1.0 based on the following equation:

$$
p=\frac{e^{\beta_{0}+\beta_{i} x_{i} \ldots+\beta_{p} x_{p}}}{1+e^{\beta_{0}+\beta_{i} x_{i} \ldots+\beta_{p} x_{p}}}
$$

The model utilized for this project compared study sites to each other and seasons (breeding season and each non-breeding subseason) to each other, and included an interaction component between study site and season. The model was run for each of the following prey 
categories: Mammals, Birds, Reptiles/Amphibians, Insects, Dermaptera, Orthoptera, Coleoptera, Arachnida, and Crustacea. An alpha of 0.05 was used to determine if there was a difference in the frequency of prey consumed between sites, seasons, and for the interaction term.

To examine the differences in the frequency of consumption of specific prey items between study sites and seasons as identified in the logistic regression analysis, I graphed proportions of pellets containing specific prey items with 95\% confidence intervals calculated for binomial population parameters using Zar (1996, page 525).

\section{Nest Burrows vs. Non-Nest Burrows}

I examined the difference in food habits between owls that were nesting and owls that were not nesting. In May and June of 2005, all burrows that were occupied by adult owls and/or showed signs of nesting (e.g., nest decorations, accumulation of prey remains and pellets) were watched from about one hour before sunrise to up to two hours after sunrise to determine if owlets were present. Burrows were observed on multiple days as necessary until observers were satisfied that no owlets were present. A burrow was considered to be a nest burrow if at least one owlet was observed over the course of the breeding season. All other burrows were considered non-nest burrows. I extracted from the full pellet data set those data collected at all burrows during the 2005 breeding season (March to August). I then sorted the data for each site based on whether the burrow was a nest burrow. I calculated the species richness, ShannonWeiner diversity index, and evenness for nest and non-nest burrows at each study site. I utilized logistic regression to analyze individual prey categories and graphed the proportions of pellets containing each prey category with associated 95\% confidence intervals for proportions. All statistical analyses on the nest vs. non-nest burrow dataset used the same calculations as described above for the full pellet dataset. 


\section{$\underline{\text { Results }}$}

\section{Pellet Contents}

I collected and analyzed a total of 1477 pellets: 138 from WW, 149 from AER, 280 from FKC, and 910 from BAK (Figure 2.7). Numbers of pellets collected during the breeding $(n=743)$ and non-breeding seasons $(n=734)$, each six months long, were similar. More pellets were collected during the hot/dry period of the non-breeding season $(n=443)$ than during the cold/wet period of the non-breeding season $(n=291)$.

Of the total number of pellets analyzed, 908 (61\%) contained only invertebrate remains, 57 (4\%) contained only mammal remains, and $512(35 \%)$ contained a combination of both mammal and invertebrate remains.

Three phyla were identified in the pellets: Chordata, Arthropoda, and Mollusca. A total of seven classes of prey were identified: Mammalia, Aves, Amphibia, Reptilia, Insecta, Arachnida, and Gastropoda. Twenty-four additional lower taxonomic categories were identified (Tables 2.1 through 2.4). Mammals and insects were the most commonly consumed and were the most diverse. Three mammal orders were identified: Lagomorpha (rabbits and hares), Chiroptera (bats), and Rodentia. Five insect orders were identified: Dermaptera (earwigs), Orthoptera (grasshoppers), Hymenoptera (bees and ants), Mantodea (praying mantis), and Coleoptera (beetles). Six families within order Coleoptera were identified: Curculionoidae (weevils), Elateridae (click beetles), Tenebrionidae (darkling ground beetles), Scarabidae (scarab beetles), Carabidae (carabid beetles), and Staphylinidae (rove beetles).

\section{Prey Diversity and Evenness}

Species richness, Shannon-Weiner diversity index, and evenness values for each study site and season are reported in Table 2.5, and are shown in Figures 2.9 and 2.10, respectively. Tables 2.6 and 2.7 show $t$-values for comparison of Shannon-Weiner diversity index values among sites and seasons. 
Burrowing owl diet at WW showed the highest overall diversity $\left(H^{\prime}=2.377\right)$ (Table 2.5 and Figure 2.9.). BAK $\left(H^{\prime}=2.264\right)$ and $A E R\left(H^{\prime}=2.258\right)$ were second and third, respectively, in overall diversity of prey consumed with relatively similar values, and FKC $\left(H^{\prime}=2.129\right)$ showed the lowest overall diversity. On a seasonal basis, diversity at BAK was higher during the breeding season $\left(H^{\prime}=2.293\right)$ and hot/dry season $\left(H^{\prime}=2.279\right)$ compared to all other sites. FKC was the lowest during the breeding season $\left(H^{\prime}=2.180\right)$ and AER was the lowest during the hot/dry season $\left(H^{\prime}=1.821\right)$. FKC was highest during the cold/wet season $\left(H^{\prime}=1.949\right)$.

The $t$-tests identified differences in prey diversity between sites and seasons (Tables 2.6 and 2.7). Within sites, the breeding and hot/dry seasons were the same at WW $(p=0.957)$ and $\operatorname{BAK}(p=0.773)$, while they differed for AER $(p=<0.001)$ and FKC $(p=<0.001)$. The cold/wet season differed from both the breeding and hold/dry seasons for both WW and BAK (all p-values $<0.001)$, but were the same for AER ( $p=0.005$ and $p=0.767$, respecitvely) and FKC ( $p=0.028$ and $p=0.314$, respecitvely).

Within seasons there were no differences between sites during the breeding season. WW and BAK were the same for the breeding $(p=0.635)$, hot/dry $(p=0.818)$, and cold/wet $(p=0.002)$ seasons, as well as for the overall 12-month study period $(p=0.012)$. AER and FKC were the same for the breeding $(p=0.280)$, hot $/ d r y(p=0.959)$, and cold/wet $(p=0.610)$ seasons, as well as for the overall 12-month study period $(p=0.066)$.

Evenness in overall prey consumption was highly variable by site and season (Table 2.5, Figure 2.10). Overall evenness was highest at WW $\left(J^{\prime}=0.822\right)$, and lowest at BAK $\left(J^{\prime}=0.679\right)$. WW and BAK both showed an increase in prey generalization from the breeding season to the hot/dry season, then a trend toward specialization during the cold/wet season, while the trend at AER was the opposite. Evenness at FKC was relatively steady from one season to the next.

\section{Prey Consumption by Site}

The logistic regression identified significant differences in the consumption of mammals, insects, reptiles/amphibians, Coleoptera, Orthoptera, Dermaptera, and Arachnida (Table 2.8). Logistic regression was not performed for Gastropod, Mantodea, or Hymenoptera as these prey 
were present in trace amounts, or for non-prey items including soil, vegetation, and man-made items. The proportions of pellets containing each prey category for each site are graphed in Figures 2.11 through 2.22 and summarized in Table 2.9.

Mammals were the most frequently consumed vertebrate (Table 2.9), but mammal consumption differed among sites $\left(X^{2}=80.113, p<0.001\right)$. Mammal consumption was highest at WW (60.1\% of pellets) and lowest at BAK (9.7\% of pellets) (Figure 2.11). Reptile/amphibian consumption differed by site as well $\left(X^{2}=14.985, p=0.002\right)$. Reptiles/amphibians were consumed at all sites except AER, and were consumed in greater proportions at BAK (6.8\% of pellets) than WW (1.4\% of pellets) and FKC (1.1\% of pellets), neither of which were signficantly different from AER ( $p=0.712$ and $p=0.872$, respectively) (Figure 2.12). Bird consumption was not influenced by site $\left(X^{2}=1.812, p=0.612\right)$ (Figure 2.13).

Site was a significant factor for the insect orders Coleoptera $\left(X^{2}=20.285, p<0.001\right)$, Dermaptera $\left(X^{2}=21.636, p<0.001\right)$, and Orthoptera $\left(X^{2}=33.133, p=<0.001\right)$. Coleoptera was consumed most frequently at AER ( $82.6 \%$ of pellets) and lowest at WW (58.7\% of pellets) (Figure 2.14). Dermaptera was consumed in trace amounts at AER (2.0\% of pellets) and were consumed most frequently at BAK (48.5\% of pellets) (Figure 2.15$)$. Orthoptera was consumed in relatively similar proportions at AER, WW, and FKC (41.6\%, 46.4\%, and $41.4 \%$ of pellets, respectively) and less frequently at BAK (30.8\% of pellets) (Figure 2.16). Insect consumption overall did not differ by site $\left(X^{2}=4.852, p=0.183\right)$ as $<82 \%$ of all pellets at all sites contained insects (Figure 2.17 ).

Among non-insect invertebrates, arachnid consumption was different between sites $\left(X^{2}=57.895, p<0.001\right)$, with the most frequent consumption observed at AER and WW $(17.4 \%$ and $31.9 \%$ of pellets, respectively). Frequency of arachnid consumption was lower at BAK $(2.1 \%$ of all pellets) and FKC (7.0\% of pellets) (Figure 2.18).

Consumption of non-prey items soil $\left(X^{2}=20.365, p<0.001\right)$ and vegetation $\left(X^{2}=10.906\right.$, $p=0.012$ ) were significantly different among sites. Notably, both were absent at WW and were consumed in trace amounts at AER (Figures 2.20 through 2.22). Each was more frequently consumed at BAK. 


\section{Prey Consumption by Season}

Prey consumption differed by season for mammals $\left(X^{2}=14.553, p=0.001\right)$, Coleoptera $\left(X^{2}=7.600, p=0.022\right)$, Dermaptera $\left(X^{2}=8.064, p=0.018\right)$, and vegetation $\left(X^{2}=13.979, p=0.001\right)$ (Table 2.8). Consumption of mammals during the breeding season was not different from the cold/wet season $(p=0.928)$ but was different from the hot $/ d r y$ season $(p=<0.001)$. The same seasonal pattern of difference was observed for Coleoptera (breeding $=$ cold/wet, $p=0.174$; breeding $\neq$ hot/dry, $\mathrm{p}=0.012$ ).

The opposite pattern was observed for Dermaptera and vegetation. Whereas the breeding and cold/wet seasons were different from each other $(p=0.008$ and $p=0.001$, respectively), no difference was detected between the breeding and hot/dry seasons ( $p=0.286$ and $\mathrm{p}=0.135)$.

\section{Site by Season Interaction}

The site by season interaction was significant for mammal $\left(X^{2}=31.738, p<0.001\right)$, insect $\left(X^{2}=14.980, \mathrm{p}=0.020\right)$, Coleoptera $\left(X^{2}=21.433, \mathrm{p}=0.002\right)$, Orthoptera $\left(X^{2}=82.415, \mathrm{p}<0.001\right)$, and soil $\left(X^{2}=21.954, p=0.001\right)($ Table 2.8).

Mammal consumption was highest during the breeding season for all sites except for WW, where mammals were consumed in greater proportions during the hot/dry season $(76.9 \%)$ (Figure 2.11). WW showed the greatest fluctuation of mammal presence in pellets between seasons, ranging from a low of $6.1 \%$ of pellets during the cold/wet season to a high of $76.9 \%$ of pellets during the hot/dry season. By contrast, the smallest fluctuation between seasons was observed at BAK, where mammals were present in $13.1 \%$ of pellets during the breeding season and $6.8 \%$ of pellets during the cold/wet and hot/dry seasons. AER and FKC showed similar patterns of high mammal consumption during the breeding season, second highest consumption during the cold/wet season, and lowest during the hot/dry season.

Insects in general were consumed in very high frequencies at all sites during all seasons (Figure 2.17). The lowest observed frequency of occurrence was at WW during the cold/wet 
season ( $67.3 \%$ of pellets). Insects were most frequently consumed during the cold/wet season at WW (100\%) and during the hot/dry season at AER (97.9\%), FKC (100\%), and BAK (93.9\%).

The seasonal pattern of consumption of Coleoptera differed by site. At WW, Coleoptera was found in pellets in the highest frequency during the cold/wet season (100\% of pellets), but only about half as many pellets contained Coleoptera during the breeding (50.0\%) and hot/dry (57.7\%) seasons (Figure 2.14). At AER and BAK, Coleoptera consumption was highest during the hot/dry season (93.8\% and $84.3 \%$ of pellets, respectively). At FKC, Coleoptera consumption was highest during the breeding season (79.3\%). Coleoptera consumption was not lower than $57.7 \%$ of pellets for any site or season.

The frequency of consumption of Orthoptera was similar between WW, AER, and BAK, with consumption highest during the breeding season and lowest during the cold/wet season (Figure 2.16). At FKC, Orthoptera were consumed most frequently during the hot/dry season and least frequently during the cold/wet season. WW showed the greatest fluctuation in consumption of Orthoptera, ranging from $74.3 \%$ during the breeding season to none consumed during the cold/wet season. AER and BAK showed similar low seasonal fluctuations in Orthoptera consumption, with $32.3 \%$ difference between the breeding and cold/wet seasons.

\section{Food Habits for Nest vs. Non-nest Burrows}

The overall patterns of prey consumption were the same between nest burrows and nonnest burrows at each site (Figures 2.23, 2.24, and 2.25) and there were no significant differences among Shannon-Weiner diversity indices (Table 2.11). The logistic regression did not detect significant differences in consumption of any prey category based on comparison to a Bonferronicorrected alpha value (Table 2.12).

\section{Discussion}

\section{Urbanization Gradient}

Each of my study sites has been altered for human uses to some degree. Lands that have not been disturbed by humans in some fashion are very rare, and agricultural and urban development continues to encroach into the remaining natural lands. Native wildlife species are 
continually being pressured to adapt to changes to their natural habitats or face severe population declines and possibly extinction. Understanding how wild species survive in human-altered landscapes will be key to developing future conservation strategies.

Taken together, my study sites represent the gradient of human landscape disturbances to which burrowing owls are exposed. WW is the most "natural" as it has experienced the least alteration, with cattle grazing the predominant use. It is also a relatively large and continuous area of grassland habitat and is surrounded on most sides by grassland habitats, leading to a relatively uniform habitat structure over a greater area. The large size of this grassland area also means that owls can be buffered from human activities on adjacent parcels. AER is also largely a "natural" habitat, but portions of the site have historically been subjected to more intensive agricultural uses than grazing and many of these areas are occupied by very dense and tall grasses and forbs that are less suitable for burrowing owl habitation. AER also comprises several disjunct, relatively small grassland and shrubland areas surrounded by a wider variety of agricultural uses including grazed grassland, row crops, orchards, and vineyards. As such, burrowing owls occupying AER are exposed to a more diverse of habitat structure than at WW, and they are more likely to be disturbed by human activities on adjacent parcels.

FKC and BAK are the most disturbed study sites. At FKC, burrows are primarily restricted to the canal banks where they are subject to frequent disturbance from canal maintenance activities. Surrounding lands are subject to a diverse array of agricultural uses, leading to relatively moderate to high diversity of habitat structure. Given the very small area that the canal occupies and the proximity to adjacent land uses, burrowing owls occupying FKC may be disturbed by a moderate to high degree by human activities on adjacent parcels.

BAK is by far the most human-altered site occupied by burrowing owls. BAK offers a high diversity of microhabitats in which burrowing owls have been observed including canals, drainage basins, undeveloped lots, parks, golf courses, the Kern River riparian corridor, and residential, commercial, and industrial developments. However, just as at FKC, burrow availability is restricted to areas that are not paved and otherwise not heavily disturbed (e.g., landscaped parks), and owls at BAK are likely to be disturbed by human activities. 
FKC and BAK are unique in that water is present at these sites throughout the year, while WW and AER lack surface water most of the year. Burrowing owls may not require a water source to survive, but they have been observed drinking water in captivity (Coulombe, 1971), suggesting they may take advantage of water when it is present. This water is also important to potential prey species that may not be available in drier areas, such as amphibians and some bird and mammal (e.g., bats) species that require access to water.

Burrowing owl diet varies by season and between human-altered landscapes in the San Joaquin Valley. While BAK and WW are the least alike in terms of human-alteration, prey diversity was highest at both of these sites; however, the high diversity of prey at WW may be biased by the relatively small number of pellets collected at this site. AER and FKC appear to be more similar than expected. Despite the larger area of natural habitat at AER compared to FKC, the similarities in prey diversity between these sites may be due to the mosaic of agricultural habitats present at both locations. The fact that some agricultural areas adjacent to FKC were fallow and used for sheep grazing during my study may have increased the similarity between the sites as well.

Most studies of burrowing owl food habits have been conducted in natural settings comparable to WW, and these studies generally showed a similar diversity of prey (Green et al., 1993; Plumpton and Lutz, 1993; Sissons, 2003). Studies in grasslands with more diverse habitat structure and/or surrounded by agricultural uses identified similar diversity of prey as I saw at AER (Conroy and Chesemore, 1987; Moulton et al., 2006). Moulton et al. (2006) found that twice as many rodent taxa were consumed by nesting owls in the more agricultural setting compared to the more natural setting. This illustrates that a mosaic of habitats created by human-alteration of the landscape is likely to result in a greater diversity of prey available.

The large number of unique taxa and the high diversity of prey consumed at BAK is likely a result of the high diversity of microhabitats available for foraging. A similar array of species was observed in burrowing owl pellets collected at an urban study site in Florida (Mrykalo et al., 2009). It is notable that reptiles and bats were only found at BAK, and other studies reported burrowing 
owls consuming these prey species in urban environments elsewhere (Hoetker and Gobalet, 1999; Sánchez et al., 2008).

Many studies highlight the benefits to wildlife residing in urban landscapes. The diversity and stability of prey is one benefit commonly attributed to the success of species in urban landscapes. When it comes to diet, the expectation is that generalist and opportunistic feeders will adapt more readily to human-altered landscapes (Kark et al., 2007; Kristan 


\section{Non-breeding Season Diet}

The seasonal variation in prey observed in the pellets is likely influenced by seasonal variation in prey availability. The concept of prey availability really reflects a combination of prey abundance and prey accessibility. Studies that have determined prey availability by conducting surveys of prey populations often do not consider the biology of the prey species and how that affects its accessibility to a predator (Moulton et al., 2006; Sodhi and Oliphant, 1993). The presence of a prey species at any particular location does not equate to that prey species being accessible to burrowing owls. Some prey species may be more abundant during certain periods of the year due to reproductive activity and/or due to behavioral responses to annual cycles and changes in weather (e.g., outside of dormancy periods); but these prey species may not be any more accessible due to seasonal variation in habitat structure, particularly in natural habitats. For example, WW and AER can be vegetated with very tall and dense annual grasses during the summer and early fall months following the growing season. During this time of year, rodent and ground-dwelling insects may be highly abundant but harder to detect and capture. When the grasses die off the habitat may be more open and prey species may be more easily detected and captured.

In landscapes where habitat structure is less influenced by seasonal variation, such as at FKC and especially BAK, prey species may be buffered against natural weather patterns that result in seasonal changes to vegetation and, thus, may be more available year-round. However, depending upon how prey species utilize these microhabitats, they may not be substantially more accessible even as their abundance increases.

When prey availability is high, burrowing owls may be more selective for species that are more beneficial to their overall nutritional goals. It is well documented that overall prey diversity, and especially mammal consumption, increases during the breeding season when nutritional demands for egg-laying females and growing owlets are highest (Hall et al., 2009; MacCraken et al., 1985; Maser et al., 1971; Thomsen, 1971). I observed that larger mammal species such as pocket gophers and California ground squirrels tended to only be consumed during the breeding season while smaller rodent species tended to be consumed in greater proportions during at least 
one of the non-breeding seasons. It is reasonable to expect that when young have fledged, adults shift foraging habits to smaller prey items that are easier to capture and consume. Furthermore, newly fledged owlets with less foraging skill and experience may focus on smaller prey that are easier to handle.

I observed that mammal consumption was proportionally higher during the cold/wet season than the hot/dry season for most sites (Hall et al., 2009). It is reasonable to expect that the diversity of prey is lowest during the coldest and wettest portion of the year, particular with respect to exothermic species (invertebrates, reptiles, and amphibians) (Hall et al., 2009). Burrowing owls may also be increasing their intake of specific prey species, particularly vertebrates, in preparation for the forthcoming breeding season. In reality, it is probably a combination of both. However, the similarities in prey consumption between nest and non-nest burrows at each site suggests that burrowing owl biology may be a substantial driver in the selection of prey species regardless of seasonal variation in prey availability.

\section{Reproduction and Diet}

The effects of variation in the species of prey consumed on burrowing owl survival and productivity has not been established. While a greater diversity of prey may be available in human-altered areas, an increasing reliance on invertebrate prey may be detrimental to productivity due to a lack of sufficient nutrition. Vertebrates are nutritionally important, particularly for nutrients such as calcium which females require high amounts of during egg production (St. Louis and Breebaart, 1991). Thus, vertebrate biomass is considered important to reproductive success. The amount of energy expended to capture an equivalent biomass of invertebrate prey to one individual vertebrate prey would be many times greater. Burrowing owls focusing their efforts on invertebrates that are more accessible in agricultural and urban environments may not be consuming sufficient calories and nutrients and may have reduced reproductive success, and possibly reduced overall health. Owls in the Imperial Valley have been observed to feed almost exclusively on invertebrates and have shown the lowest productivity in California (DeSante et al., 2004; Rosenberg and Haley, 2004; York et al., 2002). Whether or not this is causative or correlative is unknown, but similar observations have been made for other species. Tella et al. 
(1996) found that lesser kestrels (Falco naumanni) have higher nest success in urban landscapes, but also have higher nestling starvation rates, which they attributed to lower prey availability compared to rural landscapes.

\section{Conclusion}

This is the first study to comprehensively quantify the food habits of the burrowing owl at multiple study sites over the same 12-month period anywhere within the species range. This is also one of few studies that have simultaneously collected data in habitats exposed to a gradient of human alteration, ranging from relatively natural grasslands to densely developed urban areas. This study also contributes to the small number or reports of food habits during the non-breeding season. Additional long-term research will contribute greatly to understanding burrowing owl ecology in human-altered landscapes, which is vital to developing successful conservation strategies.

Lands within the range of burrowing owls within California will continue to be developed, resulting in fewer acres of open natural habitat available for this species. Much of the San Joaquin Valley is already developed for urban or agricultural uses; however urban development will continue to expand and will consume areas currently in agricultural use. California's population is projected to increase $1.3 \%$ annually between 2010 and 2020 , reaching 44 million by 2020 (California Department of Finance, 2007). The San Joaquin Valley is expected to be home to 11.2 percent of the state-wide population, just over 5 million residents. Kern County, the location of three of my study sites, is expected to experience a $24.9 \%$ population increase in the coming decade resulting in additional residential and commercial development. Other forms of development are also increasingly affecting natural habitats, such as solar arrays, oil extraction, and transportation infrastructure.

Food habits are only one factor in determining the productivity and survival of burrowing owls in human altered landscapes, and while prey species may be more stable and accessible to burrowing owls, there are a number of unique hazards not typical of natural landscapes that burrowing owls face. Exposure to pesticides is likely to be more common and may negatively 
affect reproductive success. Septon and Marks (1996) observed thinning of peregrine falcon (Falco peregrines) egg shells in towns in the Great Lakes region. Gervais et al. (2003) also observed egg shell thinning in burrowing owls nesting in agricultural complexes in the San Joaquin Valley and Imperial Valley of California. Disease transmission may also be a problem in human-altered landscapes. High rates of Cooper's hawk (Accipiter cooperii) nestling mortality have been attributed to an avian disease, trichomoniasis, transmitted from consumed doves (Family Columbidae)(Estes and Mannan, 2003).

\section{Where Do We Go From Here?}

Burrowing owls are clearly able to adapt to human-altered landscapes, and may even prefer such areas. If burrowing owls can survive and reproduce successfully in agricultural and urban environments, then conservation strategies such as urban open space resources may preserve burrowing owl populations, and possibly encourage growth. However, a greater understanding of overall burrowing owl ecology is necessary for the development of adequate conservation strategies.

There is clearly a relationship between human alteration of habitat and burrowing owl diet; however, more research is needed, particularly in urban landscapes. A clearer picture of prey availability, considering both accessibility and abundance during different times of the year, should be developed. But before prey availability can be adequately assessed, the availability of foraging habitat needs to be determined. Several studies have examined foraging behavior in natural landscapes (Poulin and Todd, 2006; Haug and Oliphant, 1990), but identifying where burrowing owls forage in agricultural and urban landscapes is not as well understood. Long-term studies of both burrowing owl diet and prey availability are necessary to better understand this dynamic.

The effects of local weather patterns and climate change on prey availability could also be explored to identify shifts in prey diversity and availability through a long-term research effort at sites with varying degrees of human alteration. Some prey species may be more stable, either through continued presence of certain prey species throughout the year or the presence of a wider diversity of prey species from which burrowing owls can choose. Increased stability and 
availability of prey in urban areas has been observed as a benefit to other predators including Cooper's hawk nesting in urban areas (Estes and Mannan, 2003) and Mississippi kites (Ictinia mississippiensis) in urban and agricultural areas (Parker, 1996). Prey availability may go through greater cycles of highs and lows in more natural settings, which would likely result in similar cyclical reproductive output from burrowing owls. However, prey diversity and availability for burrowing owls needs to be thoroughly documented in human-altered landscapes.

Beyond diet, other aspects of burrowing owl ecology in human-altered environments should be studied in greater detail. It is important to understand how reproductive success varies between natural and artificial landscapes, and how other factors affect reproduction and survival such as diet, mortality factors, resource competition with other species (e.g., San Joaquin kit foxes [Vulpes macrotis mutica] in BAK), and both direct and indirect human impacts. It may also be useful to understand if the burrowing owl population within the San Joaquin Valley is comprised of residents, migrants, or a combination of both.

\section{Limitation, Assumptions, Biases}

Burrowing owl ecology, like that of many other wildlife species, is reflective of the particular region the owl inhabits is located. While the composition of prey I observed is specific to the San Joaquin Valley, the general patterns of prey consumption I observed likely apply to similarly human-altered landscapes. Seasonal patterns observed are likely most applicable to the southern portion of the burrowing owls' North American range. The patterns observed between nest and non-nest burrows would be applicable to burrowing owls throughout their range. The details reported in burrowing owl food habits studies vary greatly, making them difficult to directly compare to my study. Many did not identify all prey to similar taxonomic levels or did not report the complete array of taxa that they identified. The methods of pellet collection and analysis also vary between my study and many others that have been conducted.

I examined burrowing owl food habits during one year, which included a period of above average precipitation during the $2004 / 2005$ winter rainy season following a pattern of drought. Local weather patterns can greatly affect habitat condition (e.g., vegetative growth) and prey availability; however, it is hoped that the generalist, opportunistic nature of burrowing owls gives 
them the ability to adapt to changes in prey that may result from changes in local weather patterns.

The importance of some prey items may be understated through pellet analysis. Softbodied prey species tend to be more fully digested, and some prey species may not be consumed in large enough portions to facilitate identification from pellet remains. For example, birds may be more important to burrowing owl diet than is commonly reported, particularly in urban environments where bird abundance is expected to be more stable (Estes and Mannan, 2003). However, bird remains may be more difficult to identify in pellets, or altogether absent, if burrowing owls do not consume skeletal parts or diagnostic feathers. Similar problems are likely encountered with amphibians (Grant, 1965), reptiles, and soft-bodied insects (e.g., moths), as well as larger vertebrate prey that burrowing owls may not consume in large pieces (Plumpton and Lutz, 1993). In addition, multiple pellets may contain remains from a single prey item, particularly large vertebrate species. As such, the abundance of such prey could be overestimated through pellet analysis.

Finally, food habits are just one part of the complex picture of burrowing owl ecology. Many other factors affect burrowing owl productivity and survival and should be addressed for individuals occupying this portion of the species' range. Such research would assist with development of effective conservation strategies for burrowing owls occurring in the San Joaquin Valley. 


\section{Literature Cited}

Bloom, P. H., and M. D. McCrary. 1996. The urban Buteo: red-shouldered hawks in southern California. Pages 31-39 in Raptors in Human Landscapes: Adaptations to Built and Cultivated Environments. Academic Press, San Diego. 396 pp.

California Department of Finance. 2007. County population projections with race/ethnic detail. Sacramento. July 2007.

City of Bakersfield. 2011. Bakersfield population and area. Prepared by the Bakersfield Planning Department. Available at:

http://www.bakersfieldcity.us/cityservices/devsrv/pdfs/population_and_housing_data.pdf

Conroy, R.M. and D.L. Chesemore. 1987. Food habits of the Burrowing Owl (Athene cunicularia) in Fresno County, California. pp. 105-110 in D.F. Williams, S. Byrne, and T.A. Rado (eds.). Endangered and sensitive species of the San Joaquin Valley, California: their biology, management, and conservation. California Energy Commission, Sacramento, California, USA.

Coulombe, H. N. 1971. Behavior and population ecology of the burrowing owl, Speotyto cunicularia, in the Imperial Valley of California. Condor 73:163-176.

DeSante, D. F., E. D. Ruhlen, S. L. Adamany, K. M. Burton, and S. Amin. 1997. A census of burrowing owls in central California in 1991. Raptor Research Reports No. 9:38-48.

DeSante, D. F., E. D. Ruhlen, and D. K. Rosenberg. 2004. Density and abundance of burrowing owls in the agricultural matrix of the Imperial Valley, California. Studies in Avian Biology 27:116-119.

DeSante, D. F., E. D. Ruhlen, and R. Scalf. 2007. The distribution and relative abundance of burrowing owls in California during 1991-1993: evidence for a declining population and thoughts on its conservation. pages 1-41, in Barclay, J.H., K.W. Hunting, J.L. Lincer, J. Linthicum, and T.A. Roberts (Eds.). 2007. Proceedings of the California Burrowing Owl Symposium, November 2003. Bird Populations Monographs No. 1. The Institute for Bird Populations and Albion Environmental, Inc., Point Reyes Station, CA, vii + 197pp.

Estes, W. A., and R. W. Mannan. 2003. Feeding behavior of Cooper's hawks at urban and rural nests in southeastern Arizona. Condor 105:107-116.

Gehlbach, F. R. 1996. Eastern screech owl in suburbia: a model of raptor urbanization. Pages 69-75 in Raptors in Human Landscapes: Adaptations to Built and Cultivated Environments. Academic Press, San Diego. 396 pp.

Gervais, J. A., D. K. Rosenberg, D. M. Fry, L. Trulio, and K. K. Sturm. 2003. Burrowing owls and agricultural pesticides: evaluation of residues and risks for three populations in California, USA. Environmental Toxicology and Chemistry 19(2):337-343.

Gervais, J. A., C. M. Hunter, and R. G. Anthony. 2006. Interactive effects of prey and p,p' DDE on burrowing owl population dynamics. Ecology Applications 16(2): 666-677.

Gervais, J. A., D. K. Rosenberg, and L. A. Comrack. 2008. Burrowing owl (Athene cunicularia) In Shuford, W. D., and T. Gardali (Eds.), California Bird Species of Special Concern: A Ranked Assessment of Species, Subspecies, and Distinct Populations of Birds of Immediate 
Conservation Concern in California. Studies of Western Birds 1. Western Field Ornithologists, Camarillo, California, and California Department of Fish and Game, Sacramento.

Gleason, R. L. and T. H. Craig. 1979. Food habits of burrowing owls in southeastern Idaho. Great Basin Naturalist 39:275-276.

Grant, R. A. 1965. The burrowing owl in Minnesota. Loon 37:2-17.

Green, G. A., R. E. Fitzner, R. G. Anthony, and L. E. Rogers. 1993. Comparative diets of burrowing owls in Oregon and Washington. Northwest Science, 67(2):88-93.

Hall, D. B., P. D. Greger, and J. R. Rosier. 2009. Regional and seasonal diet of the western burrowing owl in central Nevada. Western North American Naturalist 69(1):1-8.

Haug, E. A. and L. W. Oliphant. 1990. Movements, activity patterns, and habitat use of Burrowing Owls in Saskatchewan. Journal of Wildlife Management. 54:27-35.

Hennemann, W. and W. III. 1980. Notes on the food habits of the burrowing owl Athene cunicularia in Duval County, Florida. Florida Field Naturalist 8(1): 24-25.

Hoetker, G. M. and K. W. Gobalet. 1999. Predation on Mexican free-tailed bats by burrowing owls in California. Journal of Raptor Research 33(4):333-335.

Holroyd, G. L. and H. E. Trefry. 2010. Winter destinations and habitats of Canadian burrowing owls. Journal of Raptor Research 44(4):294-299.

Hutchinson, K. 1970. A test for comparing diversities based on the Shannon formula. Journal of Theoretical Biology 29:151-154.

Kark, S., A. Iwaniuk, Adam Schalimtzek, and E. Banker. 2007. Living in the city: can anyone become an 'urban exploiter'? Journal of Biogeography 34:638-635.

Koshear, J., C. Shafer, E. F. Van Mantgem, and R. V. Olsen. 2007. Burrowing owl management at Colonel Allensworth State Historic Park. pages 155-164, in Barclay, J.H., K.W. Hunting, J.L. Lincer, J. Linthicum, and T.A. Roberts (eds.). 2007. Proceedings of the California Burrowing Owl Symposium, November 2003. Bird Populations Monographs No. 1. The Institute for Bird Populations and Albion Environmental, Inc., Point Reyes Station, CA, vii+197 pp.

Kristan III, W. B., W. I. Boarman, J. J. Crayon. 2004 Diet composition of common ravens across the urban-wildland interface of the West Mojave Desert. Wildlife Society Bulletin 32(1):244253.

Littles, C. J., D. Williford, M. K. Skoruppa, M. C. Woodin, and G. C. Hickman. 2007. Diet of western burrowing owls wintering in southern Texas. Journal of Raptor Research 41(4):307313.

Lincer, J.L, and R.J. Clark. 2007. A bibliography on the burrowing owl in California. Pages 185197 in Barclay, J.H., K.W. Hunting, J.L. Lincer, J. Linthicum, and T.A. Roberts (eds.). 2007. Proceedings of the California Burrowing Owl Symposium, November 2003. Bird Populations Monographs No. 1. The Institute for Bird Populations and Albion Environmental, Inc., Pointe Reyes Station, CA, vii+197pp. 
MacCracken J. G., D. W. Uresk, and R. M. Hansen. 1985. Burrowing owl food in Conata Basin, South Dakota. Great Basin Naturalist 45(2):287-290

Martin, D. J. 1973. Selected aspects of burrowing owl ecology and behavior. Condor 75:446-456.

Maser, C., E. W. Hammer, and S. H. Anderson. 1971. Food habits of the burrowing owl in central Oregon. Northwest Science 45(1):19-26

Morgan, K. H., R. J. Cannings, and C. S. Guppy. 1993. Some foods eaten by a burrowing owl overwintering on southern Vancouver Island. Northwestern Naturalist 74:84-87.

Moulton, C. E., R. S. Brady, and J. R. Belthoff. 2006. Association between wildlife and agriculture: underlying mechanisms and implications in burrowing owls. Journal of Wildlife Management 70(3): 708-716.

Mrykalo, R.J., M.M. Grigione, and R.J. Sarno. 2009. A comparison of available prey and diet of Florida burrowing owls in urban and rural environments: a first study. Condor 111(3): 556559.

National Oceanic and Atmospheric Administration National Weather Service. 2000. Fog Season. Available at: http://www.wrh.noaa.gov/hnx/newslet/winter00/fogseason.htm

Parker, J. W. 1996. Urban ecology of the Mississippi kite. Pages 45-52 in Raptors in Human Landscapes: Adaptations to Built and Cultivated Environments. Academic Press, San Diego. $396 \mathrm{pp}$.

Plumpton, D. L. and R. S. Lutz. 1993. Prey selection and food habits of burrowing owls in Colorado. Great Basin Naturalist 53(3):299-304.

Poulin, R. G. 2003. Relationship between burrowing owls (Athene cunicularia), small mammals, and agriculture. Ph.D. Dissertation. University of Regina, Regina, Saskatchewan.

Poulin, R. G. and L. D. Todd. 2006. Sex and nest stage differences in the circadian foraging behaviors of nesting burrowing owls. Condor 108:856-864.

Poulin, R. G., L. D. Todd, E. A. Haug, B. A. Millsap and M. S. Martell. 2011. Burrowing owl (Athene cunicularia), The Birds of North America Online (A. Poole, Ed.). Ithaca: Cornell Lab of Ornithology; retrieved from the Birds of North American Online: http://bna.birds.cornell.edu/bna/species/061.

Remsen, J. V., Jr. 1978. Bird species of special concern in California. California Department of Fish and Game Nongame Wildlife Investigations, Wildlife Management Branch Administrative Report No. 78_1.

Roberts, T. A. and C. O. Gaber. 2007. Habitat loss and population status estimate for burrowing owls in the San Joaquin Valley. pages 70-75, in Barclay, J.H., K.W. Hunting, J.L. Lincer, J. Linthicum, and T.A. Roberts (Eds.). 2007. Proceedings of the California Burrowing Owl Symposium, November 2003. Bird Populations Monographs No. 1. The Institute for Bird Populations and Albion Environmental, Inc., Point Reyes Station, CA, vii+197 pp.

Rodriguez-Estrella, R. 1997. Nesting sites and feeding habits of the burrowing owl in the Biosphere Reserve of Mapimi, Mexico. Journal of Raptor Research 9:99-106.

Rosenberg, D. K. and K. L. Haley. 2004. The ecology of burrowing owls in the agroecosystem of the Imperial Valley, California. Studies in Avian Biology 27:120-135. 
Rosenberg, D.K., L.A. Trulio, D. Catlin, D. Chromczack, J.A. Gervais, N. Ronan, and K.A. Haley. 2007. The ecology of the burrowing owl in California. Unpubl. report to the Bureau of Land Management., $212 \mathrm{pp}$.

Sánchez, K.B., A. I. Malizia, M.S. Bó. 2008. Trophic ecology of the burrowing owl (Athene cunicularia) in urban environments of Mar Chiquita Biosphere Reserve (Buenos Aires Province, Argentina). Ornithologia Neotropical 19:71-80.

Schlatter, R.P., J.L. Yanez, H. Nuñez and F.M. Jaksić. 1980. The diet of the burrowing owl Athene cunicularia in central Chile and its relation to prey size. Auk 97:616-619.

Septon, G. A. and J. B. Marks. 1996. Eggshell thickness and contaminant analysis of reintroduced, urban nesting peregrine falcons in Wisconsin. Pages 25-30 in Raptors in Human Landscapes: Adaptations to Built and Cultivated Environments. Academic Press, San Diego. 396 pp.

Sissons, R. A. 2003. Food and habitat selection of male burrowing owls (Athene cunicularia) on southern Alberta grasslands. M.S. Thesis. University of Alberta, Edmonton, Alberta, Canada. $92 \mathrm{pp}$.

Sodhi, N. S. and L. W. Oliphant. 1993. Prey selection by urban-breeding merlins. Auk 110(4):727-735.

St. Louis , V. L., and L. Breebaart. 1991. Calcium supplements in the diet of nestling tree swallows near acid sensitive lakes. Condor 93:286-294.

State of California, Department of Finance. 2009. E-4 Population Estimates for Cities, Counties and the State, 2001-2009, with 2000 Benchmark. Sacramento, California, May 2009.

Tella, J. L., F. Hiraldo, J. A. Donazar-Sancho, and J. J. Negro. Costs and benefits of urban nesting in the lesser kestrel. Pages 53-60 in Raptors in Human Landscapes: Adaptations to Built and Cultivated Environments. Academic Press, San Diego. 396 pp.

Thomsen, L. 1971. Behavior and ecology of burrowing owls on the Oakland Municipal Airport. Condor 73:177-192.

United States Department of Agriculture. 2011. California Agricultural Statistics, 2010 Crop Year. National Agricultural Statistics Service. California Field Office. October 28, 2011.

University of Utah. 2011. Meso West. Department of Atmospheric Sciences. Retrieved from http://mesowest.utah.edu/index.html.

Wesemann, T. and M. Rowe. 1987. Factors influencing the distribution and abundance of burrowing owls in Cape Coral, Florida. Pages 129-137 in Integrating man and nature in the metropolitan environment. (Adams, L. W. and D. L. Le, Eds.) Natl. Inst. Urban Wildl. Columbia, MD.

Western Regional Climate Center. 2009. Bakersfield WSO ARPT, California (040442), Period of Record Monthly Climate Summary, Period of Record: 10/1/1937 to 4/30/2099. Available at: http://www.wrcc.dri.edu/cgi-bin/cliMAIN.pl?ca0442.

Wilkerson, R. L., and R. B. Siegel. 2010. Assessing changes in the distribution and abundance of burrowing owls in California, 1993-2007. Bird Populations 10:1-36. 
Williford, D. L., M. C. Woodin, M. K. Skoruppa, and G. C. Hickman. 2007. Characteristics of roost sites used by burrowing owls (Athene cunicularia) wintering in southern Texas. The Southwestern Naturalist 52(1):60-66.

Woodin, M. C., M. K. Skoruppa, and G. C. Hickman. 2007. Winter ecology of the western burrowing owl (Athene cunicularia hypugaea) in southern Texas, 1999-2004. U.S. Geological Survey Scientific Investigations Report 2007-5150, 33p.

York, M. M., D. K. Rosenberg, and K. K. Sturm. 2002. Diet and food-niche breadth of burrowing owls (Athene cunicularia) in the Imperial Valley, California. Western North American Naturalist 62(3):280-287.

Zar, Jerrold H. 1996. Biostatistical Analysis, 3rd edition. Upper Saddle River, New Jersey: Prentice Hall. 


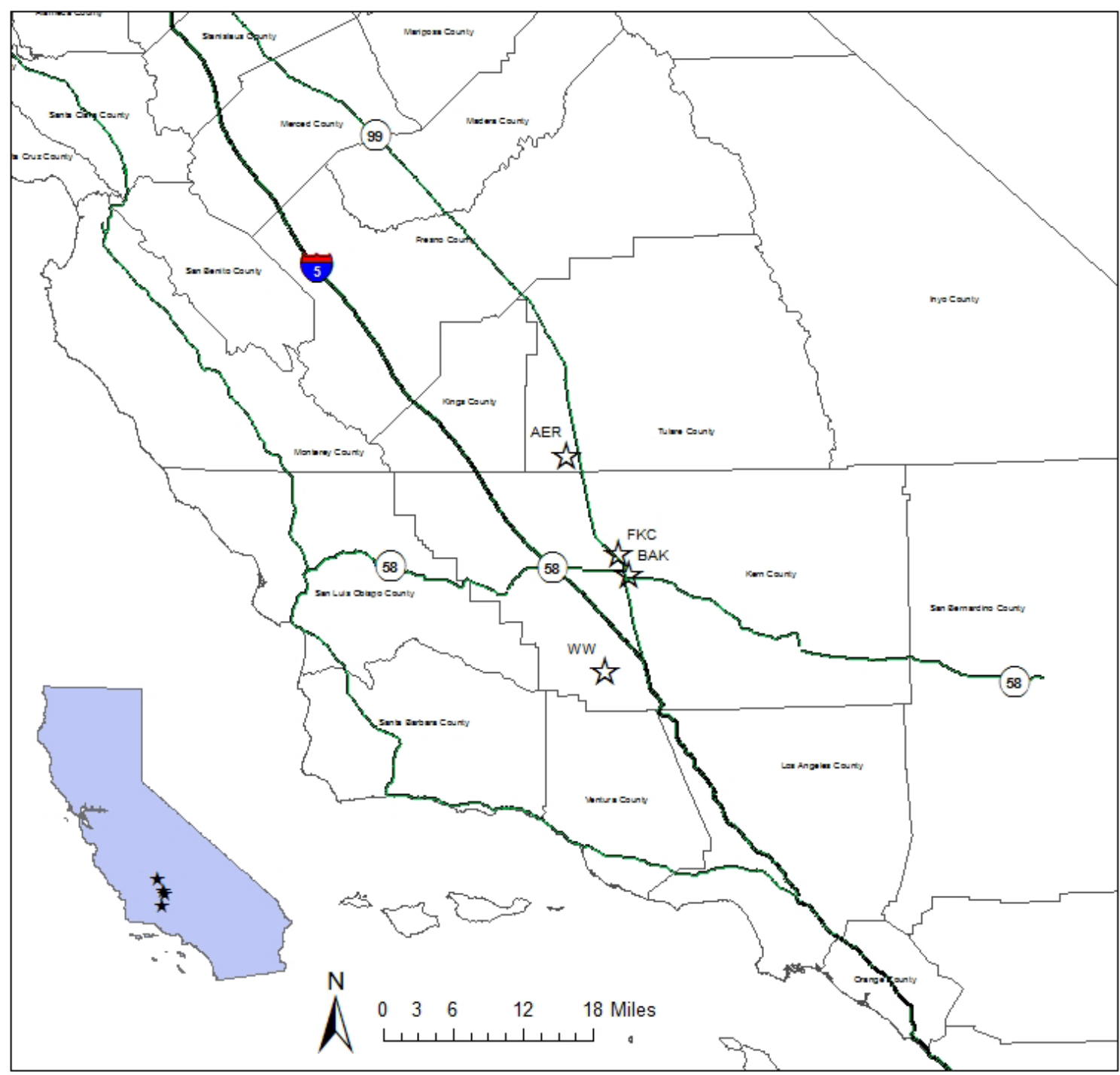

Figure 2.1. Regional view of study sites. AER - Allensworth Ecological Reserve; FKC - Friant Kern Canal; BAK - Bakersfield; WW - Wind Wolves Preserve. 


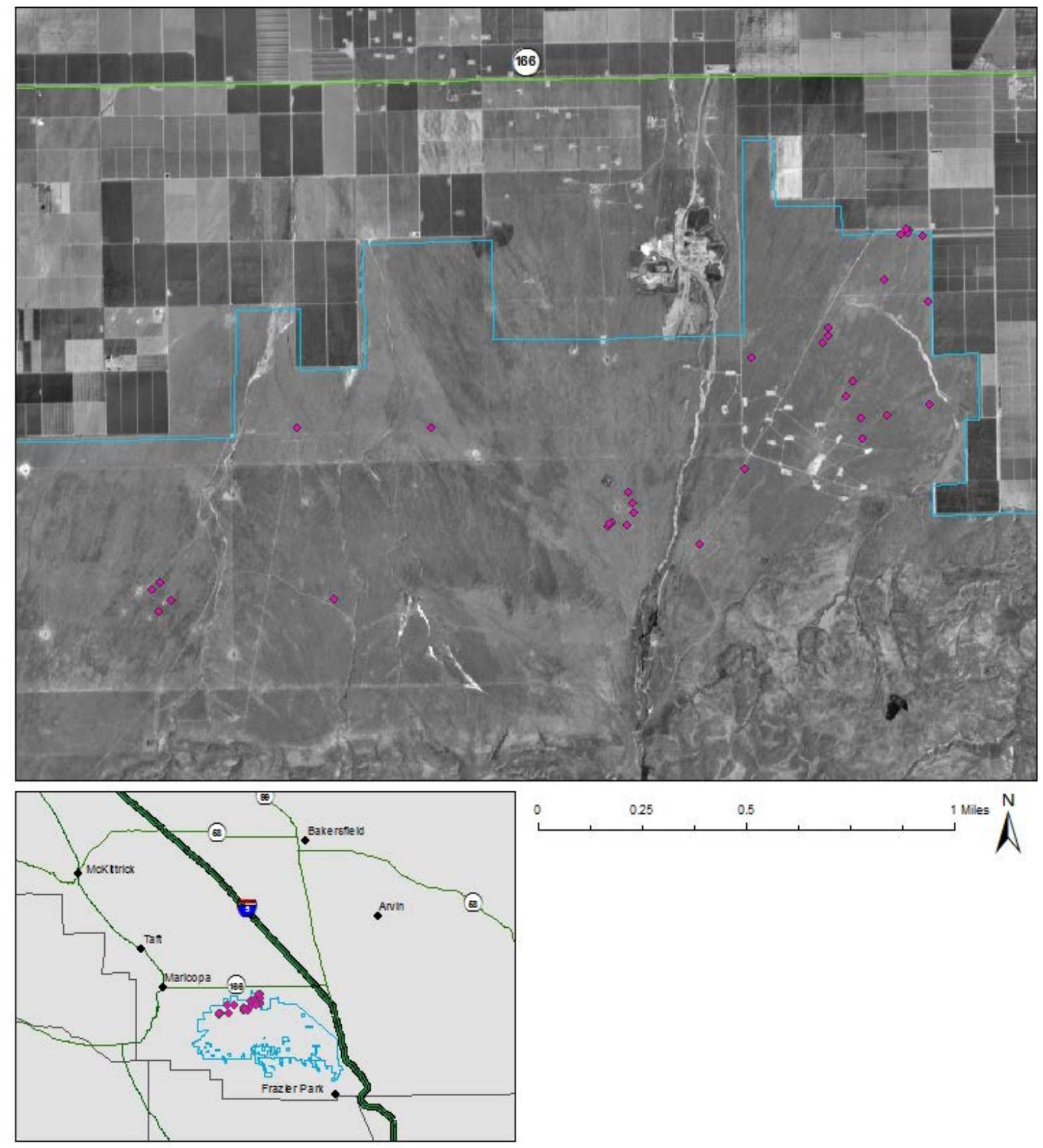

Figure 2.2. Wind Wolves (WW) Preserve study site. Preserve boundary is outlined in blue and burrows are depicted by pink dots. Imagery source: California Department of Water Resources, 2004. 

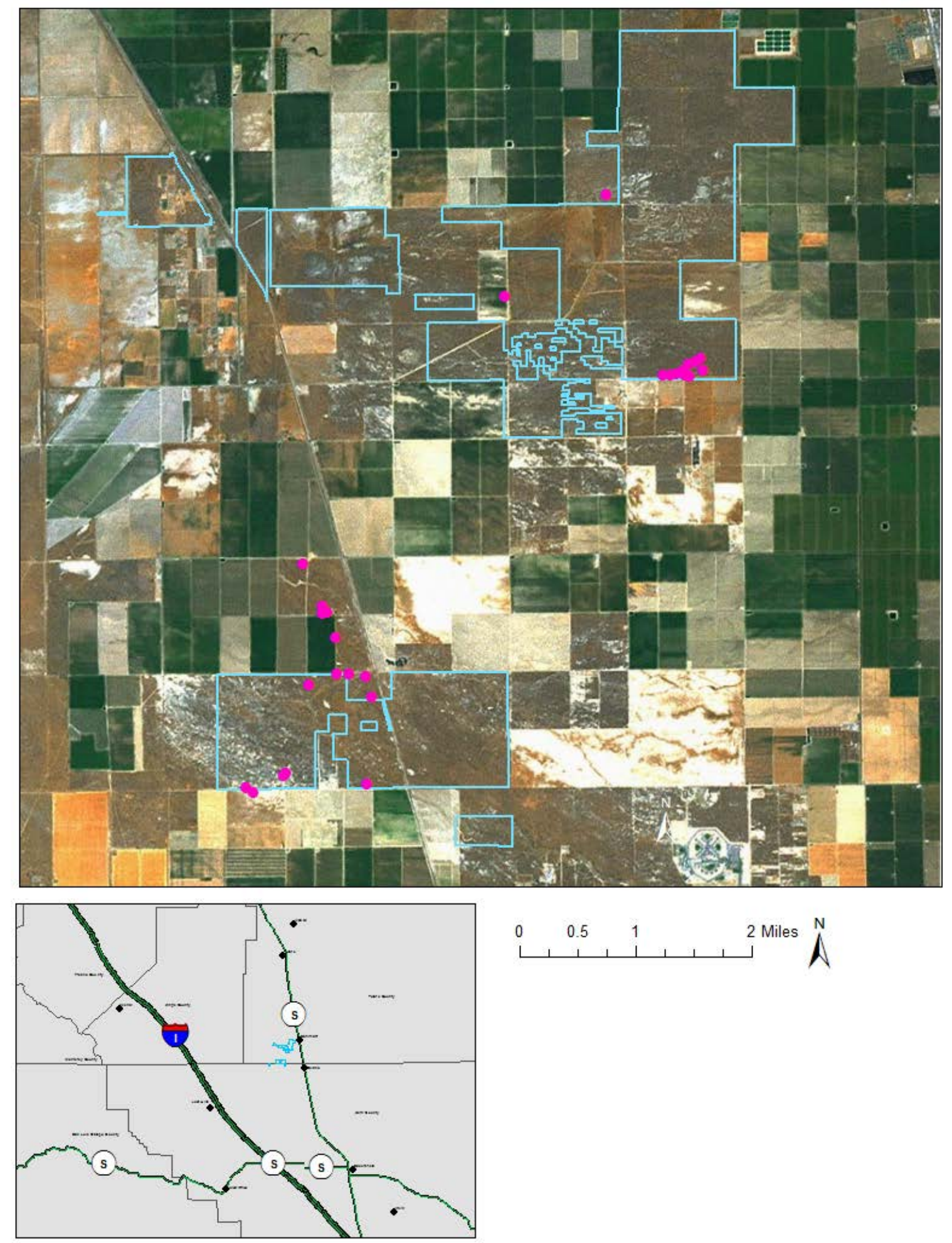

Figure 2.3. Allensworth Ecological Reserve (AER) study site. Reserve boundary is outlined in white and burrows are depicted by pink dots. Imagery source: ESRI, 2012. 


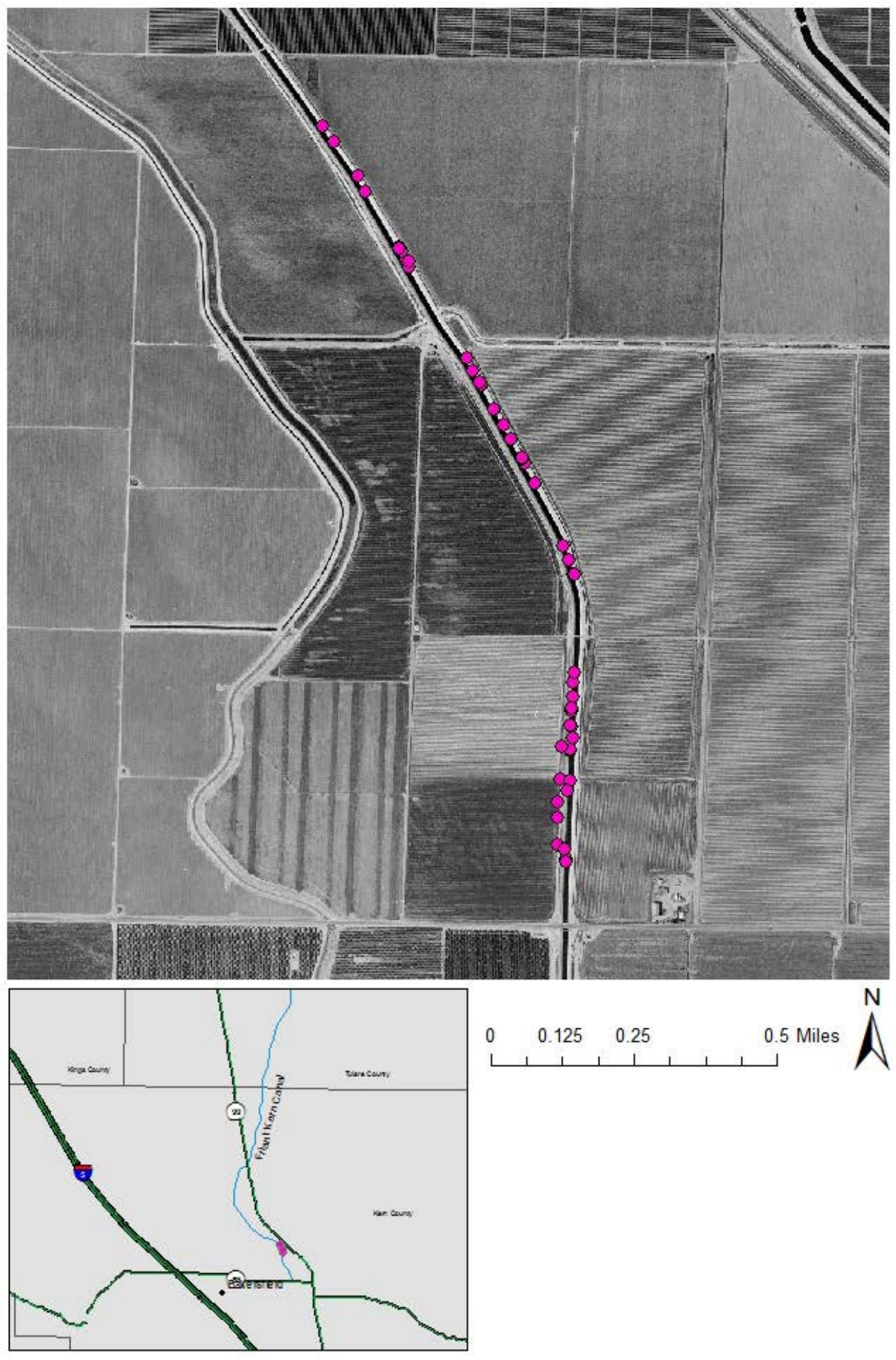

Figure 2.4. Friant Kern Canal (FKC) study site. Burrows are depicted by pink dots. Imagery source: Airphoto USA, 2003. 


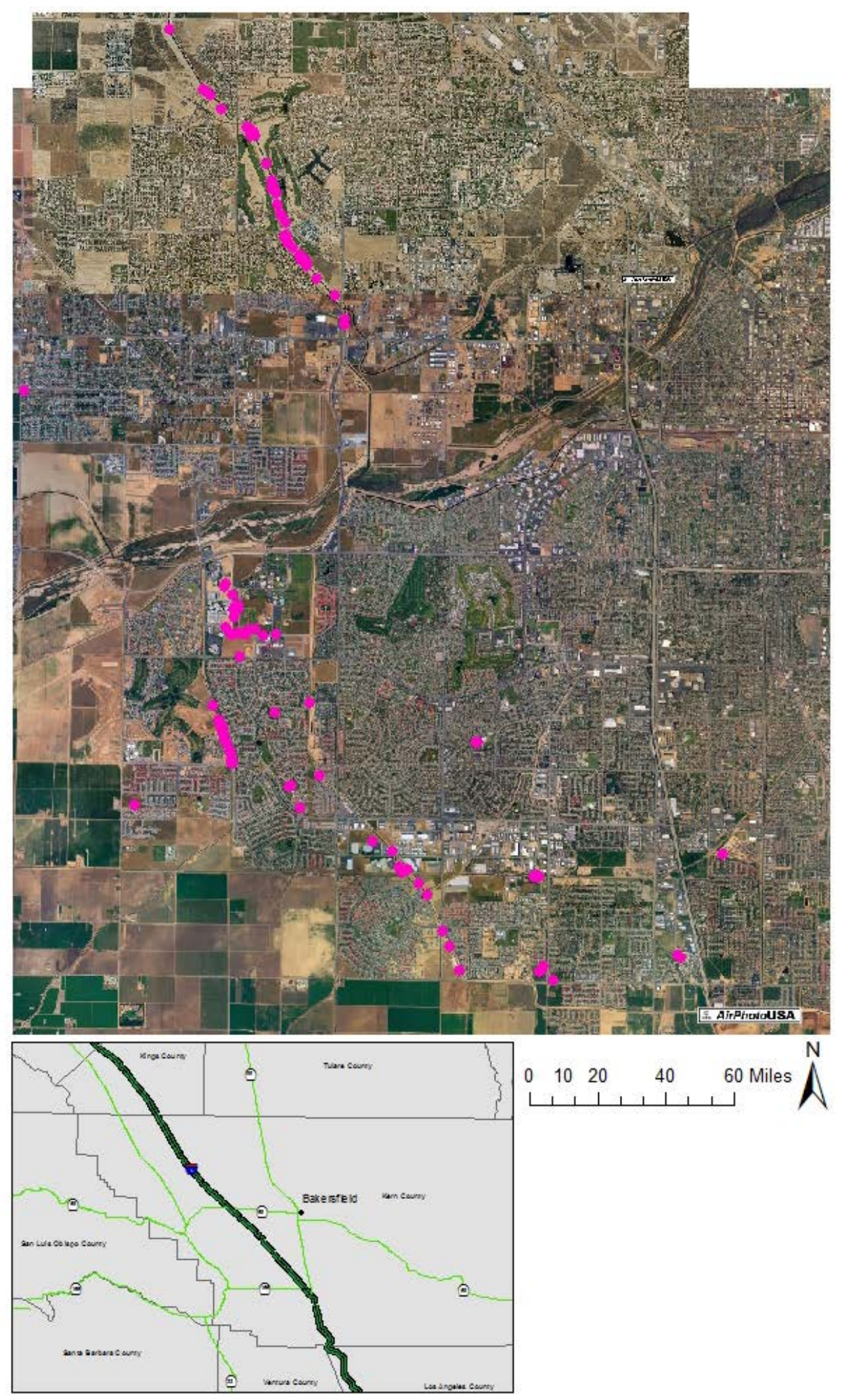

Figure 2.5. City of Bakersfield (BAK) study site. Burrows are depicted by pink dots. Imagery Source: AirPhoto USA, 2003. 


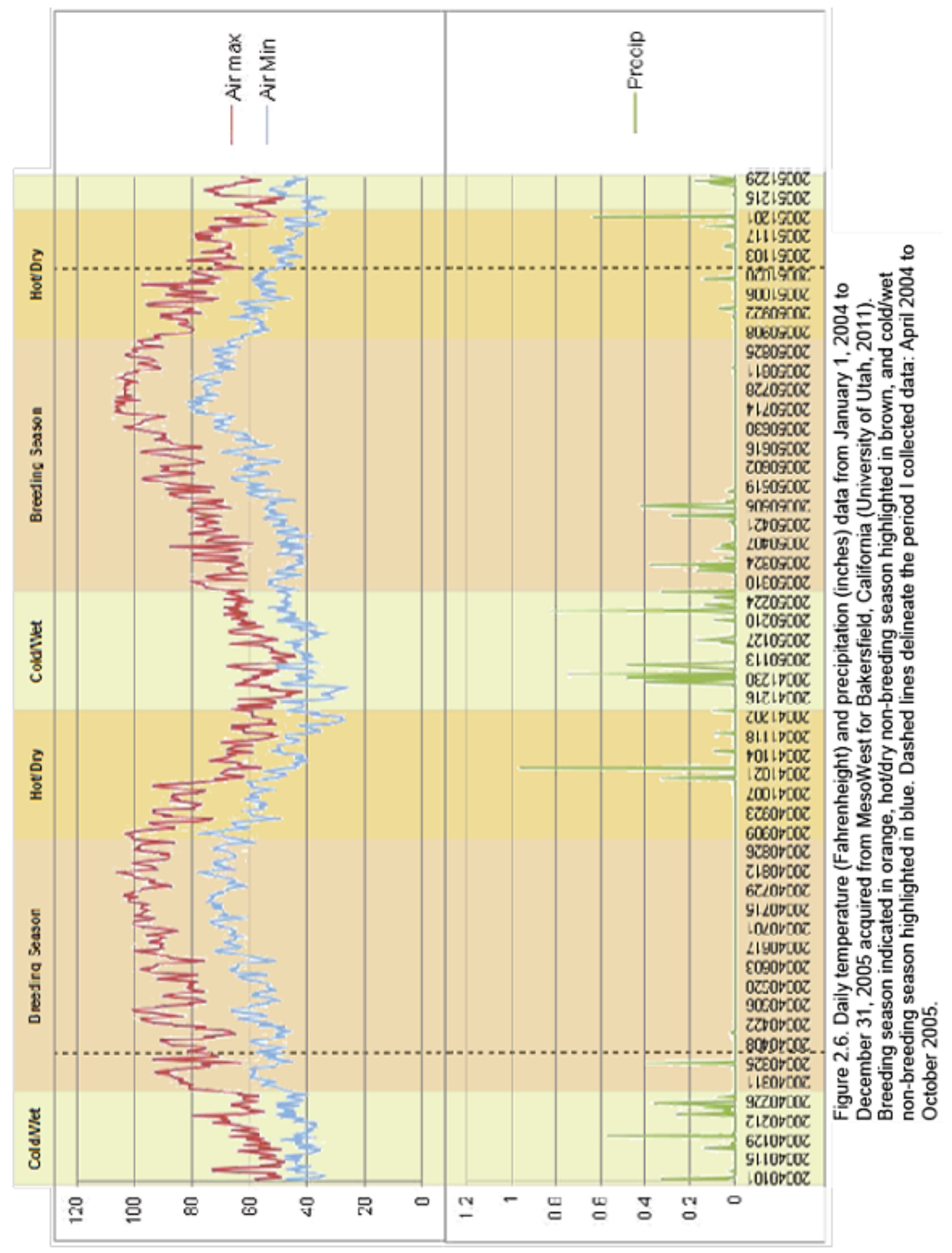




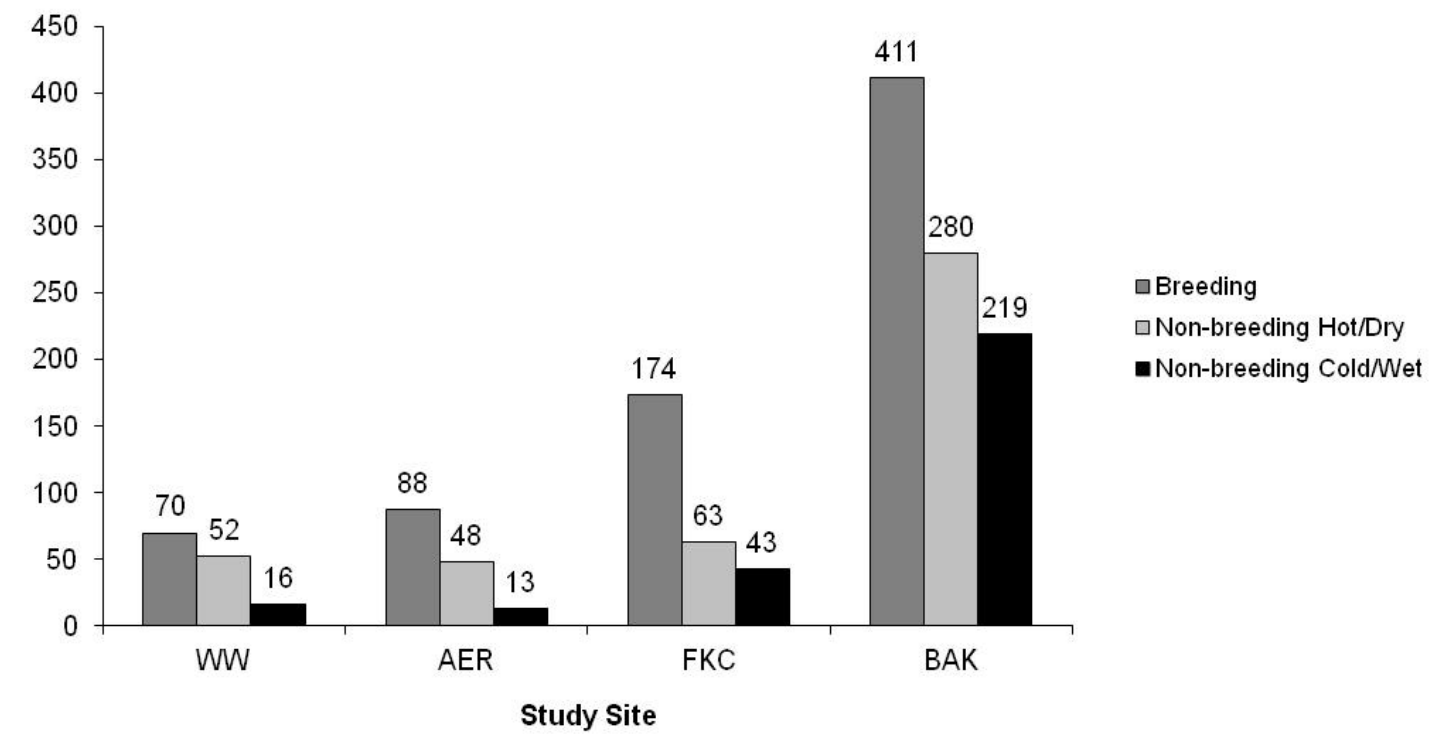

Figure 2.7. Total number of pellets collected by season for WW (138), AER (149), FKC (280), and BAK (910). 


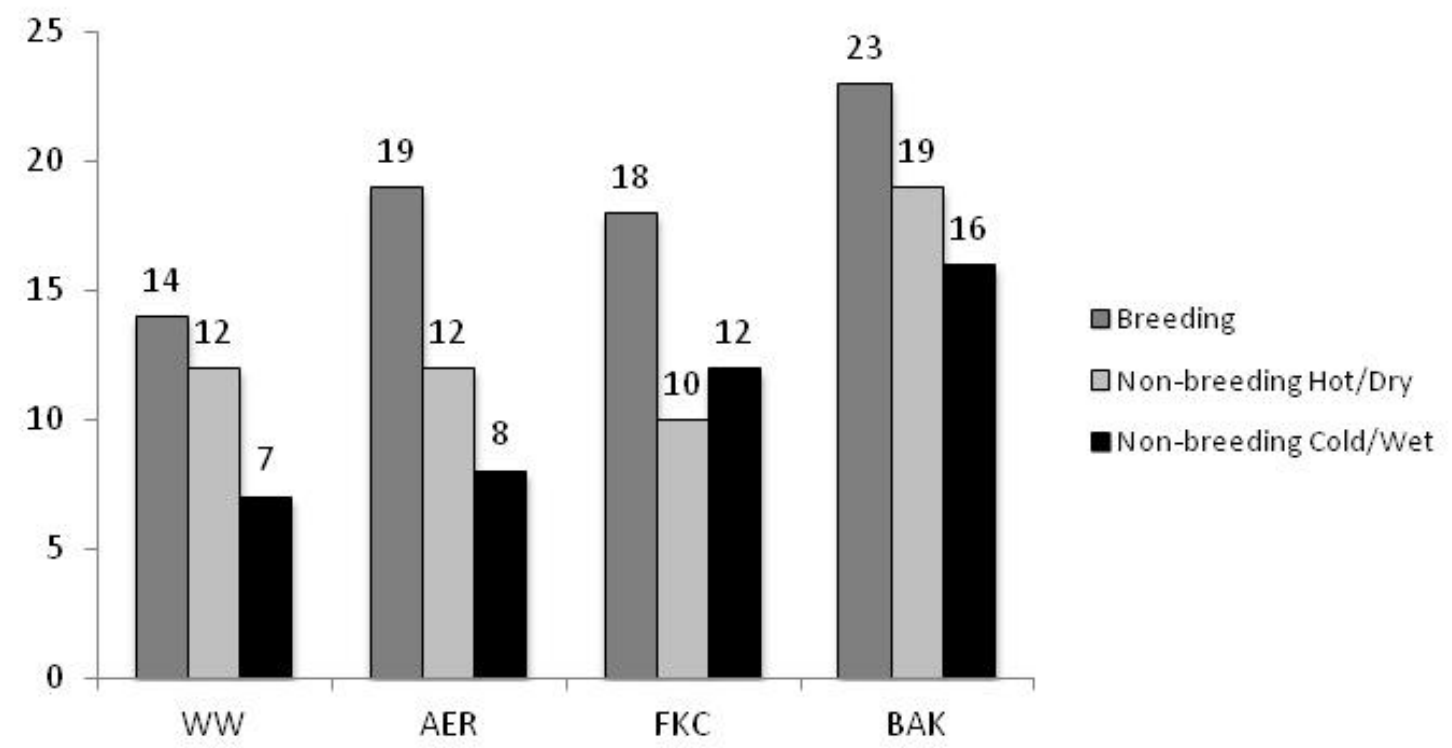

Figure 2.8. Total number of taxa represented in the pellets per season per study site. These numbers reflect the lowest taxonomic levels identified and do not include higher levels if a lower level was found. 


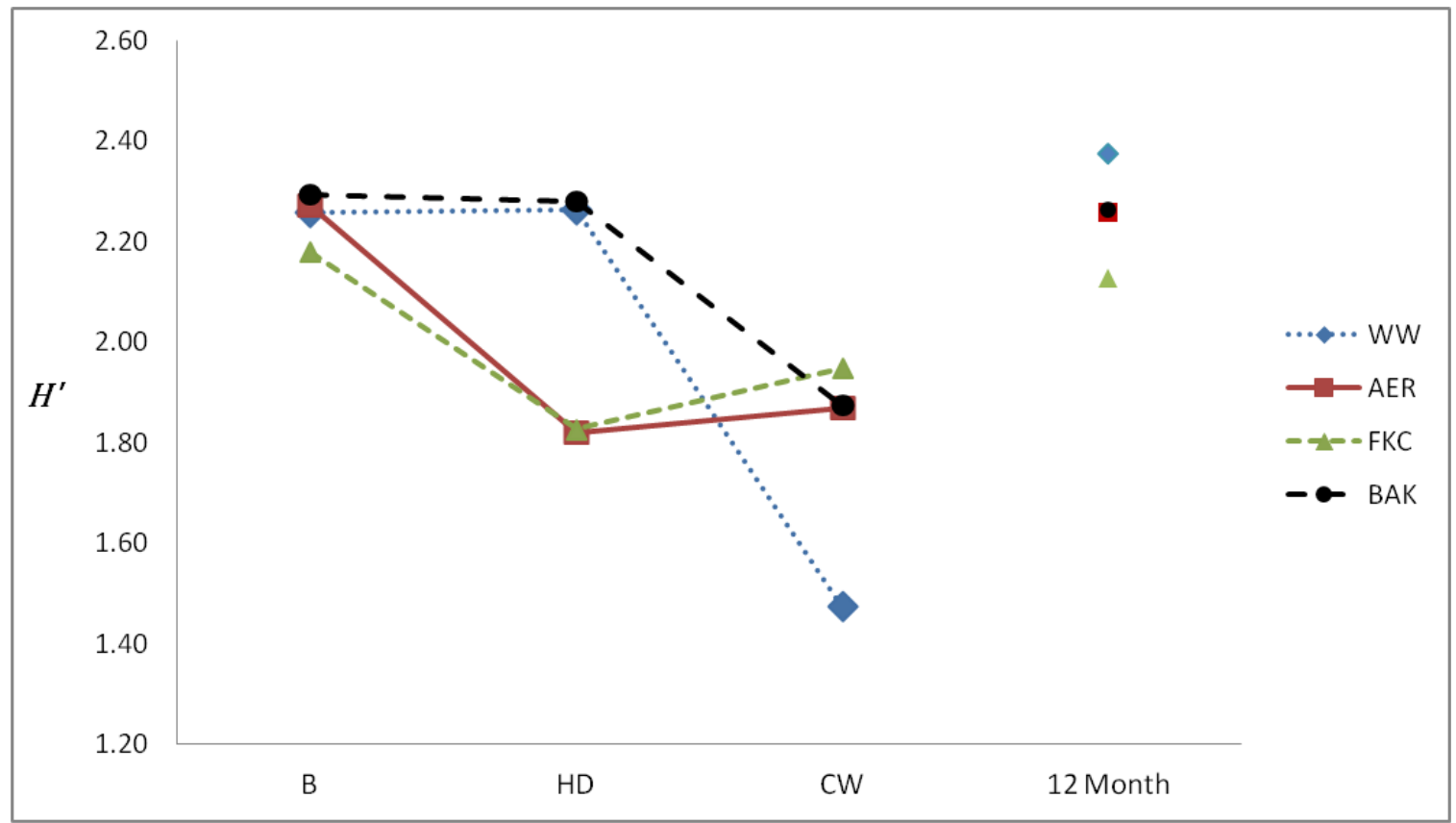

Figure 2.9. Shannon-Weiner index $(H)$ calculated for each season and for the full 12-month study period for each study site. 


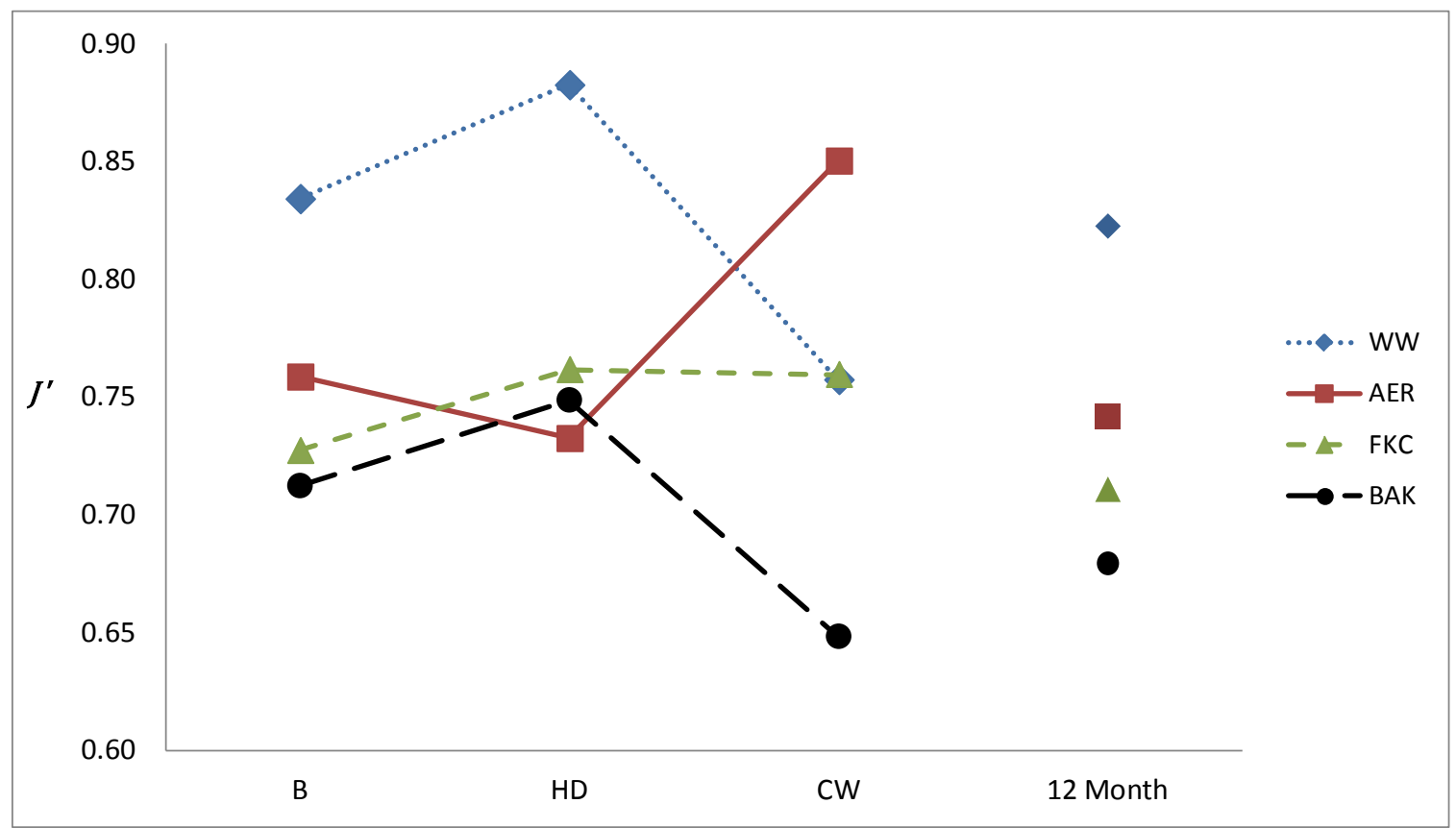

Figure 2.10. Diversity evenness $(J)$ calculated from Shannon-Weiner Index for each season and for the full 12-month study period for each study site. 


\section{Breeding - Mammal}

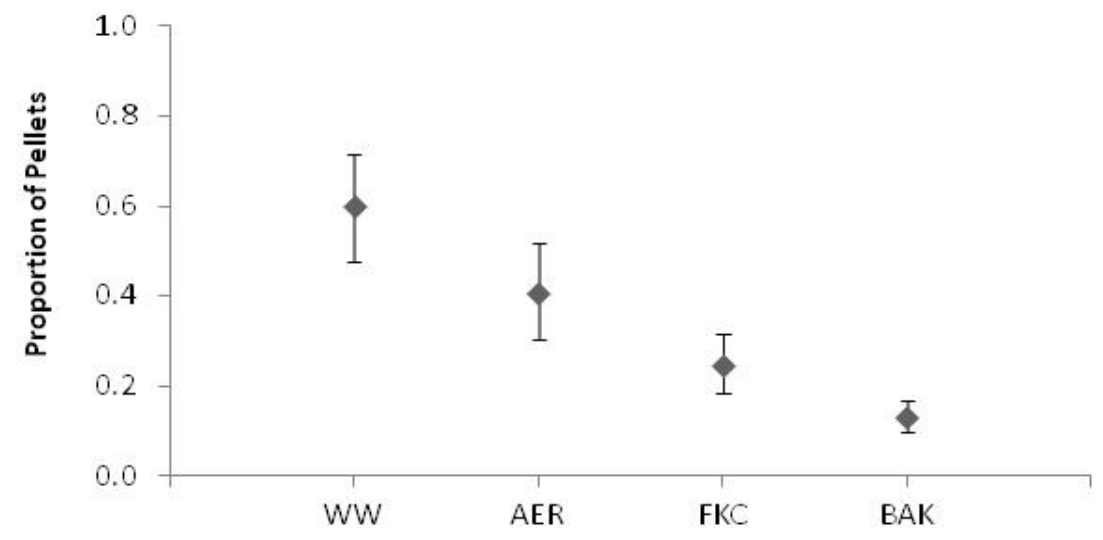

\section{Hot/Dry - Mammal}

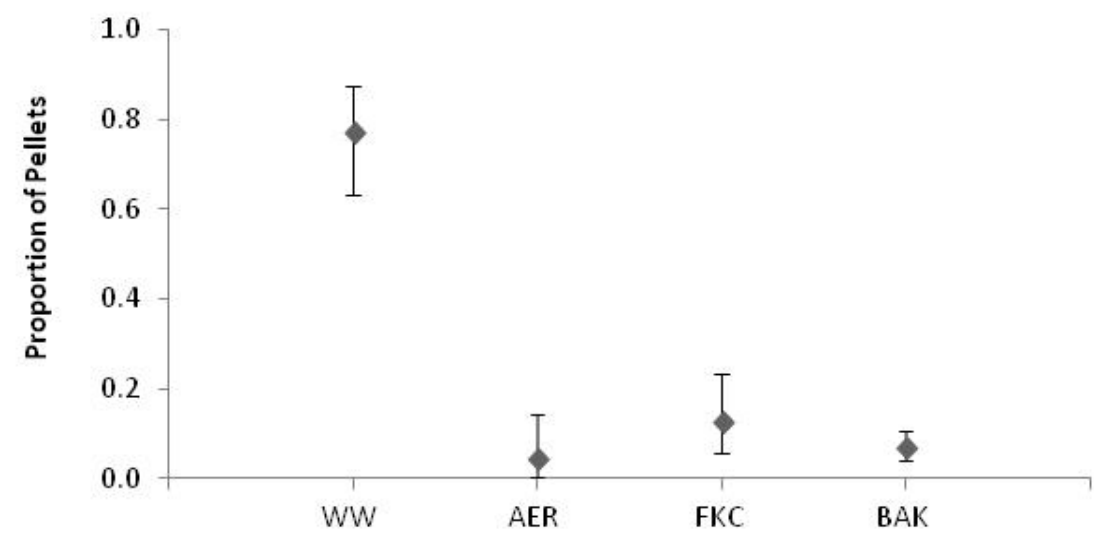

Cold/Wet - Mammal

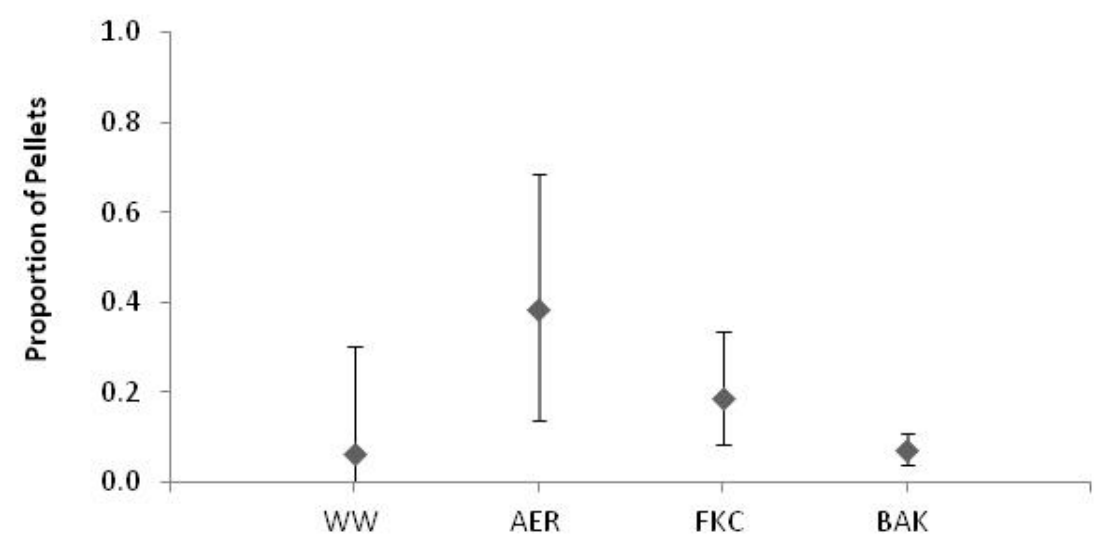

Figure 2.11. Proportions of pellets containing mammal prey items for each season. Error bars represent $95 \%$ confidence intervals. 


\section{Breeding - Reptile/Amphibian}

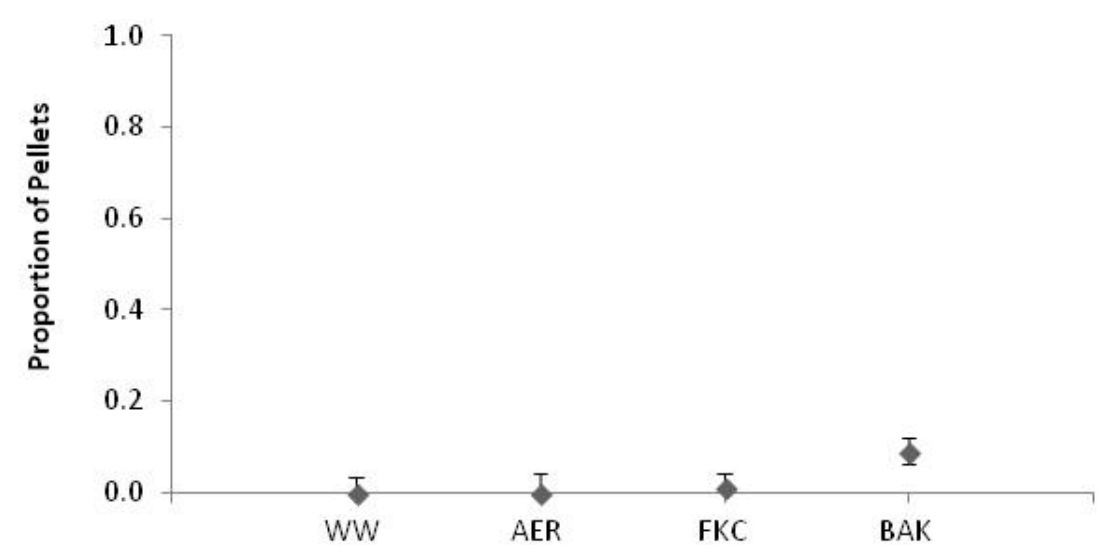

\section{Hot/Dry - Reptile/Amphibian}

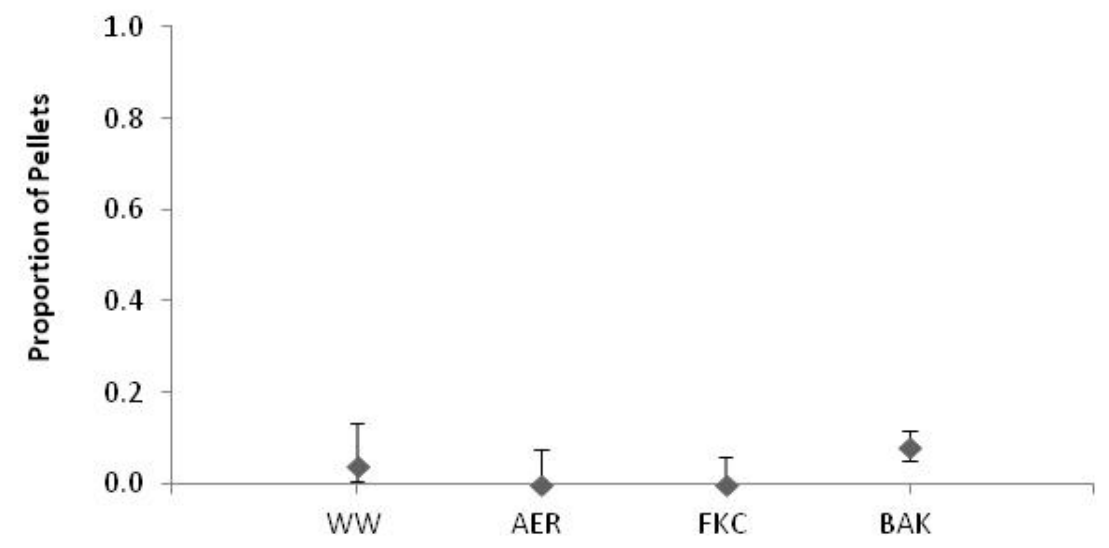

\section{Cold/Wet - Reptile/Amphibian}

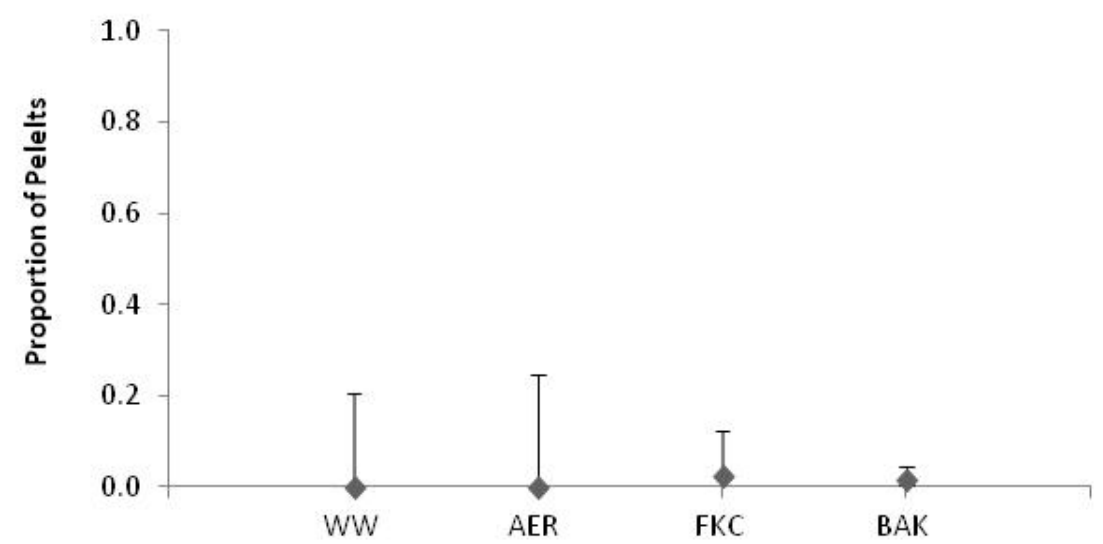

Figure 2.12. Proportions of pellets containing reptile/amphibian prey items for each season. Error bars represent 95\% confidence intervals. 


\section{Breeding - Bird}

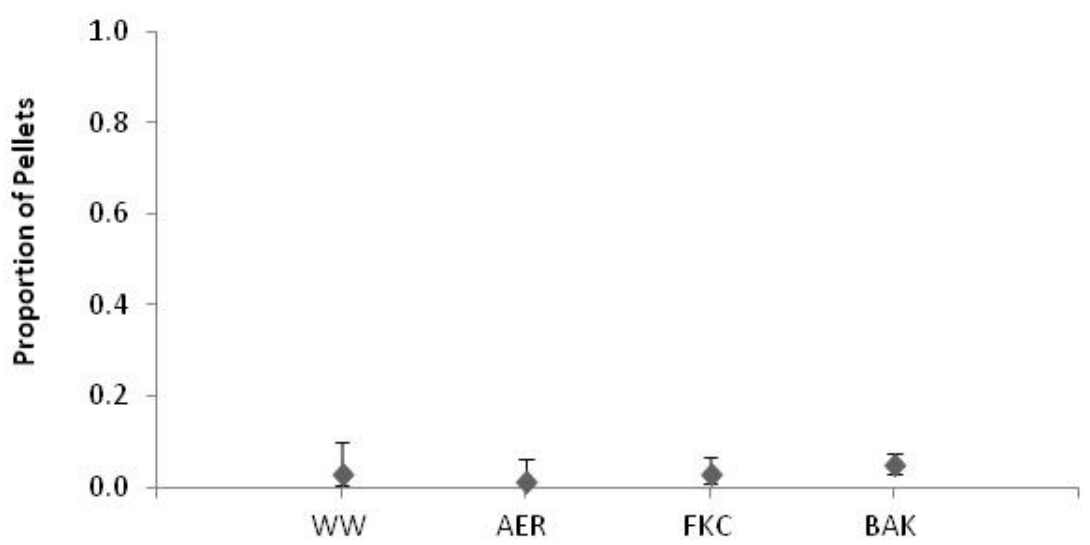

\section{Hot/Dry - Bird}

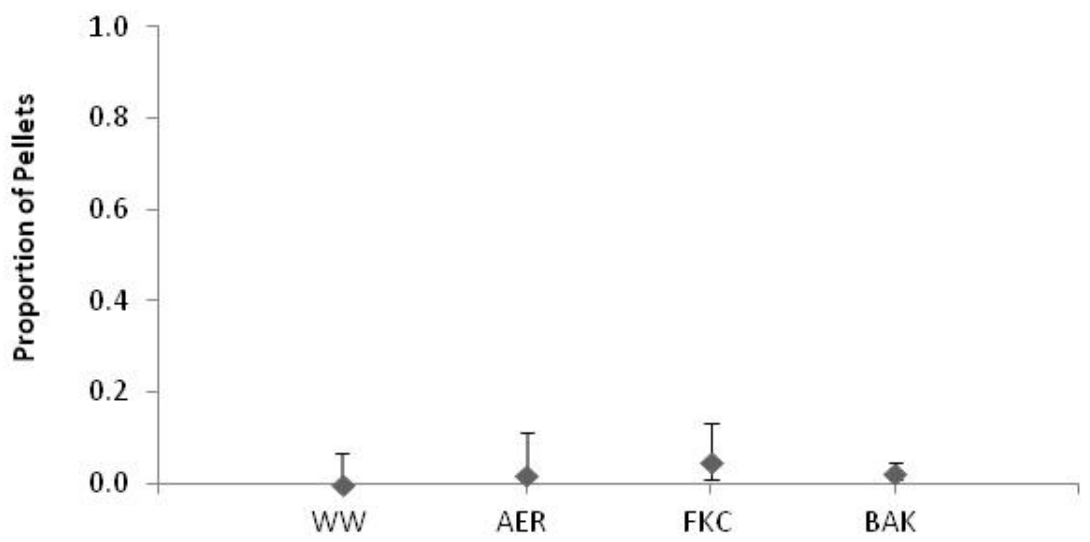

Cold/Wet - Bird

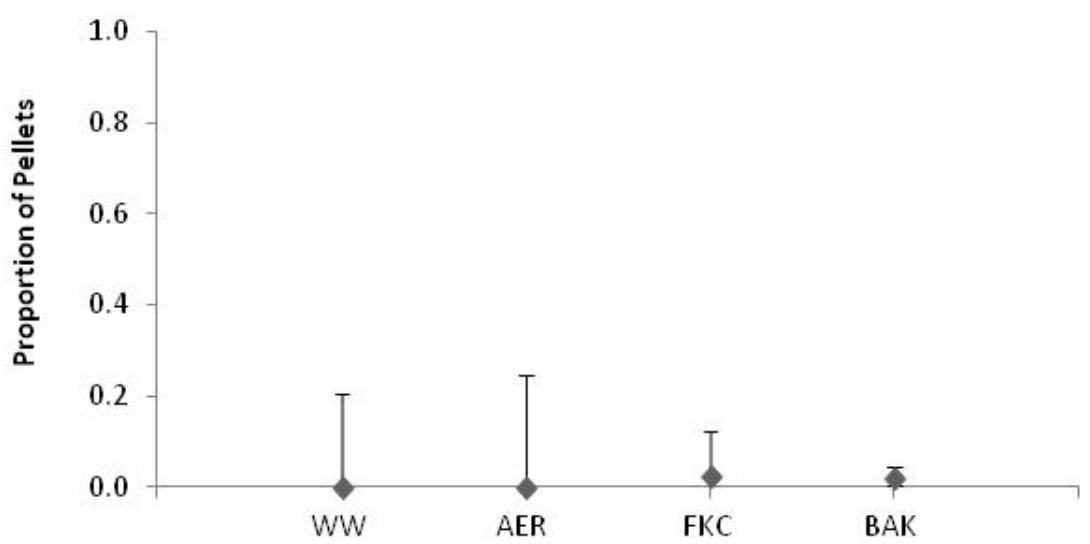

Figure 2.13. Proportions of pellets containing bird prey items for each season. Error bars represent $95 \%$ confidence intervals. 


\section{Cold/Wet - Coleoptera}

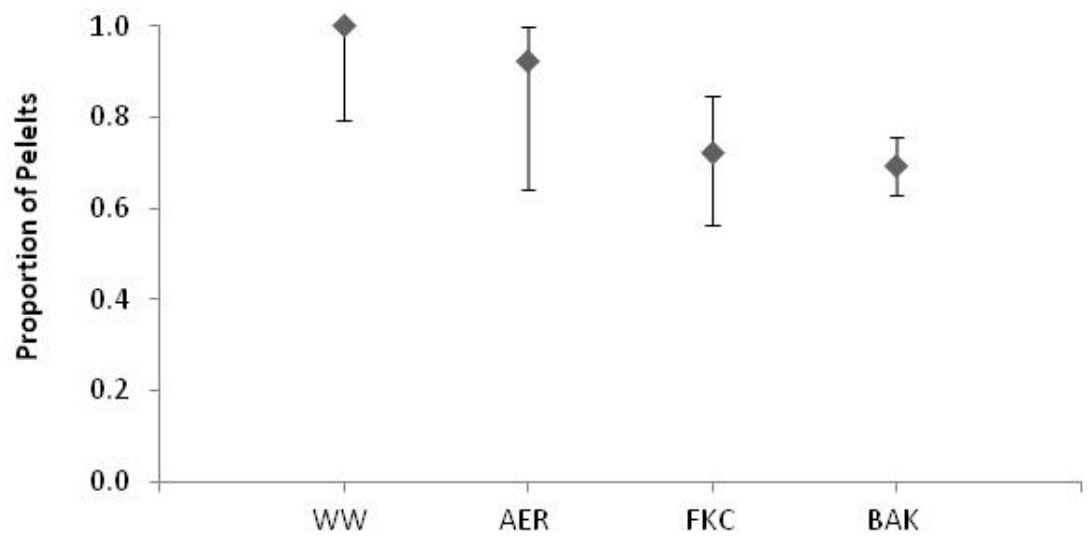

\section{Breeding - Coleoptera}

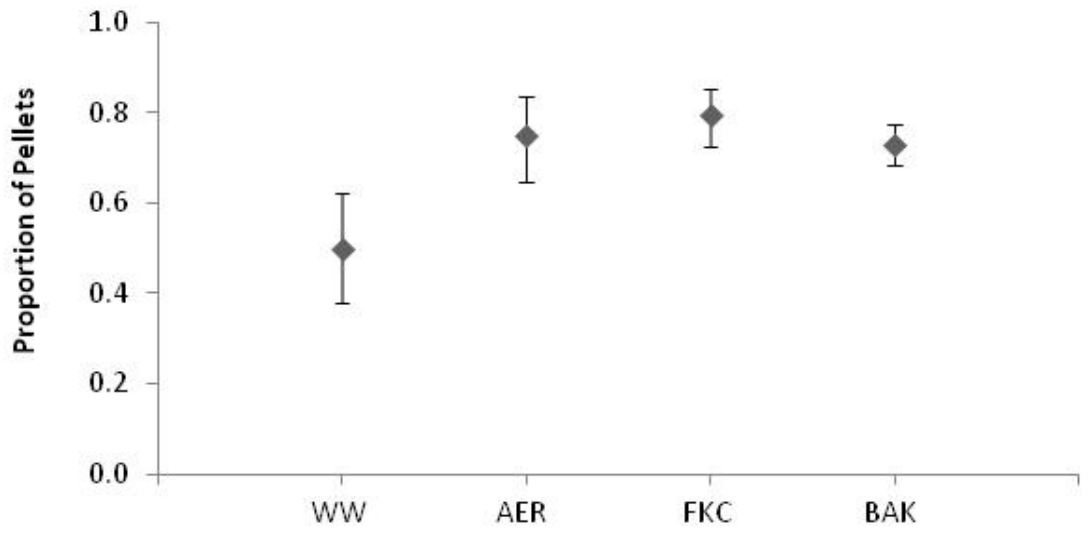

\section{Hot/Dry - Coleoptera}

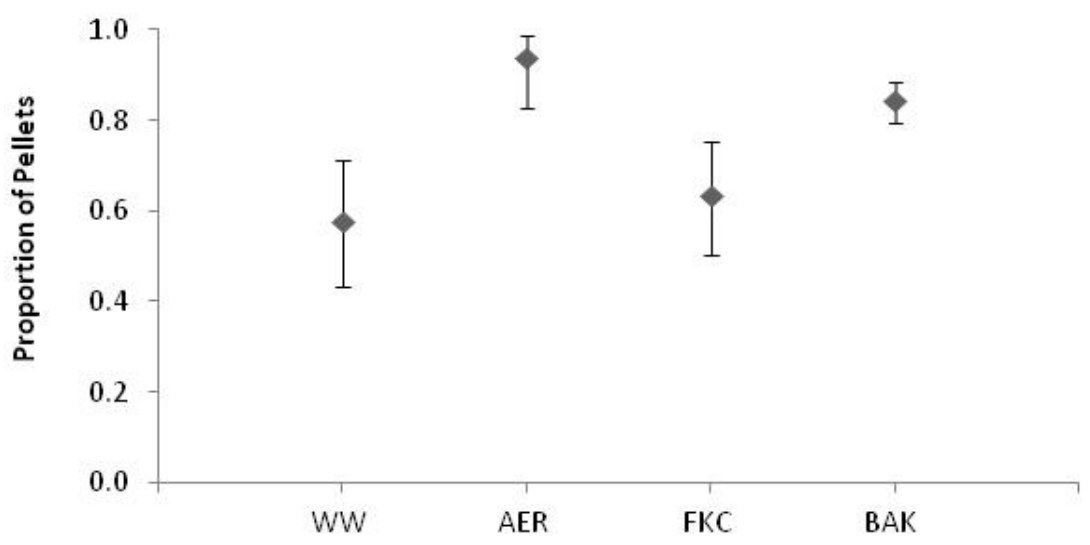

Figure 2.14. Proportion of pellets containing Coleoptera prey items for each season. Error bars represent $95 \%$ confidence intervals. 


\section{Breeding - Dermaptera}

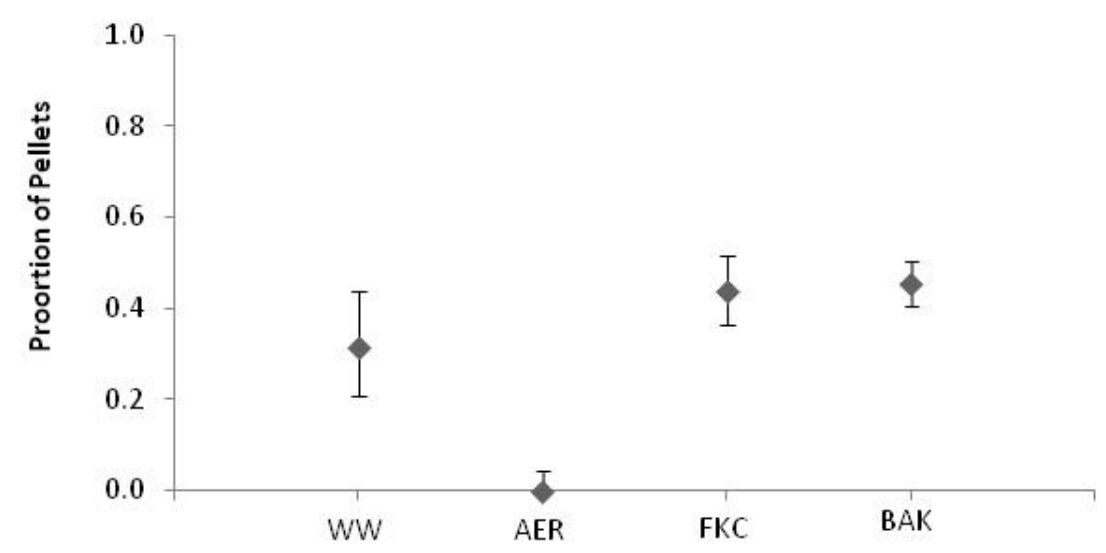

Hot/Dry - Dermaptera

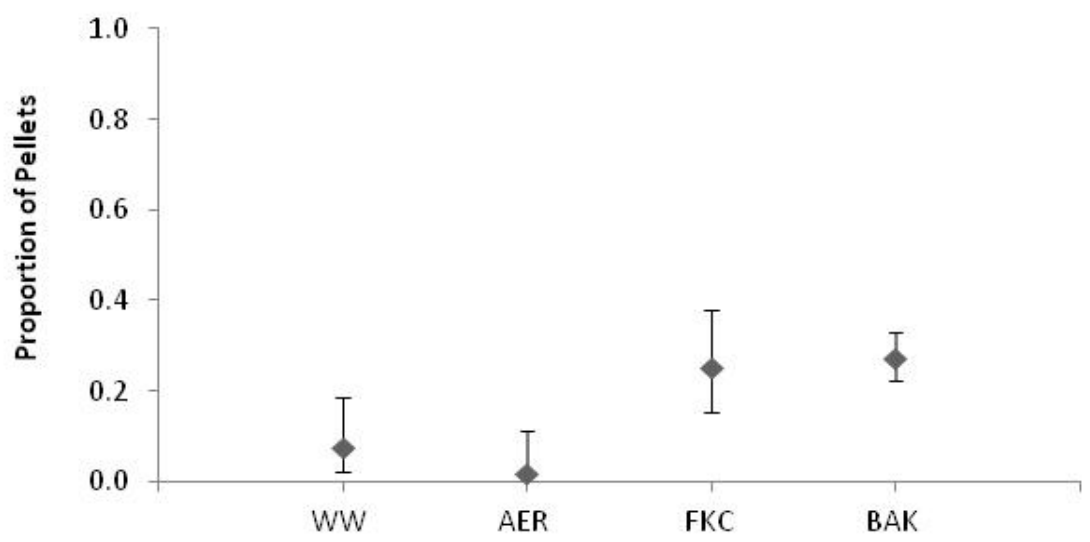

\section{Cold/Wet - Dermaptera}

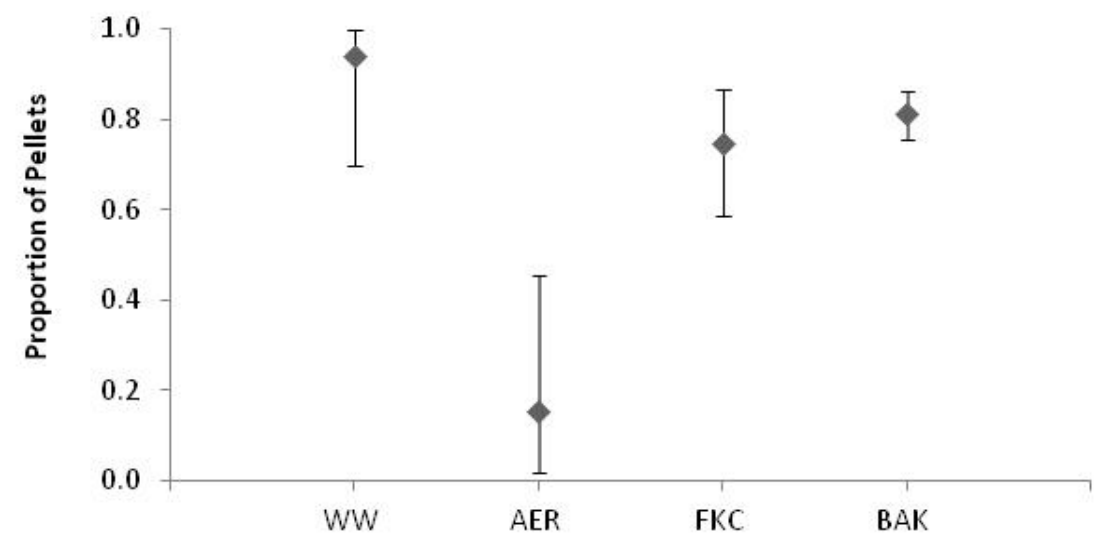

Figure 2.15. Proportion of pellets containing Dermaptera prey items for each season. Error bars represent $95 \%$ confidence intervals. 
Breeding - Orthoptera

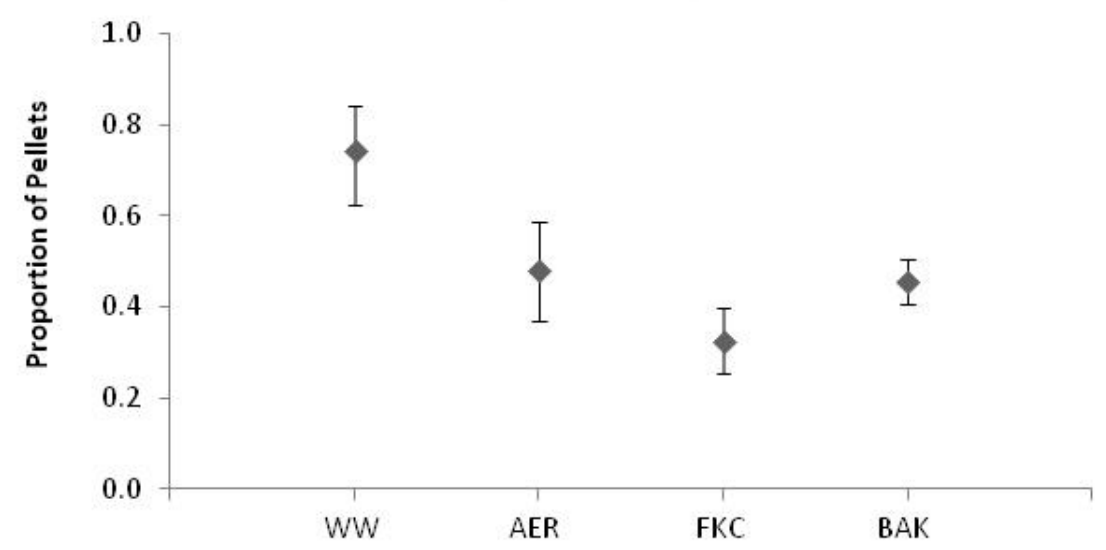

Hot/Dry - Orthoptera

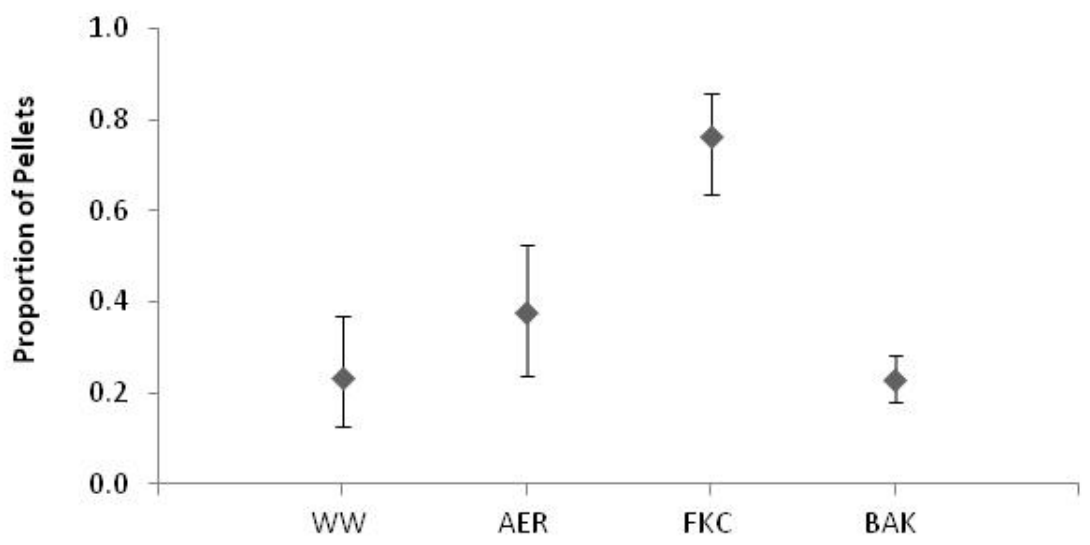

Cold/Wet - Orthoptera

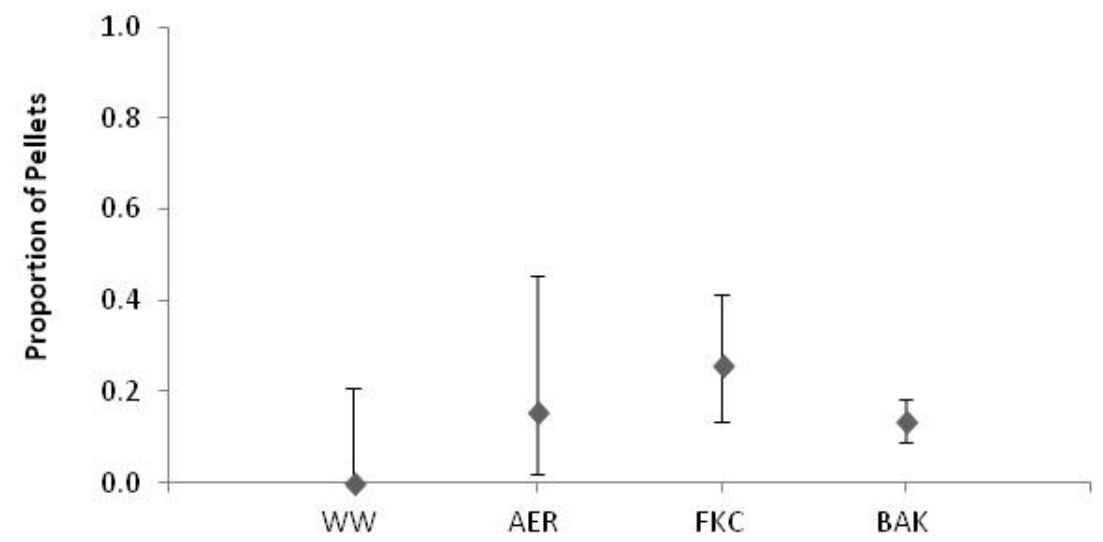

Figure 2.16. Proportion of pellets containing Orthoptera prey items for each season. Error bars represent $95 \%$ confidence intervals. 


\section{Breeding-Insect}

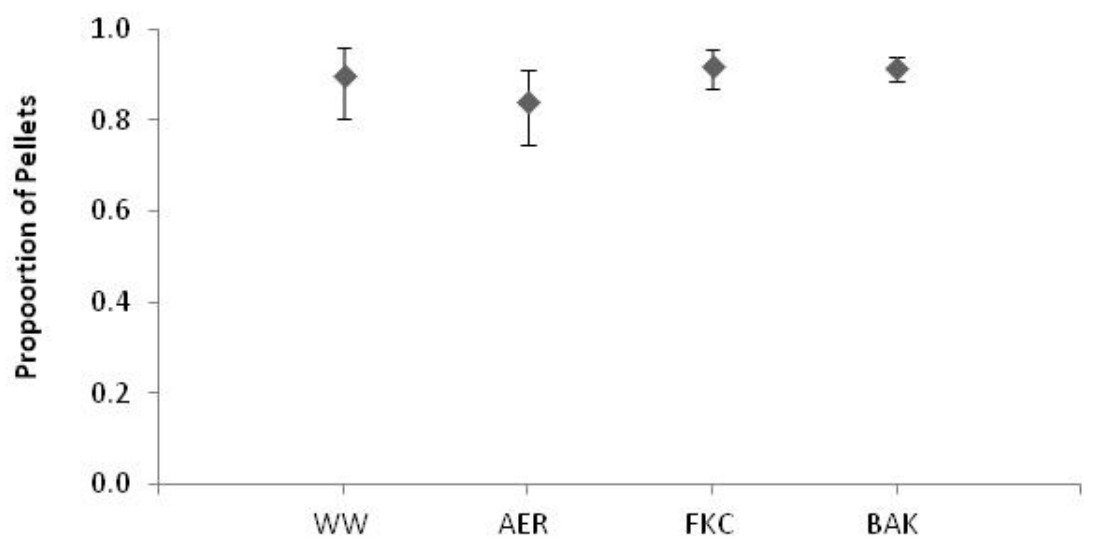

\section{Hot/Dry - Insect}

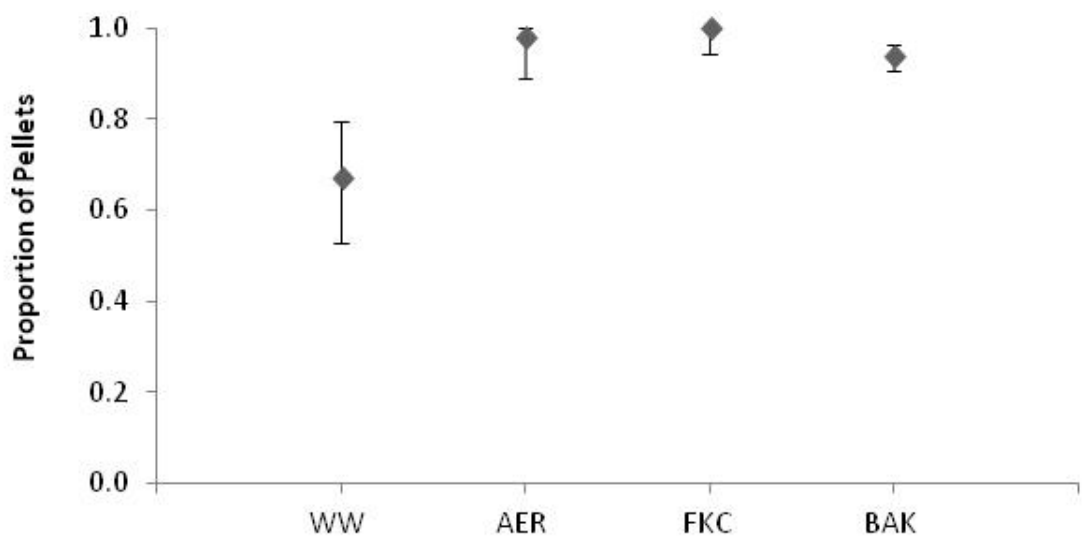

Cold/Wet - Insect

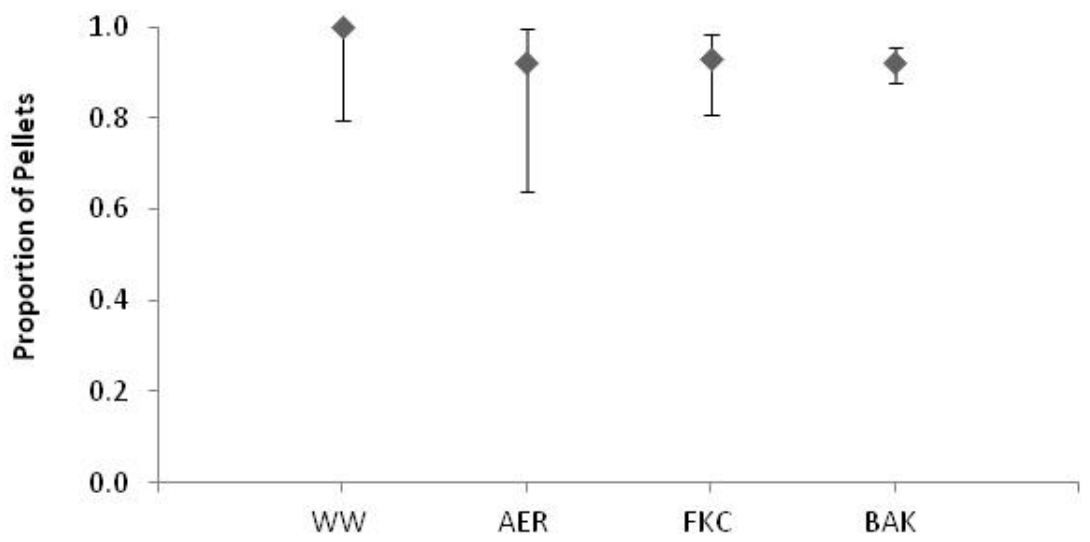

Figure 2.17. Proportion of pellets containing insect prey items for each season. Error bars represent $95 \%$ confidence intervals. 


\section{Breeding - Arachnida}

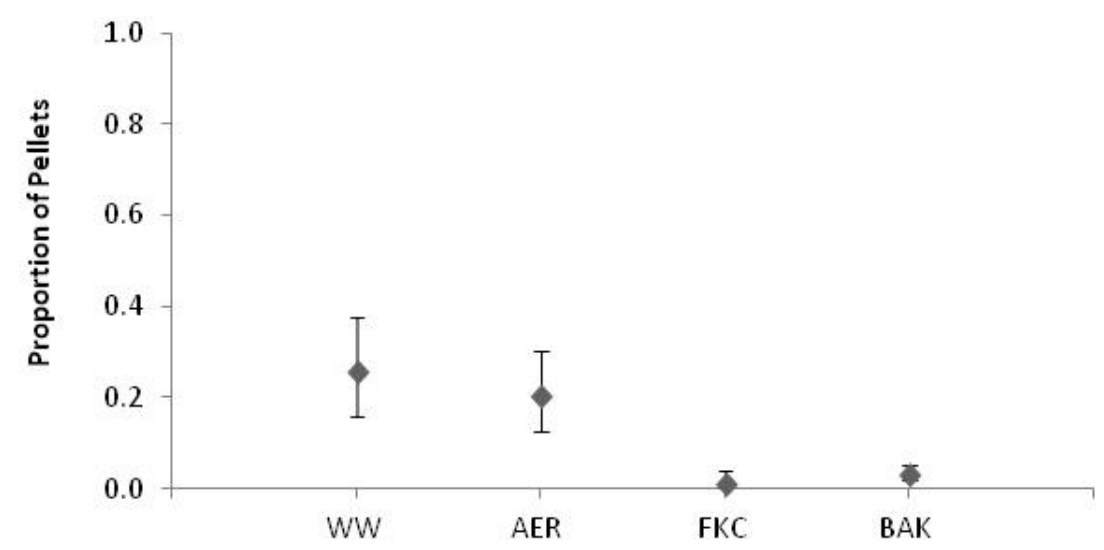

Hot/Dry - Arachnida

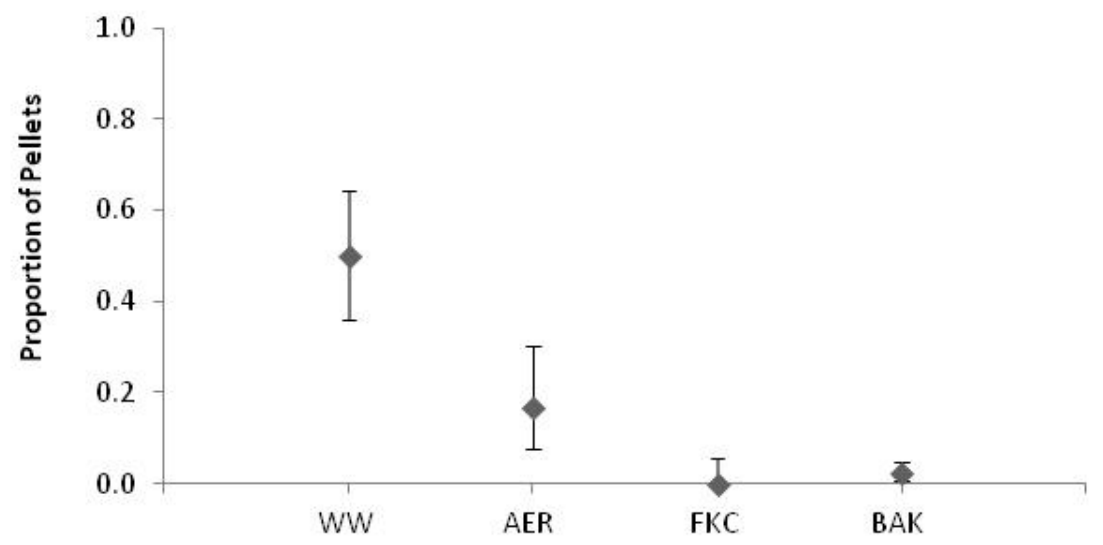

\section{Cold/Wet - Arachnida}

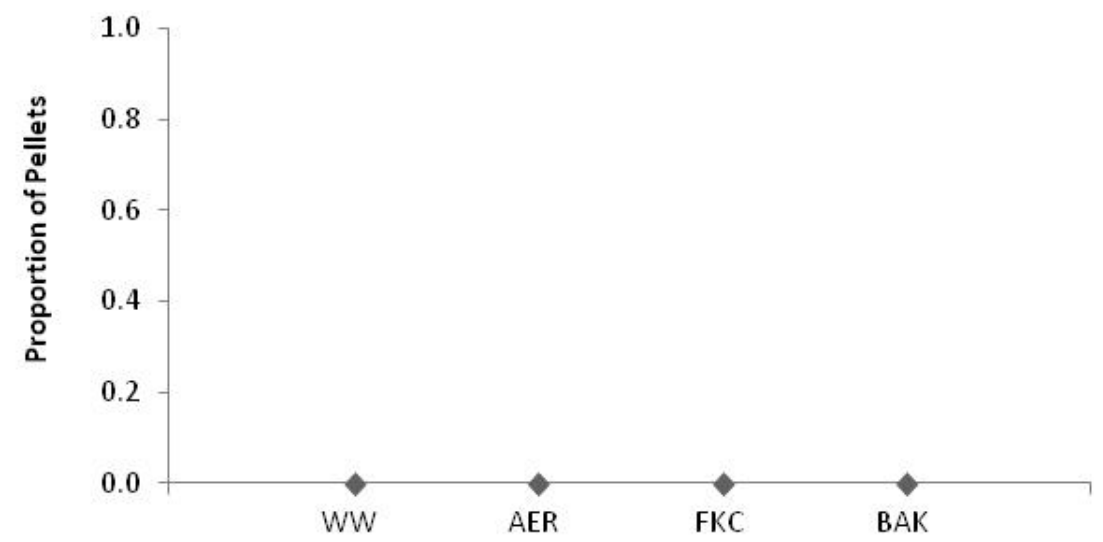

Figure 2.18. Proportion of pellets containing Arachnida prey items for each season. Error bars represent $95 \%$ confidence intervals. 


\section{Hot/Dry - Crustacean}

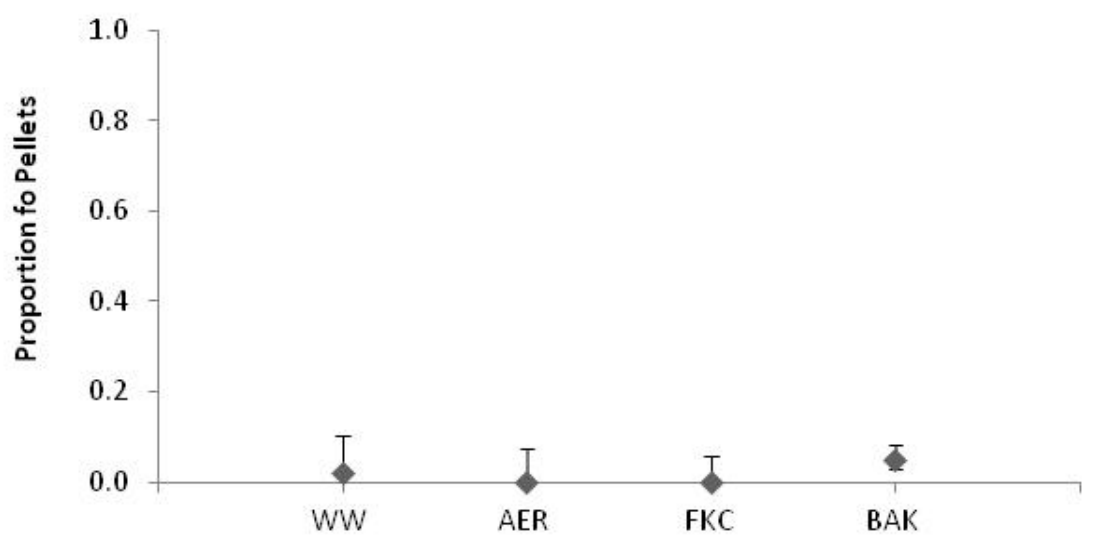

Cold/Wet - Crustacean

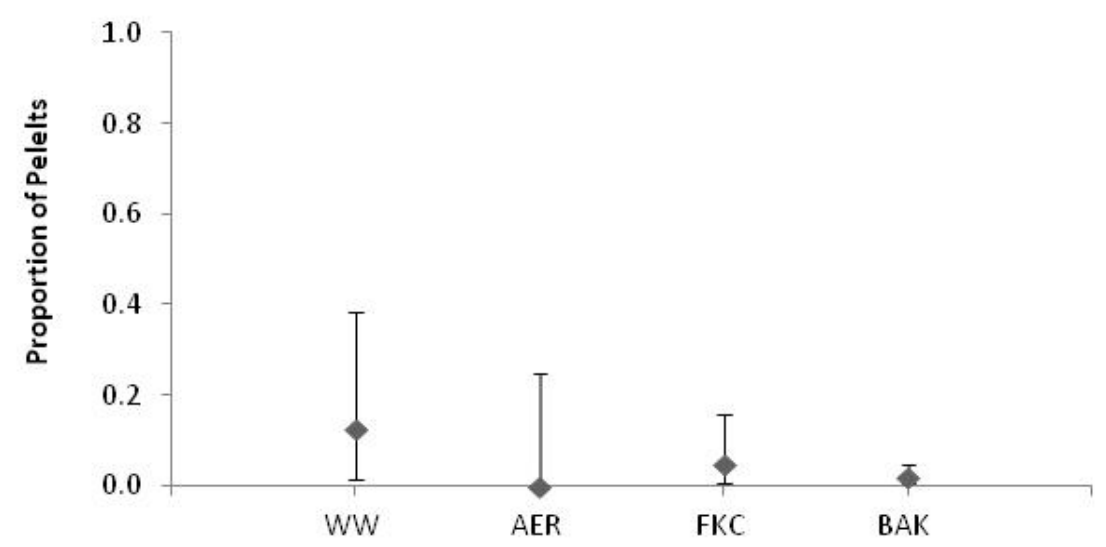

\section{Breeding - Crustacean}

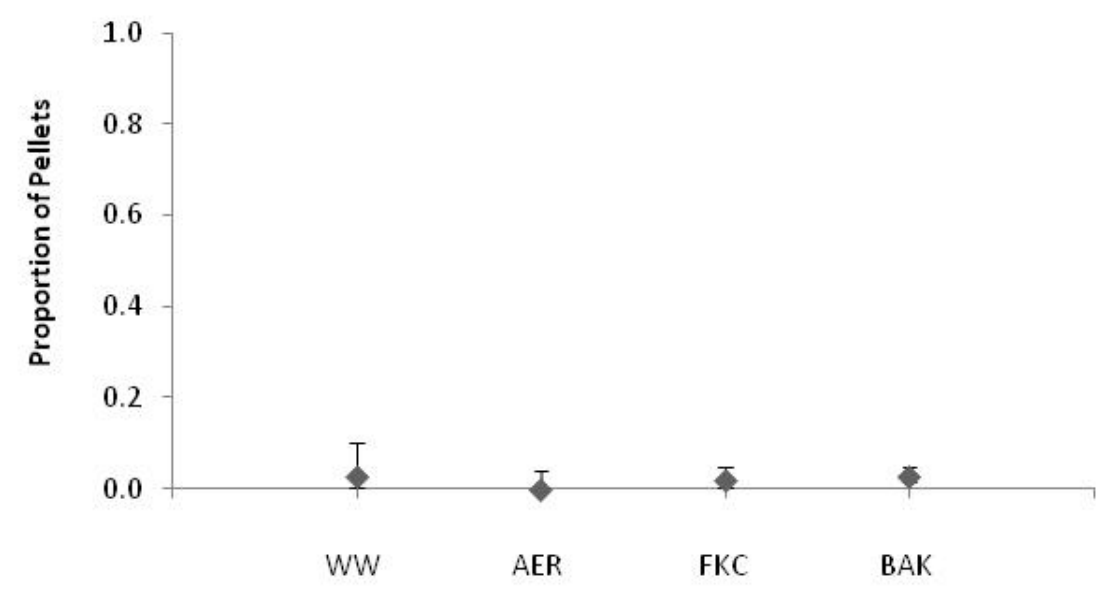

Figure 2.19. Proportion of pellets containing Crustacean prey items for each season. Error bars represent $95 \%$ confidence intervals. 


\section{Breeding - Soil}

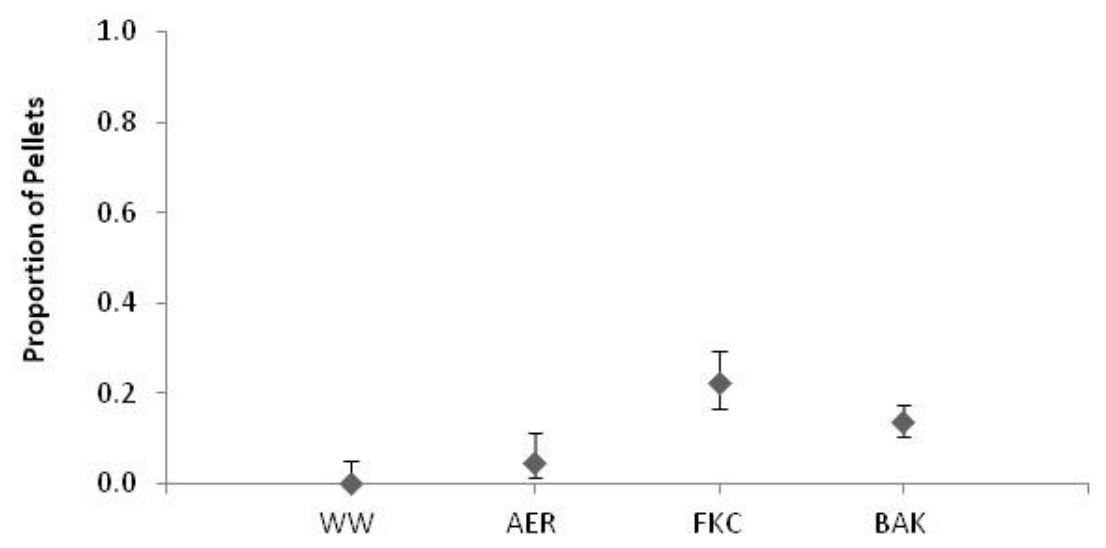

\section{Cold/Wet - Soil}

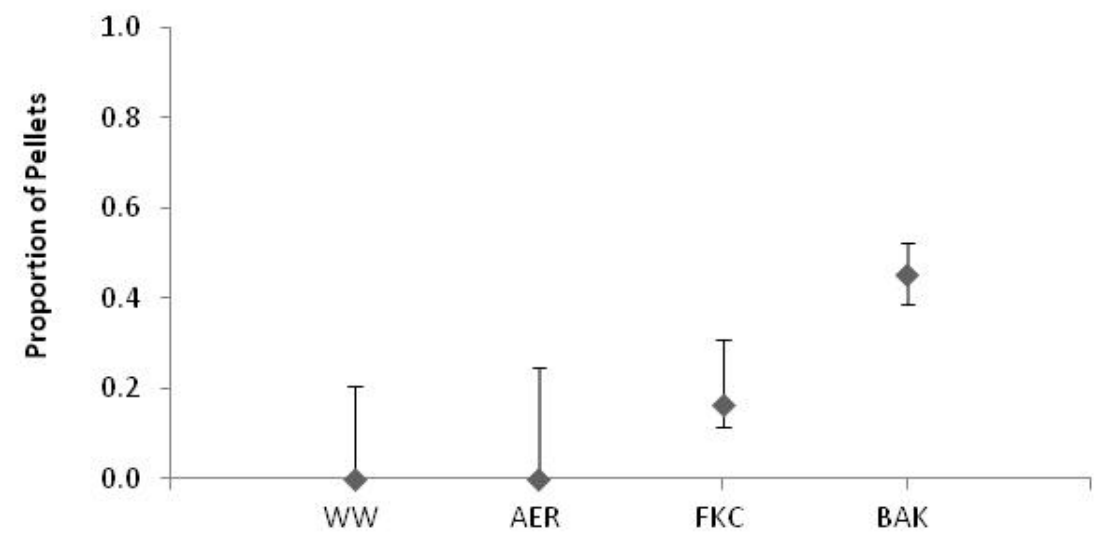

Hot/Dry - Soil

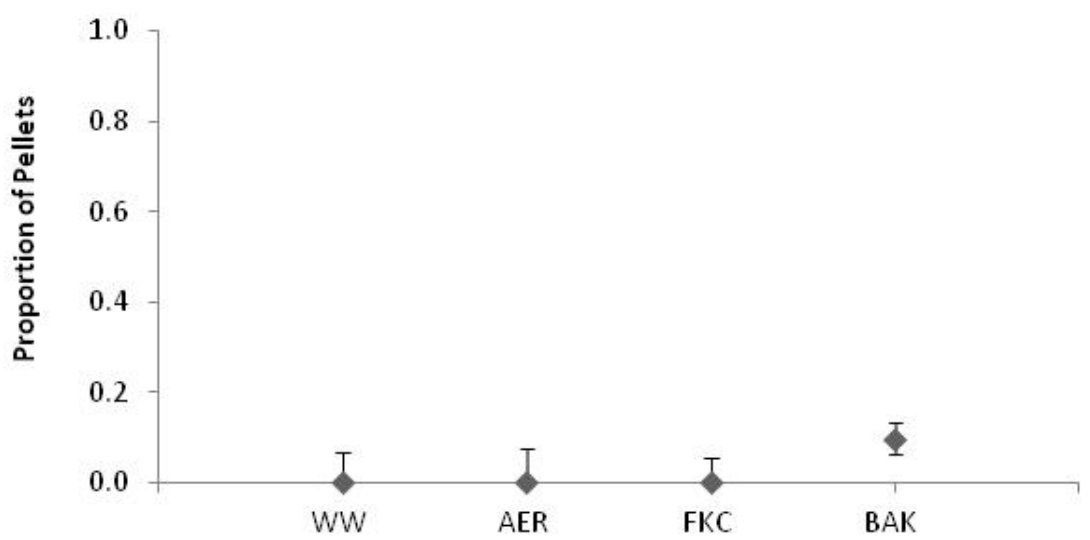

Figure 2.20. Proportion of pellets containing soil for each season. Error bars represent 95\% confidence intervals. 


\section{Hot/Dry - Vegetation}

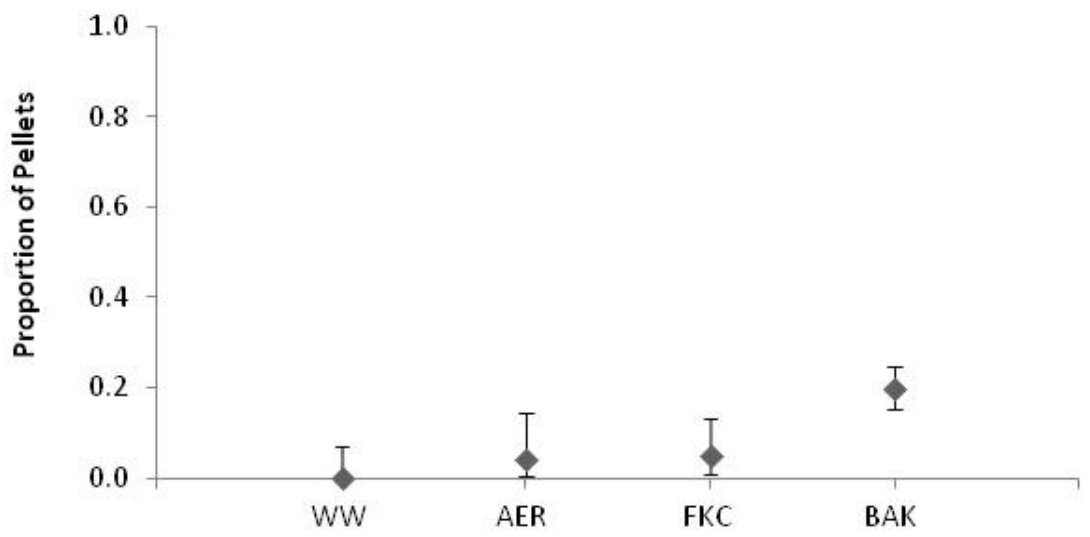

Cold/Wet - Vegetation

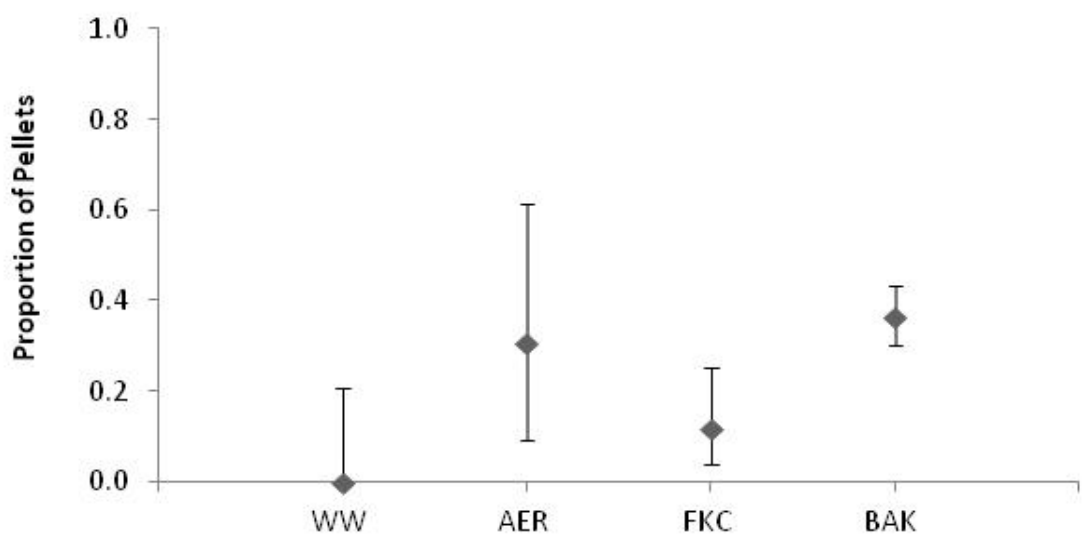

\section{Breeding - Vegetation}

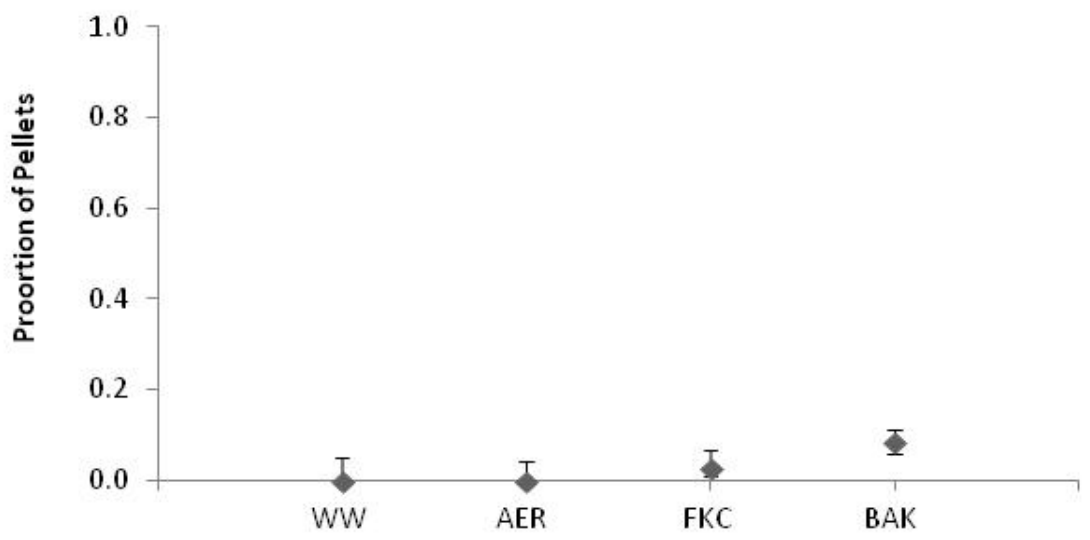

Figure 2.21. Proportion of pellets containing vegetation for each season. Error bars represent $95 \%$ confidence intervals. 


\section{Breeding - Man-made}

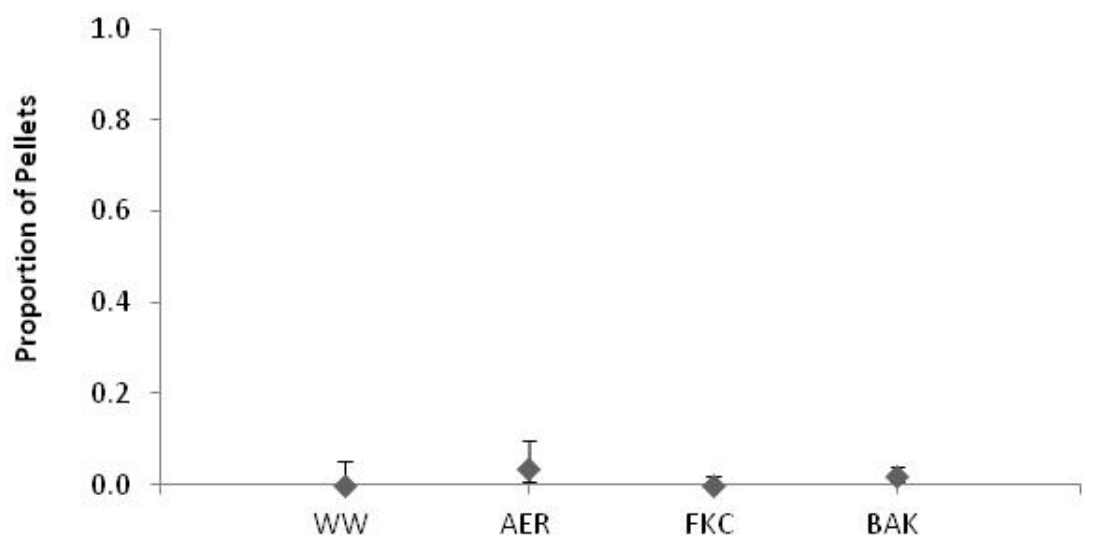

Hot/Dry - Man-made

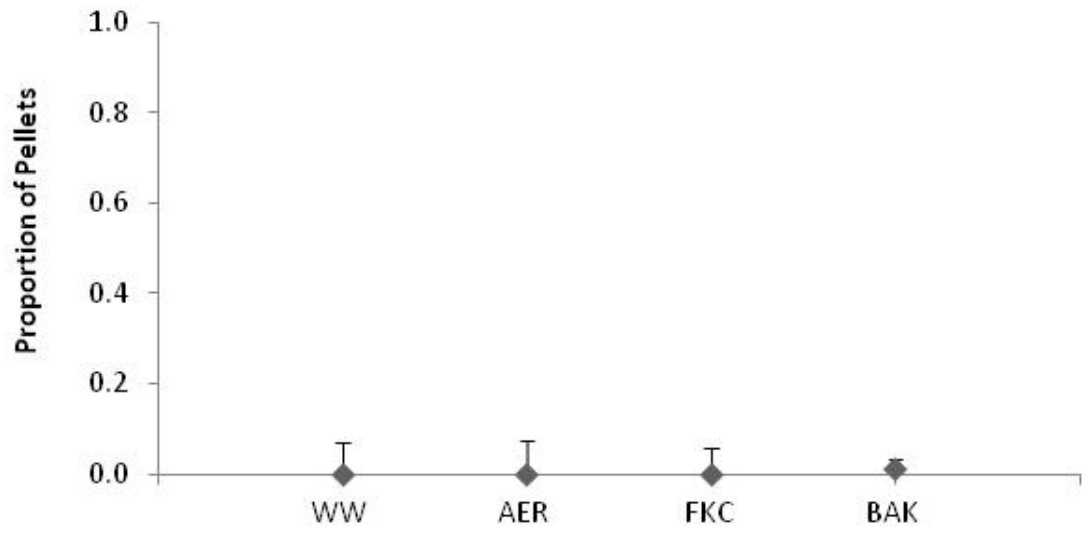

\section{Cold/Wet - Man-made}

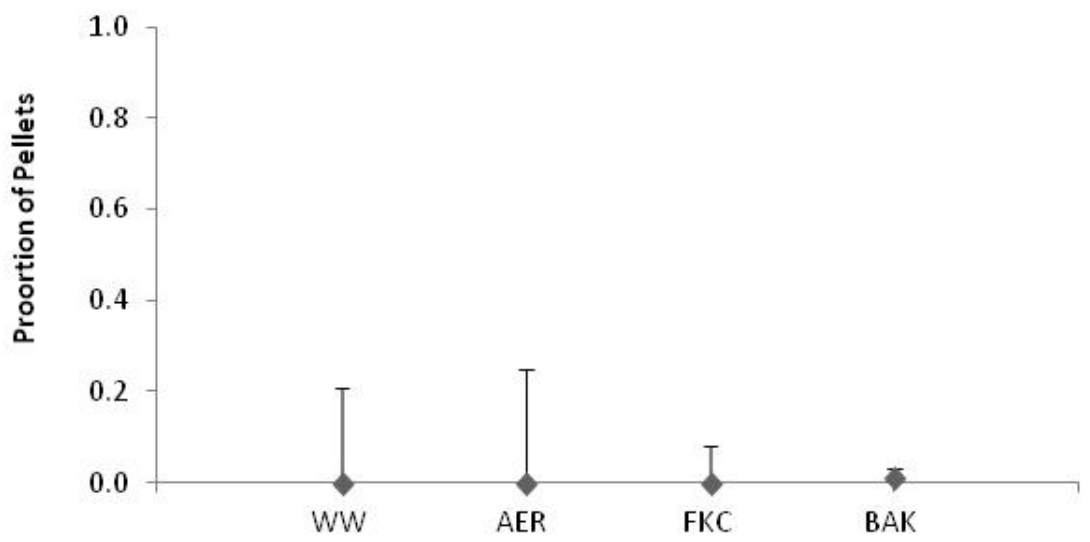

Figure 2.22. Proportion of pellets containing man-made items for each season. Error bars represent $95 \%$ confidence intervals. 


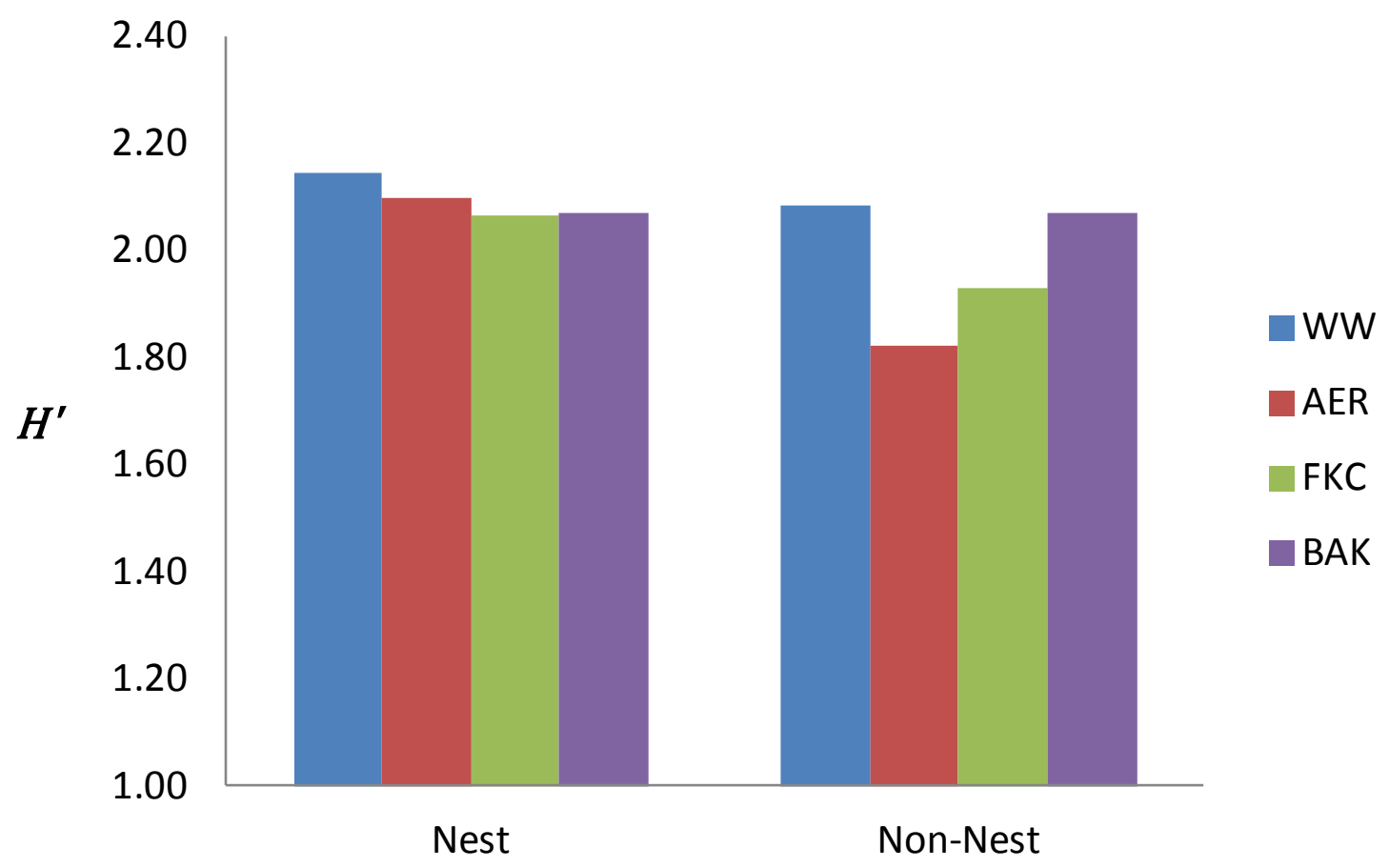

Figure 2.23. Shannon-Weiner index values $(H)$ calculated for nest and non-nest burrows for each study site. 


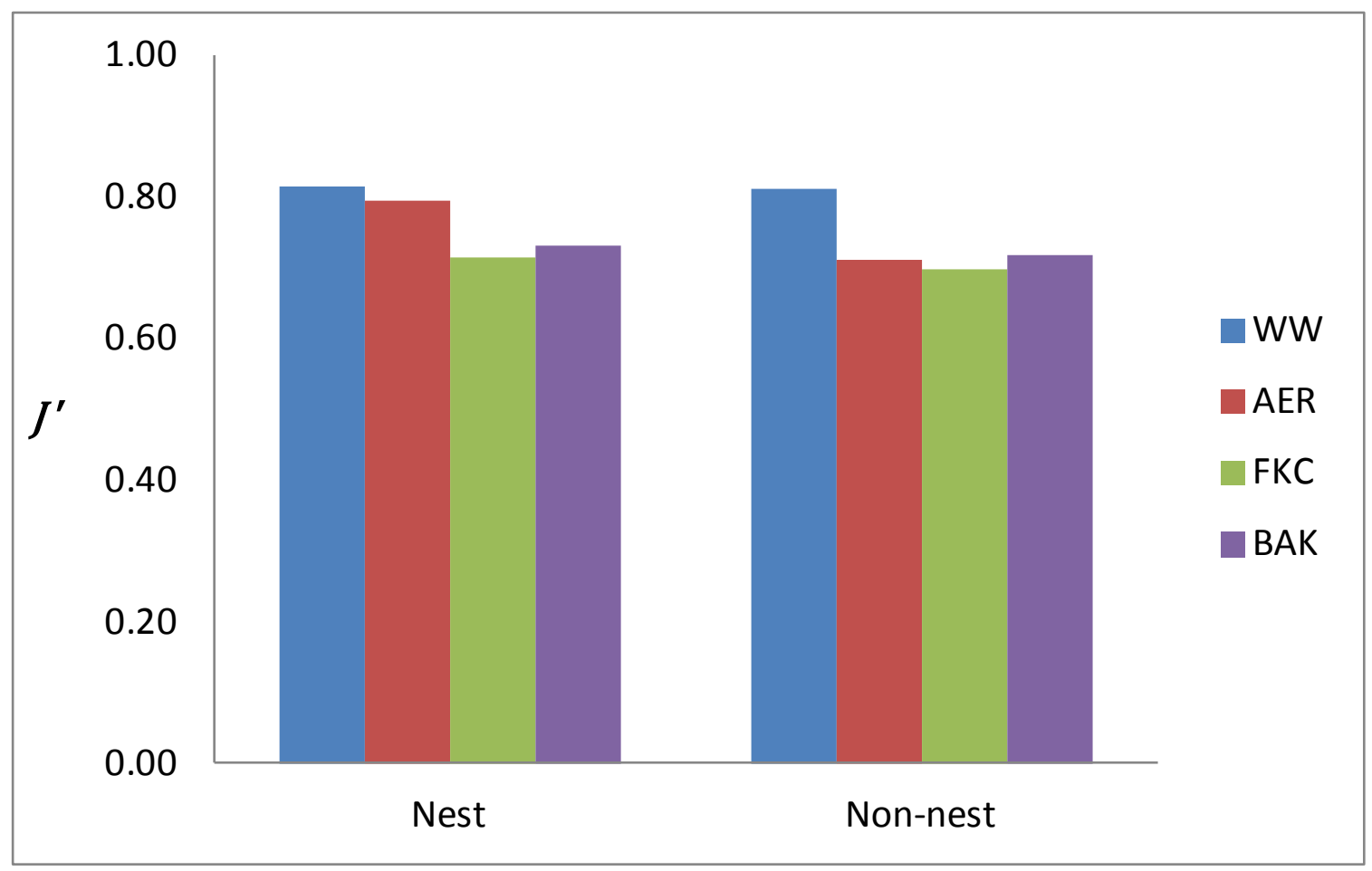

Figure 2.24. Diversity evenness $(J)$ calculated from Shannon-Weiner Index for nest and non-nest burrows for each study site. 


\section{a) WW}

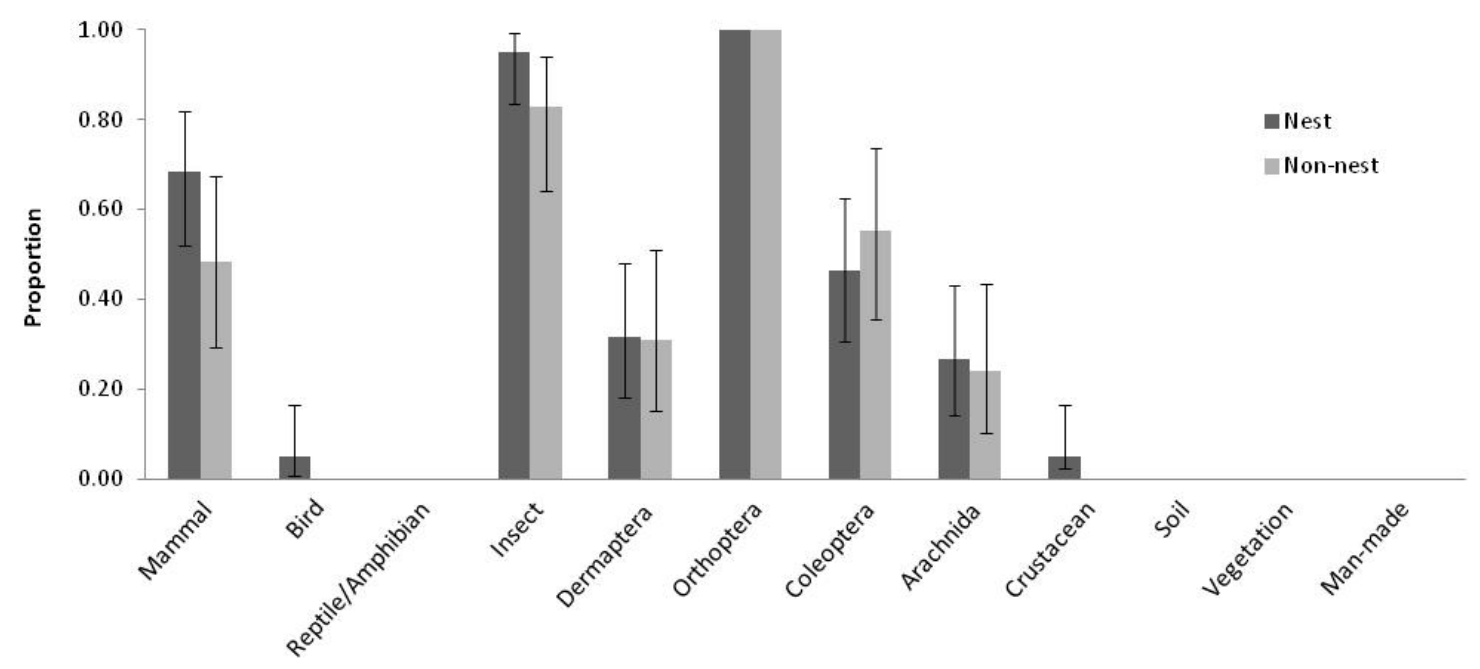

b) AER

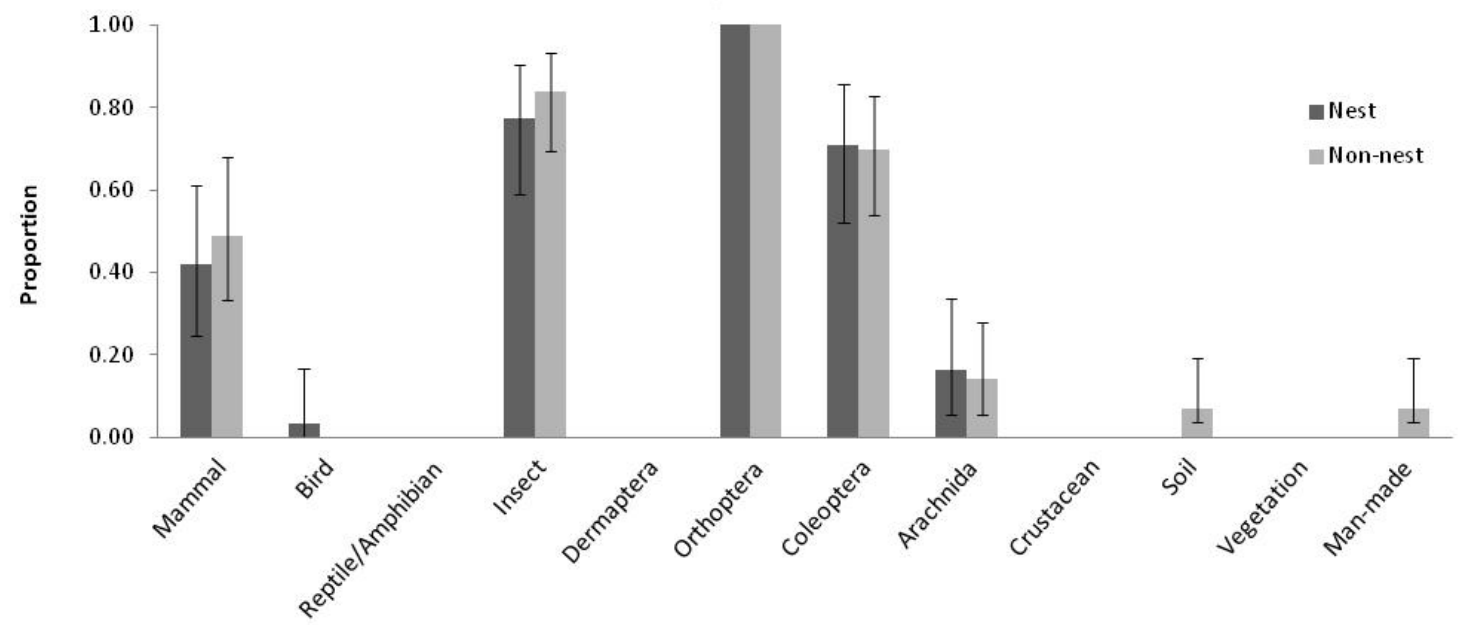

Figure 2.25. Proportion of pellets containing prey categories for nest burrows and non-nest burrows for each study site. Error bars represent 95\% confidence intervals. 

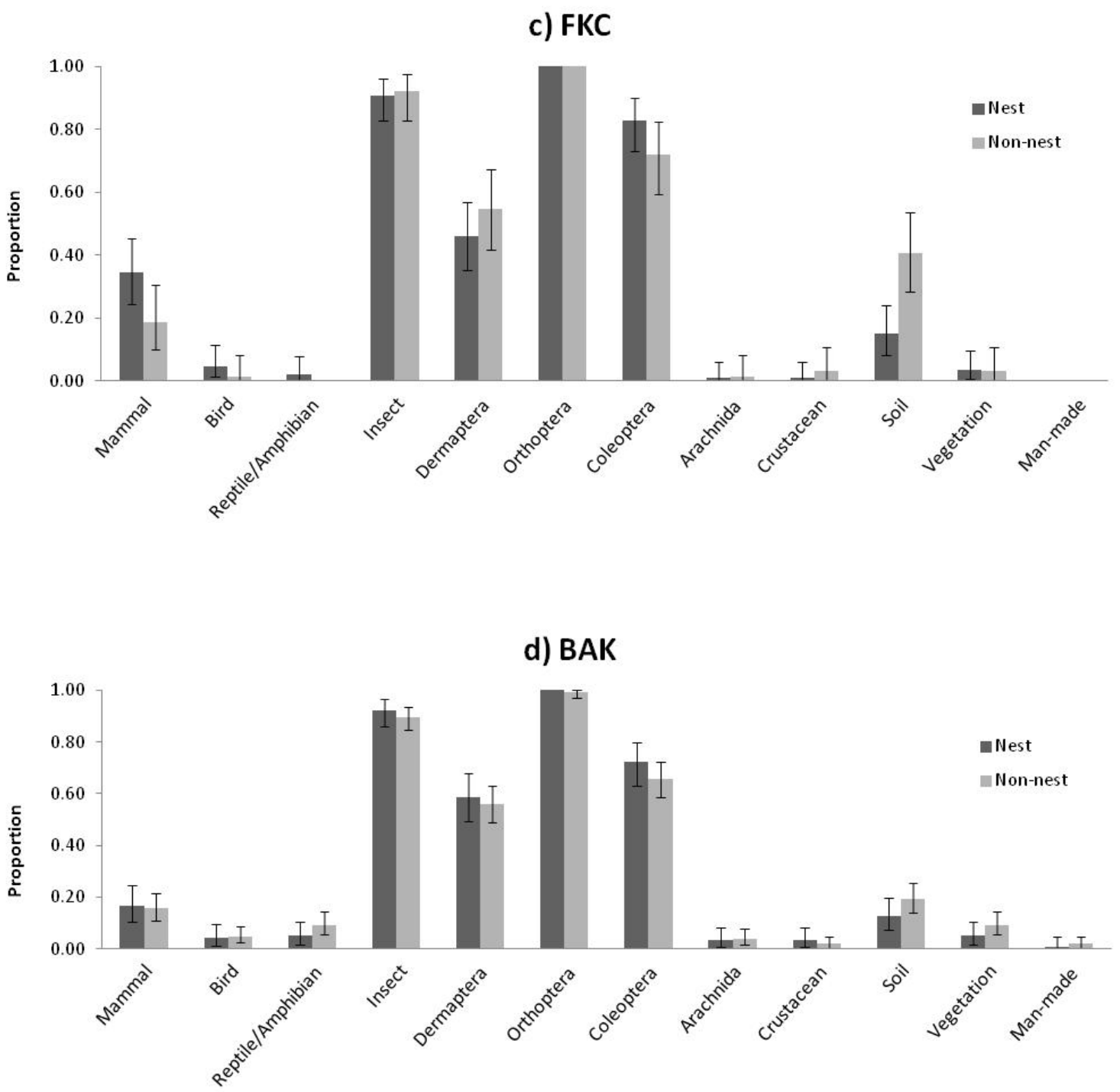

Figure 2.25 con't. 


\begin{tabular}{|c|c|c|c|c|}
\hline \multirow{2}{*}{$\begin{array}{c}\text { Wind Wolves } \\
\text { Preserve }\end{array}$} & \multirow{2}{*}{ Site Total } & \multirow{2}{*}{ Breeding } & \multicolumn{2}{|c|}{ Non-Breeding } \\
\hline & & & Hot/Dry & Cold/Wet \\
\hline Number of pellets collected: & 138 & 70 & 52 & 16 \\
\hline \multicolumn{5}{|l|}{ VERTEBRATES } \\
\hline Amphibia & $0.014(2)$ & - & $0.038(2)$ & - \\
\hline Aves & $0.014(2)$ & $0.029(2)$ & - & - \\
\hline Mammalia & $0.601(83)$ & $0.600(42)$ & $0.769(40)$ & $0.063(1)$ \\
\hline Lagomorpha & - & - & - & - \\
\hline Rodentia & $0.601(83)$ & $0.600(42)$ & $0.769(40)$ & $0.063(1)$ \\
\hline Ammospermophilus nelsoni & - & & - & - \\
\hline Dipodomys spp. & $0.029(4)$ & $0.057(4)$ & - & - \\
\hline Microtus californicus & - & - & - & - \\
\hline Mus musculus & - & - & - & - \\
\hline Myotis spp. & - & - & - & - \\
\hline Perognathus inornatus & $0.196(27)$ & $0.129(9)$ & $0.327(17)$ & $0.063(1)$ \\
\hline Peromyscus maniculatus & $0.065(9)$ & $0.071(5)$ & $0.077(4)$ & - \\
\hline Rattus sp. & - & - & - & - \\
\hline Reithrodontomys megalotis & $0.065(9)$ & $0.057(4)$ & $0.096(5)$ & - \\
\hline Spermophilus beecheyi & - & - & 然 & - \\
\hline Thomomys bottae & $0.007(1)$ & $0.014(1)$ & - & - \\
\hline Unknown Mammal & $0.246(34)$ & 0.271 (19) & $0.288(15)$ & - \\
\hline Reptilia & - & - & - & - \\
\hline \multicolumn{5}{|l|}{ INVERTEBRATES } \\
\hline Arachnida & $0.319(44)$ & $0.257(18)$ & $0.500(26)$ & - \\
\hline Scorpiones & $0.319(44)$ & $0.257(18)$ & $0.500(26)$ & - \\
\hline Solpugidae & - & - & - & _. \\
\hline Crustacea & $0.036(5)$ & $0.029(2)$ & $0.019(1)$ & $0.125(2)$ \\
\hline Insecta & $0.826(114)$ & $0.900(63)$ & $0.673(35)$ & $1.000(16)$ \\
\hline Coleoptera & $0.587(81)$ & $0.500(35)$ & $0.577(30)$ & $1.000(16)$ \\
\hline Carabidae & $0.326(45)$ & $0.271(19)$ & 0.269 (14) & $0.750(12)$ \\
\hline Curculionoidae & $0.007(1)$ & - & 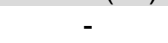 & $0.063(1)$ \\
\hline Elateridae & $0.007(1)$ & - & $0.019(1)$ & - \\
\hline Scarabaeidae & $0.239(33)$ & $0.100(7)$ & 0.269 (14) & $0.750(12)$ \\
\hline Staphylinidae & $0.029(4)$ & $0.057(4)$ & - & - \\
\hline Tenebrionidae & $0.174(24)$ & $0.171(12)$ & $0.212(11)$ & $0.063(1)$ \\
\hline Dermaptera & $0.297(41)$ & $0.314(22)$ & $0.077(4)$ & $0.938(15)$ \\
\hline Hymenoptera & - & - & - & - \\
\hline Mantodea & - & - & - & - \\
\hline Orthoptera & $0.464(64)$ & $0.743(52)$ & $0.231(12)$ & - \\
\hline Unknown Arthropod & - & - & - & - \\
\hline Mollusca & - & - & - & - \\
\hline Gastropoda & - & - & - & - \\
\hline \multicolumn{5}{|l|}{ NON-PREY } \\
\hline Soil & - & - & - & - \\
\hline Veg & - & - & - & - \\
\hline Man-made & - & - & - & - \\
\hline
\end{tabular}

Table 2.1. Prey identified by proportion of total pellets collected at natural study site Wind Wolves Preserve (WW). Number of pellets containing each prey item is reported in parentheses. 


\begin{tabular}{|c|c|c|c|c|}
\hline \multirow{2}{*}{$\begin{array}{c}\text { Allensworth } \\
\text { Ecological Reserve }\end{array}$} & \multirow{2}{*}{ Site Total } & \multirow{2}{*}{ Breeding } & \multicolumn{2}{|c|}{ Non-Breeding } \\
\hline & & & Hot/Dry & Cold/Wet \\
\hline Number of pellets collected: & 149 & 88 & 48 & 13 \\
\hline \multicolumn{5}{|l|}{ VERTEBRATES } \\
\hline Amphibia & - & - & - & - \\
\hline Aves & $0.020(3)$ & $0.011(2)$ & $0.021(1)$ & - \\
\hline Mammalia & $0.289(43)$ & $0.409(36)$ & $0.042(2)$ & $0.385(5)$ \\
\hline Lagomorpha & $0.007(1)$ & $0.011(1)$ & - & - \\
\hline Rodentia & $0.289(43)$ & $0.398(36)$ & $0.042(2)$ & $0.385(5)$ \\
\hline Ammospermophilus nelsoni & - & - & - & - \\
\hline Dipodomys spp. & $0.134(2)$ & $0.023(2)$ & - & - \\
\hline Microtus californicus & $0.007(1)$ & $0.011(1)$ & - & - \\
\hline Mus musculus & $0.007(1)$ & $0.011(1)$ & $0.021(1)$ & - \\
\hline Myotis spp. & - & - & - & - \\
\hline Perognathus inornatus & $0.027(4)$ & $0.045(4)$ & - & - \\
\hline Peromyscus maniculatus & $0.034(5)$ & $0.034(3)$ & $0.021(1)$ & $0.077(1)$ \\
\hline Rattus sp. & - & - & - & - \\
\hline Reithrodontomys megalotis & $0.027(4)$ & $0.045(4)$ & - & - \\
\hline Spermophilus beecheyi & $0.007(1)$ & $0.011(1)$ & - & - \\
\hline Thomomys bottae & - & - & - & - \\
\hline Unknown Mammal & $0.161(24)$ & $0.227(20)$ & - & $0.308(4)$ \\
\hline Reptilia & & - & - & - \\
\hline \multicolumn{5}{|l|}{ INVERTEBRATES } \\
\hline Arachnida & $0.174(26)$ & $0.205(18)$ & $0.167(8)$ & - \\
\hline Scorpiones & $0.168(25)$ & $0.193(17)$ & $0.167(8)$ & - \\
\hline Solpugidae & $0.007(1)$ & $0.011(1)$ & - & - \\
\hline Crustacea & - & - & - & - \\
\hline Insecta & $0.893(133)$ & $0.841(74)$ & $0.979(47)$ & $0.923(12)$ \\
\hline Coleoptera & $0.826(123)$ & $0.750(66)$ & $0.938(45)$ & $0.923(12)$ \\
\hline Carabidae & $0.557(83)$ & $0.477(42)$ & $0.625(30)$ & $0.846(11)$ \\
\hline Curculionoidae & $0.081(12)$ & $0.034(3)$ & $0.042(2)$ & $0.538(7)$ \\
\hline Elateridae & $0.020(3)$ & $0.011(1)$ & $0.021(1)$ & $0.077(1)$ \\
\hline Scarabaeidae & $0.141(21)$ & $0.182(16)$ & $0.082(5)$ & - \\
\hline Staphylinidae & $0.020(3)$ & $0.023(2)$ & - & $0.077(1)$ \\
\hline Tenebrionidae & $0.309(46)$ & $0.295(26)$ & 0.396 (19) & $0.077(1)$ \\
\hline Dermaptera & $0.020(3)$ & - & $0.021(1)$ & $0.154(2)$ \\
\hline Hymenoptera & $0.047(7)$ & $0.057(5)$ & $0.042(2)$ & - \\
\hline Mantodea & - & - & - & - \\
\hline Orthoptera & $0.416(62)$ & $0.477(42)$ & $0.375(18)$ & $0.154(2)$ \\
\hline Unknown Arthropod & - & - & - & - \\
\hline Mollusca & - & - & - & - \\
\hline Gastropoda & - & - & - & - \\
\hline \multicolumn{5}{|l|}{ NON-PREY } \\
\hline Soil & $0.027(4)$ & $0.045(4)$ & - & - \\
\hline Veg & $0.040(6)$ & - & $0.042(2)$ & 0.308 \\
\hline Man-made & $0.020(3)$ & $0.034(3)$ & - & - \\
\hline
\end{tabular}

Table 2.2. Prey identified by proportion of total pellets collected at natural study site Allensworth Ecological Reserve (AER). Number of pellets containing each prey item is reported in parentheses. 


\begin{tabular}{|c|c|c|c|c|}
\hline \multirow{2}{*}{ Friant Kern Canal } & \multirow{2}{*}{ Site Total } & \multirow{2}{*}{ BREEDING } & \multicolumn{2}{|c|}{ NON-BREEDING } \\
\hline & & & HOT/DRY & COLD/WET \\
\hline Number of pellets collected: & 280 & 174 & 63 & 43 \\
\hline \multicolumn{5}{|l|}{ VERTEBRATES } \\
\hline Amphibia & $0.011(3)$ & $0.011(2)$ & - & $0.023(1)$ \\
\hline Aves & $0.032(9)$ & $0.029(5)$ & $0.048(3)$ & $0.023(1)$ \\
\hline $\begin{array}{l}\text { Mammalia } \\
\text { Lagomorpha }\end{array}$ & $0.211(59)$ & $\begin{array}{c}0.247(43) \\
-\end{array}$ & $0.127(8)$ & $0.187(8)$ \\
\hline Rodentia & $0.211(59)$ & $0.247(43)$ & $0.127(8)$ & $0.187(8)$ \\
\hline Ammospermophilus nelsoni & - & - & - & - \\
\hline Dipodomys spp. & - & - & - & - \\
\hline Microtus californicus & - & - & - & - \\
\hline Mus musculus & $0.018(5)$ & $0.011(2)$ & $0.032(2)$ & $0.023(1)$ \\
\hline Myotis spp. & - & - & - & - \\
\hline Perognathus inornatus & $0.004(1)$ & $0.006(1)$ & - & - \\
\hline $\begin{array}{l}\text { Peromyscus maniculatus } \\
\text { Rattus sp. }\end{array}$ & $0.039(11)$ & $0.057(10)$ & $\begin{array}{l}- \\
-\end{array}$ & $\begin{array}{c}0.023(1) \\
-\end{array}$ \\
\hline Reithrodontomys megalotis & $0.029(8)$ & $0.023(4)$ & $0.032(2)$ & $0.047(2)$ \\
\hline Spermophilus beecheyi & - & - & - & - \\
\hline Thomomys bottae & $0.011(3)$ & $0.017(3)$ & - & - \\
\hline Unknown Mammal & $0.118(33)$ & $0.138(24)$ & $0.063(4)$ & $0.116(5)$ \\
\hline Reptilia & - & - & - & - \\
\hline \multicolumn{5}{|l|}{ INVERTEBRATES } \\
\hline Arachnida & $0.007(2)$ & $0.011(2)$ & - & - \\
\hline Solpugidae & $0.007(2)$ & $0.011(2)$ & - & - \\
\hline Scorpiones & - & - & - & - \\
\hline Crustacea & $0.018(5)$ & $0.017(3)$ & - & $0.047(2)$ \\
\hline Insecta & $0.939(263)$ & $0.920(160)$ & $1.000(63)$ & $0.930(40)$ \\
\hline Coleoptera & $0.746(209)$ & $0.793(138)$ & $0.635(40)$ & $0.721(31)$ \\
\hline Carabidae & $0.589(165)$ & $0.615(107)$ & $0.524(33)$ & $0.581(25)$ \\
\hline Curculionoidae & $0.246(69)$ & $0.247(43)$ & $0.159(10)$ & $0.372(16)$ \\
\hline Elateridae & $0.064(18)$ & 0.057 (10) & $0.063(4)$ & $0.093(4)$ \\
\hline Scarabaeidae & $0.204(57)$ & $0.236(41)$ & $0.190(12)$ & $0.093(4)$ \\
\hline Staphylinidae & & 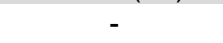 & 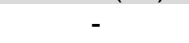 & - \\
\hline Tenebrionidae & $0.025(7)$ & $0.040(7)$ & - & - \\
\hline Dermaptera & $0.443(124)$ & $0.437(76)$ & $0.254(16)$ & $0.744(32)$ \\
\hline Hymenoptera & $0.007(2)$ & $0.006(1)$ & $0.016(1)$ & - \\
\hline Mantodea & $0.004(1)$ & $0.006(1)$ & & 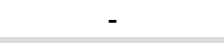 \\
\hline Orthoptera & $0.411(115)$ & $0.322(56)$ & $0.762(48)$ & $0.256(11)$ \\
\hline Unknown Arthropod & $0.014(4)$ & $0.023(4)$ & - & - \\
\hline Mollusca & - & & - & - \\
\hline Gastropoda & - & - & - & - \\
\hline \multicolumn{5}{|l|}{ NON-PREY } \\
\hline Soil & $0.164(46)$ & $0.224(39)$ & - & $0.163(7)$ \\
\hline Veg & $0.046(13)$ & $0.029(5)$ & $0.048(3)$ & $0.116(5)$ \\
\hline Man-made & & - & - & - \\
\hline
\end{tabular}

Table 2.3. Prey identified by proportion of total pellets collected at agricultural study site Friant Kern Canal (FKC). Number of pellets containing each prey item is reported in parentheses. 


\begin{tabular}{|c|c|c|c|c|}
\hline \multirow{2}{*}{ City of Bakersfield } & \multirow{2}{*}{ Site Totals } & \multirow{2}{*}{ Breeding } & \multicolumn{2}{|c|}{ Non-Breeding } \\
\hline & & & HOT/DRY & COLD/WET \\
\hline Number of pellets collected: & 910 & 411 & 280 & 219 \\
\hline \multicolumn{5}{|l|}{ VERTEBRATES } \\
\hline Amphibia & $0.063(57)$ & $0.083(34)$ & $0.071(20)$ & $0.014(3)$ \\
\hline Aves & $0.033(30)$ & $0.049(20)$ & $0.021(6)$ & $0.018(4)$ \\
\hline Mammalia & $0.097(88)$ & $0.131(54)$ & $0.068(19)$ & $0.068(15)$ \\
\hline Lagomorpha & - & - & - & - \\
\hline Rodentia & $0.097(88)$ & $0.131(54)$ & $0.068(19)$ & $0.068(15)$ \\
\hline Ammospermophilus nelsoni & - & - & (1) & ) \\
\hline Dipodomys spp. & - & - & - & - \\
\hline Microtus californicus & $0.001(1)$ & $0.002(1)$ & - & - \\
\hline Mus musculus & $0.009(8)$ & $0.005(2)$ & $0.011(3)$ & $0.014(3)$ \\
\hline Myotis spp. & $0.001(1)$ & $0.002(1)$ & - & - \\
\hline Perognathus inornatus & $0.001(1)$ & $0.002(1)$ & - & - \\
\hline Peromyscus maniculatus & $0.011(10)$ & $0.012(5)$ & $0.007(2)$ & $0.014(3)$ \\
\hline Rattus sp. & $0.001(1)$ & - & $0.004(1)$ & - \\
\hline Reithrodontomys megalotis & $0.016(15)$ & $0.012(5)$ & $0.018(5)$ & $0.023(5)$ \\
\hline Spermophilus beecheyi & $0.01(1)$ & $0.002(1)$ & & \\
\hline Thomomys bottae & $0.008(7)$ & $0.015(6)$ & - & $0.005(1)$ \\
\hline Unknown Mammal & $0.049(45)$ & $0.080(33)$ & $0.032(9)$ & $0.014(3)$ \\
\hline Reptilia & $0.005(5)$ & $0.005(2)$ & $0.007(2)$ & $0.005(1)$ \\
\hline \multicolumn{5}{|l|}{ INVERTEBRATES } \\
\hline Arachnida & $0.021(19)$ & $0.032(13)$ & $0.021(6)$ & - \\
\hline Scorpiones & $0.016(15)$ & $0.029(12)$ & $0.011(3)$ & - \\
\hline Solpugidae & $0.004(4)$ & $0.002(1)$ & $0.011(3)$ & - \\
\hline Crustacea & $0.032(29)$ & $0.027(11)$ & $0.050(14)$ & $0.018(4)$ \\
\hline Insecta & $0.924(841)$ & $0.915(376)$ & $0.939(263)$ & $0.922(202)$ \\
\hline Coleoptera & $0.756(688)$ & $0.730(300)$ & $0.843(236)$ & $0.694(152)$ \\
\hline Carabidae & $0.347(316)$ & $0.273(112)$ & $0.457(128)$ & $0.347(76)$ \\
\hline Curculionoidae & $0.320(291)$ & $0.280(115)$ & $0.304(85)$ & $0.416(91)$ \\
\hline Elateridae & $0.203(185)$ & $0.224(92)$ & $0.225(63)$ & $0.137(30)$ \\
\hline Scarabaeidae & $0.300(273)$ & $0.350(144)$ & $0.343(96)$ & $0.151(33)$ \\
\hline Staphylinidae & $0.003(3)$ & - & $0.011(3)$ & - \\
\hline Tenebrionidae & $0.056(51)$ & $0.068(28)$ & $0.075(21)$ & $0.009(2)$ \\
\hline Dermaptera & 0.485 (441) & $0.453(186)$ & $0.275(77)$ & $0.813(178)$ \\
\hline Hymenoptera & $0.004(4)$ & $0.005(2)$ & $0.007(2)$ & 列 \\
\hline Mantodea & $0.001(1)$ & - & - & $0.005(1)$ \\
\hline Orthoptera & $0.308(280)$ & $0.455(187)$ & $0.229(64)$ & $0.132(29)$ \\
\hline Unknown Arthropod & $0.008(7)$ & $0.002(1)$ & $0.007(2)$ & $0.018(4)$ \\
\hline Mollusca & $0.001(1)$ & $0.002(1)$ & - & - \\
\hline Gastropoda & $0.001(1)$ & $0.002(1)$ & - & - \\
\hline \multicolumn{5}{|l|}{ NON-PREY } \\
\hline Soil & $0.199(181)$ & $0.136(56)$ & $0.093(26)$ & $0.452(99)$ \\
\hline Veg & $0.186(169)$ & $0.083(34)$ & $0.196(55)$ & $0.365(80)$ \\
\hline Man-made & $0.014(13)$ & $0.019(8)$ & $0.011(3)$ & $0.009(2)$ \\
\hline
\end{tabular}

Table 2.4. Prey identified by proportion of total pellets collected at urban study site Bakersfield (BAK). Number of pellets containing each prey item is reported in parentheses. 


\begin{tabular}{|c|c|c|c|c|}
\hline Site & Season & $S$ & $H^{\prime}$ & $J^{\prime}$ \\
\hline \multirow{4}{*}{ ww } & $B$ & 15 & 2.259 & 0.834 \\
\hline & $H D$ & 13 & 2.264 & 0.883 \\
\hline & $\mathrm{CW}$ & 7 & 1.474 & 0.758 \\
\hline & 12 Month & 18 & 2.377 & 0.822 \\
\hline \multirow{4}{*}{ AER } & B & 20 & 2.273 & 0.759 \\
\hline & HD & 12 & 1.821 & 0.733 \\
\hline & $\mathrm{CW}$ & 9 & 1.869 & 0.850 \\
\hline & 12 Month & 21 & 2.258 & 0.742 \\
\hline \multirow{4}{*}{ FKC } & $B$ & 20 & 2.180 & 0.728 \\
\hline & $H D$ & 11 & 1.827 & 0.762 \\
\hline & $\mathrm{CW}$ & 13 & 1.949 & 0.760 \\
\hline & 12 Month & 20 & 2.129 & 0.711 \\
\hline \multirow{4}{*}{ BAK } & B & 25 & 2.293 & 0.712 \\
\hline & HD & 21 & 2.279 & 0.749 \\
\hline & $\mathrm{CW}$ & 18 & 1.874 & 0.648 \\
\hline & 12 Month & 28 & 2.264 & 0.679 \\
\hline
\end{tabular}

Table 2.5. Species richness (S), Shannon-Wiener diversity indices $(H)$, and evenness $(J)$ calculated for each season and for the entire 12-month study period for each study site. 


\begin{tabular}{|c|c|c|c|c|}
\hline & & B vs HD & $B$ vs CW & HD vs CW \\
\hline \multirow[t]{2}{*}{ WW } & $\begin{array}{l}t \text {-value } \\
\text { Degrees of freedom } \\
95 \% \text { critical } t \text {-value } \\
p \text {-value }\end{array}$ & $\begin{array}{l}0.054 \\
305.437 \\
1.967 \\
0.957\end{array}$ & $\begin{array}{l}6.070 \\
75.883 \\
1.992 \\
<0.001\end{array}$ & $\begin{array}{l}6.294 \\
67.514 \\
1.996 \\
<0.001\end{array}$ \\
\hline & $\begin{array}{l}\text { Different based on } \\
\text { Bonferroni corrected alpha } \\
\text { value }(\alpha=0.003) .\end{array}$ & No & Yes & Yes \\
\hline \multirow[t]{2}{*}{ AER } & $\begin{array}{l}t \text {-value } \\
\text { Degrees of freedom } \\
95 \% \text { critical } t \text {-value } \\
\mathrm{p} \text {-value }\end{array}$ & $\begin{array}{l}3.717 \\
180.302 \\
1.973 \\
<0.001\end{array}$ & $\begin{array}{l}2.771 \\
56.892 \\
2.00 \\
0.008\end{array}$ & $\begin{array}{l}0.297 \\
76.724 \\
1.992 \\
0.767\end{array}$ \\
\hline & $\begin{array}{l}\text { Different based on } \\
\text { Bonferroni corrected } p \text {-value } \\
(\alpha=0.003) \text {. }\end{array}$ & Yes & No & No \\
\hline \multirow[t]{2}{*}{ FKC } & $\begin{array}{l}t \text {-value } \\
\text { Degrees of freedom } \\
95 \% \text { critical } t \text {-value } \\
\text { p-value }\end{array}$ & $\begin{array}{l}3.767 \\
249.204 \\
1.970 \\
<0.001\end{array}$ & $\begin{array}{l}2.221 \\
162.441 \\
1.975 \\
0.028\end{array}$ & $\begin{array}{l}1.010 \\
224.185 \\
1.971 \\
0.314\end{array}$ \\
\hline & $\begin{array}{l}\text { Different based on } \\
\text { Bonferroni corrected } p \text {-value } \\
(\alpha=0.003) \text {. }\end{array}$ & Yes & No & No \\
\hline \multirow[t]{2}{*}{ BAK } & $\begin{array}{l}t \text {-value } \\
\text { Degrees of freedom } \\
95 \% \text { critical } t \text {-value } \\
p \text {-value }\end{array}$ & $\begin{array}{l}0.289 \\
1291.303 \\
1.962 \\
0.773\end{array}$ & $\begin{array}{l}7.260 \\
792.247 \\
1.963 \\
<0.001\end{array}$ & $\begin{array}{l}6.536 \\
909.457 \\
1.963 \\
<0.001\end{array}$ \\
\hline & $\begin{array}{l}\text { Different based on } \\
\text { Bonferroni corrected } p \text {-value } \\
(\alpha=0.003) \text {. }\end{array}$ & No & Yes & Yes \\
\hline
\end{tabular}

Table 2.6. Calculated $t$-values, degrees of freedom, 95\% critical t-values, and $p$-values for pairwise comparisons of Shannon-Weiner diversity indices for seasons within a site. The test-specific $p$-value was calculated for each t-test using Excel (TDIST function). This test-specific $p$-value was compared to a Bonferroni-corrected alpha value. Test-specific $p$-values falling below the Bonferroni alpha value resulted in rejection of the null hypothesis that the diversity indices do not differ. 


\begin{tabular}{|c|c|c|c|c|c|c|c|}
\hline & & $\begin{array}{c}\text { WW vs. } \\
\text { AER }\end{array}$ & $\begin{array}{c}\text { WW vs. } \\
\text { FKC }\end{array}$ & $\begin{array}{l}\text { WW vs. } \\
\text { BAK }\end{array}$ & $\begin{array}{l}\text { AER } \\
\text { vS. } \\
\text { FKC }\end{array}$ & $\begin{array}{l}\text { AER } \\
\text { vs. } \\
\text { BAK }\end{array}$ & $\begin{array}{c}\text { FKC vs. } \\
\text { BAK }\end{array}$ \\
\hline \multirow{2}{*}{ B } & $\begin{array}{l}t \text {-value } \\
\text { Degrees of freedom } \\
95 \% \text { critical } t \text {-value } \\
p \text {-value }\end{array}$ & $\begin{array}{l}0.143 \\
373.031 \\
1.966 \\
0.886\end{array}$ & $\begin{array}{l}0.979 \\
395.250 \\
1.966 \\
0.328\end{array}$ & $\begin{array}{l}0.476 \\
256.748 \\
1.969 \\
0.635\end{array}$ & $\begin{array}{l}1.083 \\
388.922 \\
1.966 \\
0.280\end{array}$ & $\begin{array}{l}0.262 \\
262.481 \\
1.969 \\
0.794\end{array}$ & $\begin{array}{l}1.972 \\
684.501 \\
1.963 \\
0.049\end{array}$ \\
\hline & $\begin{array}{l}\text { Different based on } \\
\text { Bonferroni corrected } \\
\text { alpha value } \\
(\alpha=0.001) .\end{array}$ & No & No & No & No & No & No \\
\hline \multirow{2}{*}{ HD } & $\begin{array}{l}t \text {-value } \\
\text { Degrees of freedom } \\
95 \% \text { critical } t \text {-value } \\
p \text {-value }\end{array}$ & $\begin{array}{l}3.886 \\
144.965 \\
1.977 \\
<0.001\end{array}$ & $\begin{array}{l}4.493 \\
240.149 \\
1.970 \\
<0.001\end{array}$ & $\begin{array}{l}0.236 \\
246.118 \\
1.970 \\
0.818\end{array}$ & $\begin{array}{l}0.051 \\
169.720 \\
1.974 \\
0.959\end{array}$ & $\begin{array}{l}4.337 \\
114.622 \\
1.981 \\
<0.001\end{array}$ & $\begin{array}{l}5.179 \\
196.879 \\
1.972 \\
<0.001\end{array}$ \\
\hline & $\begin{array}{l}\text { Different based on } \\
\text { Bonferroni corrected } \\
\text { alpha value } \\
(\alpha=0.001) .\end{array}$ & Yes & Yes & No & No & Yes & Yes \\
\hline \multirow{2}{*}{ CW } & $\begin{array}{l}t \text {-value } \\
\text { Degrees of freedom } \\
95 \% \text { critical } t \text {-value } \\
p \text {-value }\end{array}$ & $\begin{array}{l}2.320 \\
73.051 \\
1.993 \\
0.023\end{array}$ & $\begin{array}{l}3.286 \\
102.581 \\
1.983 \\
0.001\end{array}$ & $\begin{array}{l}3.256 \\
63.039 \\
1.998 \\
0.002\end{array}$ & $\begin{array}{l}0.512 \\
71.409 \\
1.994 \\
0.610\end{array}$ & $\begin{array}{l}0.039 \\
45.152 \\
2.014 \\
0.969\end{array}$ & $\begin{array}{l}0.721 \\
174.319 \\
1.974 \\
0.472\end{array}$ \\
\hline & $\begin{array}{l}\text { Different based on } \\
\text { Bonferroni corrected } \\
\text { alpha value } \\
(\alpha=0.001) .\end{array}$ & No & Yes & No & No & No & No \\
\hline \multirow{2}{*}{$\begin{array}{c}\text { 12- } \\
\text { Month }\end{array}$} & $\begin{array}{l}t \text {-value } \\
\text { Degrees of freedom } \\
95 \% \text { critical } t \text {-value } \\
p \text {-value }\end{array}$ & $\begin{array}{l}1.693 \\
570.419 \\
1.964 \\
0.091\end{array}$ & $\begin{array}{l}4.435 \\
900.995 \\
1.963 \\
<0.001\end{array}$ & $\begin{array}{l}2.533 \\
563.976 \\
1.964 \\
0.012\end{array}$ & $\begin{array}{l}1.840 \\
611.943 \\
1.964 \\
0.066\end{array}$ & $\begin{array}{l}0.085 \\
403.863 \\
1.966 \\
0.932\end{array}$ & $\begin{array}{l}3.012 \\
1031.103 \\
1.962 \\
0.003\end{array}$ \\
\hline & $\begin{array}{l}\text { Different based on } \\
\text { Bonferroni corrected } \\
\text { alpha value } \\
(\alpha=0.001) .\end{array}$ & No & Yes & No & No & No & No \\
\hline
\end{tabular}

Table 2.7. Calculated $t$-values, degrees of freedom, $95 \%$ critical $t$-values, and $p$-values for pairwise comparisons of Shannon-Weiner diversity indices for seasons between sites, and between sites for the entire 12-month study period. The test-specific $p$-value was calculated for each t-test using Excel (TDIST function). This test-specific $p$-value was compared to a Bonferroni-corrected alpha value. Test-specific $p$-values falling below the Bonferroni alpha value resulted in rejection of the null hypothesis that the diversity indices do not differ. 


\begin{tabular}{|c|c|c|c|c|c|c|}
\hline \multirow[t]{2}{*}{ Prey Item } & \multicolumn{2}{|c|}{$\begin{array}{l}\text { Site } \\
(d f=3)\end{array}$} & \multicolumn{2}{|c|}{$\begin{array}{c}\text { Season } \\
(d f=2)\end{array}$} & \multicolumn{2}{|c|}{$\begin{array}{c}\text { Site } x \text { Season } \\
(d f=6)\end{array}$} \\
\hline & $x^{2}$ & p-value & $x^{2}$ & p-value & $x^{2}$ & p-value \\
\hline Mammal & 80.113 & $<0.001$ & 14.553 & 0.001 & 31.738 & $<0.001$ \\
\hline Bird & 1.812 & 0.612 & 0.978 & 0.613 & 6.106 & 0.411 \\
\hline Reptile/Amphibian & 14.985 & 0.002 & 1.818 & 0.403 & 11.946 & 0.063 \\
\hline Insecta & 4.852 & 0.183 & 4.796 & 0.091 & 14.980 & 0.020 \\
\hline Coleoptera & 20.285 & $<0.001$ & 7.600 & 0.022 & 21.433 & 0.002 \\
\hline Dermaptera & 21.636 & $<0.001$ & 8.064 & 0.018 & 9.228 & 0.161 \\
\hline Orthoptera & 33.133 & $<0.001$ & 3.815 & 0.148 & 82.415 & $<0.001$ \\
\hline Arachnida & 57.895 & $<0.001$ & 1.455 & 0.483 & 9.926 & 0.128 \\
\hline Crustacea & 1.566 & 0.667 & 1.818 & 0.403 & 9.070 & 0.170 \\
\hline Soil & 20.365 & $<0.001$ & 1.047 & 0.593 & 21.954 & 0.001 \\
\hline Vegetation & 10.906 & 0.012 & 13.979 & 0.001 & 4.794 & 0.571 \\
\hline Man-made & 4.074 & 0.254 & 0.854 & 0.652 & 3.176 & 0.786 \\
\hline
\end{tabular}

Table 2.8. Chi-square $\left(X^{2}\right)$ values and p-values for logistic regression analysis of pellet contents based on Site, Season, and Site $x$ Season, with degrees of freedom (df) reported in parentheses. 


\begin{tabular}{|c|c|c|c|c|c|}
\hline \multirow[t]{2}{*}{ PREY } & \multirow[t]{2}{*}{ SEASON } & \multicolumn{4}{|c|}{ STUDY SITE } \\
\hline & & WW & AER & FKC & BAK \\
\hline \multirow{4}{*}{ Mammal } & $B$ & 0.600 & 0.409 & 0.247 & 0.131 \\
\hline & $\mathrm{HD}$ & 0.769 & 0.042 & 0.127 & 0.068 \\
\hline & CW & 0.063 & 0.385 & 0.187 & 0.068 \\
\hline & All Pellets & 0.601 & 0.289 & 0.211 & 0.097 \\
\hline \multirow{4}{*}{$\begin{array}{c}\text { Reptilel } \\
\text { Amphibian }\end{array}$} & $B$ & - & - & 0.011 & 0.088 \\
\hline & HD & 0.038 & - & - & 0.079 \\
\hline & $\mathrm{CW}$ & - & - & 0.023 & 0.018 \\
\hline & All Pellets & 0.014 & - & 0.011 & 0.068 \\
\hline \multirow{4}{*}{ Insecta } & $B$ & 0.900 & 0.841 & 0.920 & 0.915 \\
\hline & HD & 0.673 & 0.979 & 1.000 & 0.939 \\
\hline & $\mathrm{CW}$ & 1.000 & 0.923 & 0.930 & 0.922 \\
\hline & All Pellets & 0.826 & 0.893 & 0.939 & 0.924 \\
\hline \multirow{4}{*}{ Coleoptera } & $B$ & 0.500 & 0.750 & 0.793 & 0.730 \\
\hline & HD & 0.577 & 0.938 & 0.635 & 0.843 \\
\hline & $\mathrm{CW}$ & 1.000 & 0.923 & 0.721 & 0.694 \\
\hline & All Pellets & 0.587 & 0.826 & 0.746 & 0.756 \\
\hline \multirow{4}{*}{ Dermaptera } & $B$ & 0.314 & - & 0.437 & 0.453 \\
\hline & HD & 0.077 & 0.021 & 0.254 & 0.275 \\
\hline & $\mathrm{CW}$ & 0.297 & 0.154 & 0.744 & 0.813 \\
\hline & All Pellets & 0.297 & 0.020 & 0.443 & 0.485 \\
\hline \multirow{4}{*}{ Orthoptera } & B & 0.743 & 0.477 & 0.322 & 0.455 \\
\hline & HD & 0.231 & 0.375 & 0.762 & 0.229 \\
\hline & $\mathrm{CW}$ & - & 0.154 & 0.256 & 0.132 \\
\hline & All Pellets & 0.464 & 0.416 & 0.414 & 0.308 \\
\hline \multirow{4}{*}{ Arachnida } & $B$ & 0.257 & 0.205 & 0.011 & 0.032 \\
\hline & HD & 0.500 & 0.167 & - & 0.021 \\
\hline & $\mathrm{CW}$ & - & - & - & - \\
\hline & All Pellets & 0.319 & 0.174 & 0.070 & 0.021 \\
\hline \multirow{4}{*}{ Soil } & $B$ & - & 0.045 & 0.224 & 0.136 \\
\hline & HD & - & - & - & 0.093 \\
\hline & CW & - & - & 0.163 & 0.452 \\
\hline & All Pellets & - & 0.027 & 0.164 & 0.199 \\
\hline \multirow{4}{*}{ Vegetation } & $B$ & - & - & 0.029 & 0.083 \\
\hline & HD & - & 0.042 & 0.048 & 0.196 \\
\hline & $\mathrm{CW}$ & - & 0.308 & 0.116 & 0.365 \\
\hline & All Pellets & - & 0.040 & 0.046 & 0.186 \\
\hline
\end{tabular}

Table 2.9. Proportion of pellets containing specific prey categories compared across site and season. Prey categories included are limited to those that were present in greater than trace amounts as in Figures 2-11 through 2-14. 


\begin{tabular}{|c|c|c|c|c|}
\hline \multicolumn{1}{|c}{ Site } & Season & S & $H^{\prime}$ & $J^{\prime}$ \\
\hline \multirow{2}{*}{ WW } & Nest & 14 & 2.145 & 0.813 \\
\cline { 2 - 5 } & Non-nest & 13 & 2.083 & 0.812 \\
\hline \multirow{2}{*}{ AER } & Nest & 14 & 2.095 & 0.794 \\
& Non-nest & 13 & 1.823 & 0.711 \\
\hline \multirow{2}{*}{ FKC } & Nest & 18 & 2.062 & 0.713 \\
\cline { 2 - 5 } & Non-nest & 16 & 1.930 & 0.696 \\
\hline \multirow{2}{*}{ BAK } & Nest & 17 & 2.071 & 0.731 \\
\cline { 2 - 5 } & Non-nest & 18 & 2.071 & 0.716 \\
\hline
\end{tabular}

Table 2.10. Species richness (S), Shannon-Wiener diversity indices $(H)$, and evenness $(J)$ calculated for nest and non-nest burrows for the 2005 breeding season for each study site. 


\begin{tabular}{|c|c|c|}
\hline & & Nest vs. Non-nest \\
\hline \multirow[t]{2}{*}{ WW } & $\begin{array}{l}t \text {-value } \\
\text { Degrees of freedom } \\
95 \% \text { critical } t \text {-value } \\
p \text {-value }\end{array}$ & $\begin{array}{c}0.457 \\
172.943 \\
1.974 \\
0.648\end{array}$ \\
\hline & $\begin{array}{l}\text { Different based on } \\
\text { Bonferroni corrected alpha } \\
\text { value }(\alpha=0.014) .\end{array}$ & No \\
\hline \multirow[t]{2}{*}{ AER } & $\begin{array}{l}t \text {-value } \\
\text { Degrees of freedom } \\
95 \% \text { critical } t \text {-value } \\
p \text {-value }\end{array}$ & $\begin{array}{c}1.836 \\
189.835 \\
1.973 \\
0.068\end{array}$ \\
\hline & $\begin{array}{l}\text { Different based on } \\
\text { Bonferroni corrected alpha } \\
\text { value }(\alpha=0.014)\end{array}$ & No \\
\hline \multirow[t]{2}{*}{ FKC } & $\begin{array}{l}t \text {-value } \\
\text { Degrees of freedom } \\
95 \% \text { critical } t \text {-value } \\
\mathrm{p} \text {-value }\end{array}$ & $\begin{array}{c}1.360 \\
385.122 \\
1.966 \\
0.174\end{array}$ \\
\hline & $\begin{array}{l}\text { Different based on } \\
\text { Bonferroni corrected alpha } \\
\text { value }(\alpha=0.014)\end{array}$ & No \\
\hline \multirow[t]{2}{*}{ BAK } & $\begin{array}{l}t \text {-value } \\
\text { Degrees of freedom } \\
95 \% \text { critical } t \text {-value } \\
p \text {-value }\end{array}$ & $\begin{array}{c}0.005 \\
789.016 \\
1.963 \\
0.996\end{array}$ \\
\hline & $\begin{array}{l}\text { Different based on } \\
\text { Bonferroni corrected alpha } \\
\text { value }(\alpha=0.014) .\end{array}$ & No \\
\hline
\end{tabular}

Table 2.11. Calculated $t$-values, degrees of freedom, 95\% critical t-values, and $p$-values for pairwise comparisons of Shannon-Weiner diversity indices nest versus non-nest burrows within a site. The test-specific $p$-value was calculated for each t-test using Excel (TDIST function). Testspecific $p$-values below the Bonferroni-corrected alpha value of 0.014 resulted in rejection of the null hypothesis that the diversity indices do not differ. 


\begin{tabular}{|l|c|c|c|c|}
\hline \multicolumn{1}{|c|}{ Prey Item } & WW & AER & FKC & BAK \\
\hline Mammal & 0.105 & 0.590 & 0.042 & 0.772 \\
\hline Bird & 0.497 & 0.399 & 0.453 & 0.871 \\
\hline Reptile/Amphibian & 0.809 & 0.819 & 0.485 & 0.212 \\
\hline Insecta & 0.113 & 0.509 & 0.759 & 0.397 \\
\hline Coleoptera & 0.450 & 0.893 & 0.116 & 0.226 \\
\hline Dermaptera & 1.000 & 0.819 & 0.283 & 0.597 \\
\hline Orthoptera & -- & -- & -- & 0.944 \\
\hline Arachnida & 0.859 & 0.746 & 0.759 & 0.909 \\
\hline Crustacea & 0.497 & 0.819 & 0.430 & 0.398 \\
\hline Soil & 0.809 & 0.322 & 0.001 & 0.146 \\
\hline Vegetation & 0.809 & 0.819 & 0.984 & 0.212 \\
\hline Man-made & 0.809 & 0.322 & 0.829 & 0.637 \\
\hline
\end{tabular}

Table 2.12. P-values for logistic regression analysis of pellet contents based on nest vs. non-nest burrows, as reported for each site. Degrees of freedom $(\mathrm{df})=2$. 